\title{
Guía de práctica clínica basada en la evidencia para el manejo de la sedoanalgesia en el paciente adulto críticamente enfermo
}

\author{
E. Celis-Rodríguez ${ }^{a, *}$, C. Birchenall ${ }^{b}$, M.Á. de la Cal ${ }^{c}$, G. Castorena Arellano ${ }^{d}$, \\ A. Hernández ${ }^{e}$, D. Ceraso ${ }^{f}$, J.C. Díaz Cortés ${ }^{g}, C$. Dueñas Castell ${ }^{\text {h }}$, E.J. Jimenez ${ }^{i}$, \\ J.C. Meza ${ }^{j}$, T. Muñoz Martínez ${ }^{k}$, J.O. Sosa García', C. Pacheco Tovar ${ }^{m}$, F. Pálizas ${ }^{n}$, \\ J.M. Pardo Oviedo ${ }^{\circ}$, D-I. Pinilla ${ }^{p}$, F. Raffán-Sanabria ${ }^{q}$, N. Raimondi ${ }^{r}$, \\ C. Righy Shinotsuka ${ }^{\mathrm{S}}$, M. Suárez ${ }^{\mathrm{t}}, \mathrm{S}$. Ugarte ${ }^{\mathrm{u}}$ y S. Rubiano ${ }^{\vee}$
}

\footnotetext{
a Departamento de Medicina Crítica y Cuidado Intensivo, Hospital Universitario Fundación Santa Fe de Bogotá, Universidad de Los Andes, Bogotá, Colombia

${ }^{\mathrm{b}}$ Clínica Universiraria Colombia, Hospital Universitario Mayor-Mederi

c Hospital Universitario de Getafe,Centro de Investigación Biomédica en Red (CIBER) de Enfermedades Respiratorias, Instituto de Salud Carlos III, Madrid, España

d Anestesia y Áreas Críticas, Hospital General Manuel Gea González, Anestesiología, Universidad Nacional Autónoma de México, Fundación Clínica Médica Sur, Ciudad de México, México

e Departamento de Paciente Critico, Hospital Militar de Santiago, Universidad de Los Andes, Universidad de Valparaíso

f Terapia Intensiva Sociedad Argentina de Terapia Intensiva - Fellow Critical Care Medicine (SATI-FCCM), Unidad de Terapia Intensiva, Hospital Juan A. Fernández, Buenos Aires, Unidad de Terapia Intensiva, Sanatorio San Lucas, San Isidro, Argentina, Medicina Crítica y Terapia Intensiva, Universidad de Buenos Aires

` UCl, Hospital Universitario Fundación Santa Fe de Bogotá, Anestesia y Medicina Crítica Universidad del Bosque, Universidad del Rosario y Universidad de los Andes

${ }^{\mathrm{h}}$ Universidad de Cartagena, UCI Gestión Salud, UCI Santa Cruz de Bocagrande, Federación Panamericana e Ibérica de Medicina Crítica y Terapia Intensiva

i Federación Mundial de Sociedades de Medicina Crítica y Cuidados Intensivos, Sección de Medicina Critica, Orlando Health Corporation y Orlando Health Physicians, Unidades de Cuidados Intensivos Orlando Regional Medical Center, Medicina University of Central Florida, University of Florida y Florida State University

j Cirujano Mayor Santiago Tavara, Departamento de Medicina Crítica y de la Oficina de Educación Médica Continua del Centro Médico Naval «C.M.S.T.», Universidad Nacional Mayor de San Marcos y de la Universidad San Martín de Porres

k Servicio de Medicina Intensiva del Hospital de Cruces (Vizcaya), Coordinador del Grupo de Trabajo de Analgesia y Sedación de la SEMICYUC

' Unidad de Terapia Intensiva, Hospital Médica Sur, Centro Nacional de Excelencia Tecnológica en Salud, Secretaría de Salud (CENETEC-SALUD)

m Servicio de Terapia Intensiva, Hospital universitario de Caracas, Universidad Central de Venezuela, Centro médico Docente La Trinidad Venezuela

n Terapia Intensiva, Clínicas Bazterrica y Santa Isabel, Buenos Aires, Argentina

- Medicina Interna y en Medicina Critica y Cuidados Intensivos de la Universidad del Rosario, Filosofía de la Ciencia, Universidad del Bosque, Educación Médica en Hospital Universitario Mayor-Mederi, Unidad de Cuidados Intensivos Fundación Cardio-infantil, Universidad del Rosario, Argentina
}

\footnotetext{
* Autor para correspondencia.

Correo electrónico: edgarcelis.md@gmail.com (E. Celis-Rodríguez).
} 
Medicina Critica, Universidad del Rosario, Argentina

q Departamento de Anestesiología y Departamento de Medicina Crítica, Hospital Universitario Fundación Santa Fe de Bogotá, Facultad de Medicina de la Universidad de Los Andes, Bogotá, Anestesiología Universidad El Bosque, Bogotá, Colombia

r Terapia Intensiva, Hospital Juan A. Fernández, Buenos Aires, Argentina

s Unidade Neurointensiva, Hospital Copa D'Or, Instituto D'Or de Pesquisa e Ensino, Rio de Janeiro, Brasil

${ }^{\mathrm{t}}$ Medico Internista, Intensivista. Departamento de Emergenicas y Cuidados Críticos. Hospital Nacional Hipólito Unanue, Lima, Perú

u Universidad Andrés Bello, Servicio de Paciente Crítico, Clínica INDISA, Red de Medicina Intensiva, Santiago de Chile, Federación Panamericana e Ibérica de Medicina Crítica y Terapia Intensiva, Council World Federation of Societies of Intensive and Critical Care Medicine

${ }^{\vee}$ Especialista en Medicina Interna, Fellow en Bioética Universidad de Miami, USA

Recibido el 5 de abril de 2013; aceptado el 16 de abril de 2013

Disponible en Internet el 14 de junio de 2013

\author{
PALABRAS CLAVE \\ Agitación; \\ Analgesia; \\ Bundle; \\ Cuidado Intensivo; \\ Delirium; \\ Dolor; \\ Grado de \\ Recomendación; \\ Guía de práctica \\ clínica; \\ Medicina basada en la \\ evidencia; \\ Sedación
}

\section{KEYWORDS}

Agitation;

Analgesia;

Bundle;

\section{Resumen:}

Introducción: El óptimo manejo de la sedación, analgesia y delirium ofrece al paciente crítico comodidad y seguridad, facilita el buen desarrollo de medidas de soporte y manejo integral y disminuye complicaciones, impactando en un mejor desenlace.

Objetivo: Actualizar la Guía de práctica clínica basada en la evidencia para el manejo de la sedoanalgesia en el paciente adulto críticamente enfermo publicada en MEDICINA INTENSIVA en el 2007 y dar recomendaciones para el manejo de la sedación, analgesia y delirium.

Metodología: Se reunió un grupo de 21 intensivistas procedentes de 9 países de la Federación Panamericana e Ibérica de Sociedades de Medicina Crítica y Terapia Intensiva, 3 de ellos además especialistas en epidemiología clínica y metodología para elaboración de guías. Se acogió la propuesta del Grading of Recommendations Assessment, Development and Evaluation Working Group para emitir el grado de recomendación y evaluar la calidad de la evidencia. La fuerza de las recomendaciones fue calificada como 1 = fuerte, o 2 = débil, y la calidad de la evidencia como $\mathrm{A}=\mathrm{alta}, \mathrm{B}=$ moderada, $\mathrm{o} \mathrm{c}=$ baja. Expertos en búsqueda de literatura apoyaron con esta estrategia de búsqueda: MEDLINE a través de PUBMED, bases de datos de la biblioteca Cochrane a través de The Cochrane Library y la base de datos Literatura Latinoamericana y del Caribe en Ciencias de la Salud. Los miembros asignados a las 11 secciones de la guía, basándose en la revisión de la literatura, presentaron las recomendaciones, sustentadas y discutidas en sesiones plenarias, aprobando aquellas que superaron el $80 \%$ del consenso. La elaboración de las guías contó con el soporte de la Asociación Colombiana de Medicina Crítica y Cuidado Intensivo.

Resultados: Para la elaboración de la guía fueron finalmente seleccionadas 467 referencias, observándose un importante aumento en el número y calidad de los estudios, permitiendo realizar 64 fuertes recomendaciones con evidencia alta y moderada, contrastando con las 28 de la edición anterior.

Conclusiones: Esta guía contiene recomendaciones y sugerencias basadas en la mejor evidencia para el manejo de la sedación, analgesia y delirium del paciente crítico, incluyendo un paquete de medidas (bundle). Se destacan: evaluación del dolor y la agitación/sedación mediante escalas; usar inicialmente opioides para el control de la analgesia, adicionando técnicas multimodales para disminuir consumo de opioides; promover el menor nivel de sedación necesario, evitando la sobresedación; en caso de requerir medicamentos sedantes, escoger el más apropiado, evitando el uso rutinario de benzodiazepinas; por último, identificar factores de riesgo para delirium, prevenirlo, diagnosticarlo y manejarlo, con el medicamento más conveniente, ya sea haloperidol, antipsicóticos atípicos o dexmedetomidina, evitando el uso de benzodiazepinas y disminuyendo el uso de opioides.

(c) 2013 Elsevier España, S.L. y SEMICYUC. Todos los derechos reservados.

\section{Clinical practice guidelines for evidence-based management of sedoanalgesia in critically ill adult patients}

\section{Abstract}

Introduction: Optimal management of sedation, analgesia and delirium offers comfort and security for the critical care patient, allows support measures to be applied more easily and enables an integral approach of medical care, at the same time that lowers the incidence of complications, wich translates in better patient outcomes. 
Intensive care;

Delirium;

Pain;

Grading of

Recommendations;

Evidence based

medicine;

Sedation
Objective: To update the Guía de práctica clínica basada en la evidencia para el manejo de la sedoanalgesia en el paciente adulto críticamente enfermo published in MEDICINA INTENSIVA in 2007, and give recommendations for the management of sedation, analgesia, and delirium.

Methodology: A group of 21 intensivists from 9 countries of the Federación Panamericana e Ibérica de Sociedades de Medicina Crítica y Terapia Intensiva, 3 of them also specialists in clinical epidemiology and methodology, gathered for the development of guidelines. Assessment of evidence quality and recommendations were made based on the Grading of Recommendations Assessment, Development and Evaluation system. Strength of recommendations was classified as 1 =strong, or 2 =weak, and quality of evidence as $A=$ high, $B=$ moderate, or $C=$ low. Two authors searched the following databases: MEDLINE through PUBMED, The Cochrane Library and Literatura Latinoamericana y del Caribe en Ciencias de la Salud and retrieved pertinent information. Members assigned to the 11 sections of the guidelines, based on the literature review, formulated the recommendations, that were discussed in plenary sessions. Only those recommendations that achieved more than $80 \%$ of consensus were approved for the final document. The Colombian Association of Critical Medicine and Intensive Care (AMCl) supported the elaboration of this guidelines.

Results: Four hundred sixty-seven articles were included for review. An increase in number and quality of publications was observed. This allowed to generate 64 strong recommendations with high and moderate quality of evidence in contrast to the 28 recommendations of the previous edition.

Conclusions: This Guidelines contains recommendations and suggestions based on the best evidence available for the management of sedation, analgesia and delirium of the critically ill patient, including a bundle of strategies that serves this purpose. We highlight the assessment of pain and agitation/sedation through validated scales, the use of opioids initially to apropiate analgesic control, associated with multimodal strategies in order to reduce opioide consumption; to promote the lowest level of sedation necessary avoiding over-sedation. Also, in case of the need of sedatives, choose the most appropiate for the patient needs, avoiding the use of benzodiazepines and identify risk factors for delirium, in order to prevent its occurrence, diagnose delirium and treat it with the most suitable pharmacological agent, whether it is haloperidol, atypical antipsychotics or dexmedetomidine, once again, avoiding the use of benzodiazepines and decreasing the use of opioids.

(c) 2013 Elsevier España, S.L. and SEMICYUC. All rights reserved.

\section{Introducción}

La sedación y la analgesia son parte integral en el manejo de los pacientes críticos en las unidades de cuidados intensivos (UCl). Los objetivos de estas 2 intervenciones son proporcionar a los pacientes un nivel óptimo de comodidad con seguridad, reduciendo la ansiedad y la desorientación, facilitando el sueño y controlando adecuadamente el dolor. De este modo también se facilita que no haya interferencia con los cuidados médicos y de enfermería ${ }^{1}$. Los pacientes críticos en la $\mathrm{UCl}$ tienen riesgo de presentar ansiedad, agitación, combatividad, delirium y síndromes de abstinencia por privación (opioides, alcohol, nicotina, etc.). Es indispensable diagnosticar con la mayor exactitud estas manifestaciones clínicas, porque de ello depende su manejo adecuado ${ }^{2}$.

\section{Objetivos de la guía}

Proporcionar recomendaciones para el uso de la sedación y el manejo del dolor en pacientes adultos que ingresan a las $\mathrm{UCl}$, con o sin intubación traqueal (naso u orotraqueal) (IT) y asistencia ventilatoria, y/o con algunas patologías o condiciones específicas. Las recomendaciones se basaron en el consenso de los expertos en medicina crítica de diferentes países miembros de la Federación Panamericana e
Ibérica de Sociedades de Medicina Crítica y Terapia Intensiva (FEPIMCTI). La guía es transparente con relación a la bibliografía que sustenta el nivel de evidencia, las recomendaciones y el método usado para el desarrollo de las guías, lo que permite que sean cuestionables y que se puedan aplicar en cualquier UCI.

Para la elección de las recomendaciones no se tuvieron en cuenta las consideraciones económicas (coste/efectividad) encontradas en estudios globales, ya que las circunstancias de cada país pueden variar sustancialmente las condiciones de aplicabilidad. El informe técnico completo está disponible y puede ser solicitado por correo electrónico al coordinador de las guías en la siguiente dirección: edgarcelis.mdgmail.com.

\section{Alcance de la guía}

Las recomendaciones se han agrupado en diferentes secciones, de acuerdo con las condiciones específicas que caracterizan al grupo de enfermos a los que van dirigidas.
A. Paciente que precisa sedación consciente.
B. Monitorización de la sedoanalgesia.
C. Paciente con delirium y síndrome de abstinencia. 
D. Pacientes sin intubación endotraqueal ni asistencia ventilatoria.

E. Pacientes con intubación endotraqueal y ventilación mecánica (VM).

F. Pacientes en proceso de retirada del tubo endotraqueal y de la VM.

G. Poblaciones especiales: pacientes traumatizados, ancianos, quemados y embarazadas.

$\mathrm{H}$. Paciente en el postoperatorio inmediato de cirugía cardiovascular.

I. Paciente neurológico y neuroquirúrgico.

J. Paciente con insuficiencia renal o hepática.

$\mathrm{K}$. Paciente que requiere procedimientos especiales (traqueostomía, tubos o sondas torácicas, lavado peritoneal, lavado y desbridamiento de heridas o quemaduras).

L. Estrategias no farmacológicas o terapias complementarias.

\section{Limitaciones de la guía}

Esta guía no cubre a la población infantil, ni a la población adulta con condiciones diferentes a las mencionadas, tales como pacientes trasplantados, con muerte encefálica en proceso de donación de órganos o pacientes psiquiátricos.

\section{Usuarios}

Esta guía ha sido elaborada para ser usada por médicos, enfermeras, fisioterapeutas (terapistas) que estén involucrados en el manejo de pacientes adultos en estado crítico. También puede ser utilizada para labores docentes de residentes y estudiantes.

\section{Metodología para el desarrollo de la guía}

\section{Conformación del grupo de consenso}

Se invitó a participar en la elaboración de la guía a un total de 21 personas procedentes de 9 países. Los invitados fueron escogidos por las sociedades de medicina crítica de cada país participante, basándose en criterios como su experiencia en el tema y en la metodología para el desarrollo de guías (anexo 1).

Todos los participantes son especialistas en medicina crítica y 3 de ellos son además especialistas en epidemiología clínica y en metodología para la elaboración de guías. Dieciocho de ellos participaron en el desarrollo de las guías de 2007. El papel de los metodólogos fue orientar y apoyar a los especialistas en la búsqueda de la literatura, así como en el desarrollo y la metodología para confeccionar la guía.

\section{Desarrollo de la guía}

Los 21 expertos definieron el alcance de las guías, los temas a evaluar y las preguntas relevantes a las que se debería dar respuesta. Se designaron 2 expertos por tema.

El grupo de expertos decidió tomar como válidas y como punto de partida las conclusiones de las guías de 2007 para el manejo de la sedación y analgesia para los pacientes adultos críticos de la FEPIMCTI ${ }^{3}$. Se capacitó a los expertos en la metodología a seguir y se acogió la propuesta del
Grading of Recommendations Assessment, Development and Evaluation (GRADE) Working Group ${ }^{4}$ para emitir el grado de recomendación y evaluar la calidad de la evidencia, de acuerdo con los criterios expresados en la tabla 1.

\section{Búsqueda de la literatura biomédica}

La estrategia de búsqueda fue diseñada por expertos en búsqueda de literatura e información biomédica y revisiones sistemáticas.

Los criterios de inclusión de los artículos fueron:

1. Tipos de estudio. Ensayos clínicos con asignación aleatorizada, revisiones sistemáticas, estudios de cohortes, casos y controles, estudios descriptivos, series de casos.

2. Tipos de pacientes. Adultos, críticamente enfermos o ingresados en $\mathrm{UCl}$, en alguna de las siguientes circunstancias: sin IT; con IT y VM; en proceso de retirada de la VM y del tubo endotraqueal; en el postoperatorio inmediato de cirugía cardíaca; con enfermedad pulmonar obstructiva crónica (EPOC), con síndrome de distrés respiratorio agudo (SDRA), ancianos, mujeres embarazadas o en lactancia; politraumatizados; neurocríticos; con insuficiencia renal; con insuficiencia hepática; con agitación y/o delirium y/o síndrome de abstinencia.

3. Tipo de intervenciones. Monitorización de la sedación y sedación consciente (se incluyeron lorazepam, midazolam, propofol, diazepam, dexmedetomidina, tiopental sódico, haloperidol, clozapina, metadona, ketamina, estrategias no farmacológicas o terapias complementarias). Analgesia (se incluyeron morfina, fentanilo, remifentanilo, sufentanilo, clonidina, antiinflamatorios no esteroideos [AINE], hidromorfona, métodos de anestesia regional, analgesia controlada por el paciente [PCA]); procedimientos de inmovilización; procedimientos quirúrgicos frecuentes en la $\mathrm{UCl}$ (traqueostomía, tubos o sondas torácicas, lavado peritoneal, curas y desbridamiento de heridas o quemaduras).

La identificación de los estudios relevantes se llevó a cabo mediante una búsqueda electrónica de todos los estudios relacionados con los temas propuestos a partir del 1 de enero del año 2007.

Fueron consultados MEDLINE a través de PUBMED ( 1 enero de 2007 a 31 de julio de 2012) y las siguientes bases de datos de la biblioteca Cochrane: Cochrane Database of Systematic Reviews (CDSR), Cochrane Central Register of Controlled Trials (CENTRAL), Database of Abstracts of Reviews of Effects (DARE), National Health Service Economic Evaluation Database (NHS EED) a través de The Cochrane Library número 2, del 2012, y la base de datos Literatura Latinoamericana y del Caribe en Ciencias de la Salud (LILACS) (31 de julio de 2012). En el anexo 2 se detallan las diferentes estrategias de búsqueda en PUBMED. La búsqueda bibliográfica identificó 1.101 referencias en las diferentes bases de datos mencionadas. El coordinador del proyecto y un metodólogo seleccionaron los estudios considerados relevantes para la elaboración de las guías, y descartaron los estudios que no cumplían los criterios de inclusión o correspondían a referencias ya identificadas en otra base de datos. Posteriormente un intensivista, con formación en 
Tabla 1 Graduación de las recomendaciones

\begin{tabular}{|c|c|c|c|}
\hline $\begin{array}{l}\text { Descripción del grado } \\
\text { de recomendación }\end{array}$ & $\begin{array}{l}\text { Riesgo/beneficio y } \\
\text { barreras }\end{array}$ & Calidad metodológica de la evidencia & Implicaciones \\
\hline $\begin{array}{l}\text { 1A. Recomendación } \\
\text { fuerte. Calidad de } \\
\text { la evidencia alta }\end{array}$ & $\begin{array}{l}\text { El beneficio es } \\
\text { superior al riesgo y a } \\
\text { las barreras, o } \\
\text { viceversa }\end{array}$ & $\begin{array}{l}\text { ECA sin limitaciones importantes o } \\
\text { estudios observacionales con } \\
\text { evidencia muy fuerte }\end{array}$ & $\begin{array}{l}\text { Fuerte recomendación. Aplicable a la } \\
\text { mayoría de los pacientes en la } \\
\text { mayoría de las circunstancias, sin } \\
\text { limitaciones }\end{array}$ \\
\hline $\begin{array}{l}\text { 1B. Recomendación } \\
\text { fuerte. Calidad de } \\
\text { la evidencia } \\
\text { moderada }\end{array}$ & $\begin{array}{l}\text { El beneficio es } \\
\text { superior al riesgo y a } \\
\text { las barreras, o } \\
\text { viceversa }\end{array}$ & $\begin{array}{l}\text { ECA con importantes limitaciones } \\
\text { (resultados inconsistentes o } \\
\text { imprecisos, debilidades } \\
\text { metodológicas, evidencia indirecta) } \\
\text { o, excepcionalmente, estudios } \\
\text { observacionales con fuerte evidencia }\end{array}$ & $\begin{array}{l}\text { Fuerte recomendación. Aplicable a la } \\
\text { mayoría de los pacientes en la } \\
\text { mayoría de las circunstancias, sin } \\
\text { limitaciones }\end{array}$ \\
\hline $\begin{array}{l}\text { 1C. Recomendación } \\
\text { fuerte. Calidad de } \\
\text { la evidencia baja o } \\
\text { muy baja }\end{array}$ & $\begin{array}{l}\text { El beneficio es } \\
\text { superior al riesgo y a } \\
\text { las barreras, o } \\
\text { viceversa }\end{array}$ & $\begin{array}{l}\text { Estudios observacionales o series de } \\
\text { casos }\end{array}$ & $\begin{array}{l}\text { Fuerte recomendación, pero puede } \\
\text { cambiar cuando esté disponible una } \\
\text { mayor calidad de evidencia }\end{array}$ \\
\hline $\begin{array}{l}\text { 2A. Recomendación } \\
\text { débil. Calidad de la } \\
\text { evidencia alta }\end{array}$ & $\begin{array}{l}\text { El beneficio está casi } \\
\text { equilibrado con el } \\
\text { riesgo }\end{array}$ & $\begin{array}{l}\text { ECA sin limitaciones importantes o } \\
\text { estudios observacionales con } \\
\text { evidencia muy fuerte }\end{array}$ & $\begin{array}{l}\text { Recomendación débil. La mejor } \\
\text { acción dependerá de las } \\
\text { circunstancias del paciente o de } \\
\text { valores sociales }\end{array}$ \\
\hline $\begin{array}{l}\text { 2B. Recomendación } \\
\text { débil. Calidad de la } \\
\text { evidencia } \\
\text { moderada }\end{array}$ & $\begin{array}{l}\text { El beneficio está casi } \\
\text { equilibrado con el } \\
\text { riesgo }\end{array}$ & $\begin{array}{l}\text { ECA con importantes limitaciones } \\
\text { (resultados inconsistentes o } \\
\text { imprecisos, debilidades } \\
\text { metodológicas, evidencia indirecta) } \\
\text { o, excepcionalmente, estudios } \\
\text { observacionales con fuerte evidencia }\end{array}$ & $\begin{array}{l}\text { Recomendación débil. La mejor } \\
\text { acción dependerá de las } \\
\text { circunstancias del paciente o de } \\
\text { valores sociales }\end{array}$ \\
\hline $\begin{array}{l}\text { 2C. Recomendación } \\
\text { débil. Calidad de la } \\
\text { evidencia baja o } \\
\text { muy baja }\end{array}$ & $\begin{array}{l}\text { Incertidumbre en la } \\
\text { estimación del riesgo, } \\
\text { del beneficio y de las } \\
\text { barreras, o pueden } \\
\text { estar equilibrados }\end{array}$ & $\begin{array}{l}\text { Estudios observacionales o series de } \\
\text { casos }\end{array}$ & $\begin{array}{l}\text { Recomendación muy débil. Otras } \\
\text { alternativas pueden ser igualmente } \\
\text { razonables }\end{array}$ \\
\hline
\end{tabular}

ECA: ensayos clínicos con asignación aleatorizada.

Adaptada de Guyatt et al. ${ }^{4}$.

epidemiología clínica, evaluó los textos completos de los restantes estudios, seleccionando finalmente 201 estudios para la guía. Adicionalmente, los expertos incluyeron 266 referencias secundarias identificadas en los estudios encontrados por las búsquedas electrónicas realizadas por ellos, incluyendo algunas de ellas en la bibliografía. Los estudios en los que se fundamentaron las recomendaciones fueron evaluados, según los estándares del GRADE Working Group ${ }^{4}$, por los expertos participantes apoyados por los 3 epidemiólogos intensivistas. Esta evaluación se realizó con instrumentos estandarizados. Las propuestas para las recomendaciones fueron presentadas por un experto en una sesión plenaria, junto con la bibliografía que sustentaba la recomendación. Tras una discusión colectiva se establecieron las recomendaciones finales. Fueron incluidas como recomendaciones todas las propuestas que superaron el $80 \%$ del consenso, y retiradas aquellas recomendaciones que superaron el $80 \%$ de la votación para no ser tenidas en cuenta.

\section{Recomendaciones finales de la guía}

La distribución de las recomendaciones finales según el grado de recomendación figura en la tabla 2.
Tabla 2 Distribución de las recomendaciones finales según su grado

\begin{tabular}{ll}
\hline Grado de recomendación & Número \\
\hline $\begin{array}{l}\text { 1A. Recomendación fuerte. Calidad de la } \\
\text { evidencia alta }\end{array}$ & 4 \\
$\begin{array}{l}\text { 1B. Recomendación fuerte. Calidad de la } \\
\text { evidencia moderada }\end{array}$ & 60 \\
$\begin{array}{l}\text { 1C. Recomendación fuerte. Calidad de la } \\
\text { evidencia baja o muy baja }\end{array}$ & 50 \\
$\begin{array}{l}\text { 2A. Recomendación débil. Calidad de la } \\
\quad \text { evidencia alta }\end{array}$ & 0 \\
$\begin{array}{l}\text { 2B. Recomendación débil. Calidad de la } \\
\text { evidencia moderada }\end{array}$ & 10 \\
2C. Recomendación débil. Calidad de la \\
$\quad$ evidencia baja o muy baja
\end{tabular}

\section{Actualización de la guía}

Se propone que la guía sea actualizada a los 2 años de la fecha de publicación. 


\section{Exoneración}

Es importante recordar que las guías son solo una herramienta útil para mejorar las decisiones médicas, y que deben ser utilizadas teniendo en cuenta el criterio médico, las necesidades y preferencias de los pacientes, y la disponibilidad de los medios locales. También conviene recordar que nuevos resultados de la investigación clínica pueden proporcionar nuevas evidencias que hagan necesario cambiar la práctica usual, aun antes de que estas guías sean actualizadas.

\section{Recomendaciones, nivel de evidencia y justificación}

Esta guía se presenta como una lista de recomendaciones para cada pregunta del tema seleccionado.

\section{Recomendación general}

Todos los pacientes críticos tienen derecho a un adecuado manejo del dolor cuando lo necesiten

Grado de recomendación: fuerte. Nivel de evidencia: bajo (1C).

\section{A. Pacientes que precisan sedación consciente o cooperativa}

¿Cuáles son las escalas y elementos más sensibles para la monitorización y diagnóstico de la agitación?

A1. Se recomienda la evaluación objetiva de la presencia y cuantificación de la agitación de todo paciente con riesgo de desarrollarla en una $\mathrm{UCI}$, mediante una escala de medición validada (Richmond Agitation Sedation Scale [RASS] o Sedation-Agitation Scale [SAS]). Debe hacerse de forma sistemática y por personal entrenado en su aplicación.

Grado de recomendación: fuerte. Nivel de evidencia: moderado (1 B).

Justificación: Se define la agitación como la presencia de movimientos frecuentes de la cabeza, los brazos o las piernas y/o la desadaptación del ventilador, que persisten a pesar de los intentos de tranquilizar al paciente por parte del personal encargado de su cuidado ${ }^{5,6}$. Puede ocurrir por una toxicidad del sistema nervioso central (SNC) secundaria a los fármacos o por otras condiciones frecuentes en el paciente crítico ${ }^{7,8}$. La agitación sigue un círculo vicioso de retroalimentación en el que la respuesta defensiva del personal de atención sanitaria induce más agitación en el enfermo con la probabilidad de sufrir agresiones físicas, y autorretirada de sondas, catéteres y tubo endotraqueal ${ }^{9,10}$. El aumento de la demanda de oxígeno puede desencadenar una isquemia miocárdica $u$ otros fallos orgánicos en el paciente grave, lo que justifica la necesidad de un tratamiento rápido y eficaz ${ }^{2,11,12}$.

La escala de sedación de Ramsay (tabla 3$)^{13}$ fue validada hace más de 30 años específicamente para valorar el nivel de sedación. Incluye solo una categoría de agitación en su graduación, lo que la hace muy poco útil para cuantificar el nivel de agitación.
Tabla 3 Escala de sedación de Ramsay

\begin{tabular}{cl}
\hline Nivel & Descripción \\
\hline $\begin{array}{c}\text { Despierto } \\
1\end{array}$ & $\begin{array}{l}\text { Con ansiedad y agitación o inquieto } \\
2\end{array}$ \\
3 & $\begin{array}{l}\text { Cooperador, orientado y tranquilo } \\
\text { verbales normales }\end{array}$ \\
Dormido & $\begin{array}{l}\text { Respuesta rápida a ruidos fuertes o a la } \\
1\end{array}$ \\
2 & $\begin{array}{l}\text { Rercusión leve en el entrecejo } \\
\text { percusión leve en el entrecejo }\end{array}$ \\
3 & $\begin{array}{l}\text { Ausencia de respuesta a ruidos fuertes o a } \\
\text { la percusión leve en el entrecejo }\end{array}$
\end{tabular}

Adaptada de Ramsay et al. ${ }^{13}$.

En los últimos años se han desarrollado escalas más eficaces para valorar la agitación. Entre las que han mostrado mayor validez y fiabilidad están: la Motor Activity Assessment Scale (MAAS) ${ }^{14}$, la SAS (tabla 4) ${ }^{15,16}$ y la RASS (tabla $5)^{17}$. Las escalas RASS y SAS son fáciles de usar y recordar, lo que favorece la aceptación por el personal de la $\mathrm{UCI}^{17,18}$.

La actigrafía, que mide movimientos registrados por un acelerómetro fijo a una extremidad, se correlaciona bien con cambios en el estado neurológico medido por escalas de sedación y dolor, y podría ser útil para la identificación precoz de la agitación y su manejo ${ }^{19}$.

¿Cuáles son los factores que contribuyen a la aparición de la agitación?

A2. Se recomienda que el personal que atiende al enfermo valore y cuantifique la presencia de factores de riesgo de agitación, con el fin de iniciar precozmente el tratamiento de esos factores.

Grado de recomendación: fuerte. Nivel de evidencia: moderado (1 B).

Justificación: Los factores que contribuyen a la aparición de agitación se pueden clasificar según su origen en ${ }^{5,6,20}$ :

1. De origen exógeno (externo) o tóxico-orgánico. Se produce por la acción de tóxicos o en el curso de enfermedades médicas. Son de aparición brusca. En los casos de drogas y fármacos se produce por sobredosificación, reacciones adversas o privación.

Las sustancias capaces de causar agitación incluyen: alcohol (delirium tremens y alucinosis), tabaco (deprivación) $^{21}$, estimulantes, marihuana y alucinógenos. Entre los medicamentos están: atropina, corticosteroides, fenitoína, barbitúricos, fenotiazinas, antidepresivos tricíclicos y disulfiram. Entre las causas tóxico-orgánicas figuran: epilepsia, hematoma subdural, accidente cerebrovascular, encefalopatía hipertensiva, hemorragia subaracnoidea, tumores intracraneales, sepsis, infección por el virus de la inmunodeficiencia humana con afectación del SNC, hipotiroidismo, psicosis puerperal, fiebre ${ }^{22}$ e hipoglucemia. También pueden aparecer en las encefalopatías asociadas a insuficiencia hepática e insuficiencia renal.

2. De origen psicógeno. Una situación de estrés en enfermos con personalidades susceptibles que se descompensan fácilmente. 
Tabla 4 Sedation-Agitation Scale (SAS)

\begin{tabular}{|c|c|c|}
\hline Puntuación & Nivel de sedación & Respuesta \\
\hline 7 & Agitación peligrosa & $\begin{array}{l}\text { Intenta la retirada del tubo endotraqueal y de los catéteres; intenta salirse de la } \\
\text { cama, arremete contra el personal }\end{array}$ \\
\hline 6 & Muy agitado & No se calma al hablarle, muerde el tubo, necesita contención física \\
\hline 5 & Agitado & Ansioso o con agitación moderada, intenta sentarse, pero se calma al estimulo verbal \\
\hline 4 & Calmado y cooperador & Calmado o fácilmente despertable, obedece órdenes \\
\hline 3 & Sedado & $\begin{array}{l}\text { Difícil de despertar, se despierta con estímulos verbales o con movimientos suaves, } \\
\text { pero se vuelve a dormir enseguida. Obedece órdenes sencillas }\end{array}$ \\
\hline 2 & Muy sedado & $\begin{array}{l}\text { Puede despertar con estimulo físico, pero no se comunica, ni obedece órdenes. } \\
\text { Puede moverse espontáneamente }\end{array}$ \\
\hline 1 & No despertable & $\begin{array}{l}\text { Puede moverse o gesticular levemente con estímulos dolorosos, pero no se comunica } \\
\text { ni obedece órdenes }\end{array}$ \\
\hline
\end{tabular}

Adaptada de Riker et al. ${ }^{15}$.

Tabla 5 Richmond Agitation Sedation Scale (RASS)

\begin{tabular}{|c|c|c|c|}
\hline Puntuación & Denominación & Descripción & Exploración \\
\hline+4 & Combativo & Combativo, violento, con peligro inmediato para el personal & Observar al paciente \\
\hline+3 & Muy agitado & Agresivo, intenta retirarse los tubos o catéteres & \\
\hline+2 & Agitado & $\begin{array}{l}\text { Movimientos frecuentes y sin propósito; «lucha» con el } \\
\text { ventilador }\end{array}$ & \\
\hline+1 & Inquieto & Ansioso, pero sin movimientos agresivos o vigorosos & \\
\hline 0 & Alerta y calmado & & \\
\hline-1 & Somnoliento & $\begin{array}{l}\text { No está plenamente alerta, pero se mantiene ( } \geq 10 \mathrm{~s} \text { ) } \\
\text { despierto (apertura de ojos y seguimiento con la mirada) a } \\
\text { la llamada }\end{array}$ & $\begin{array}{l}\text { Llamar al enfermo por su } \\
\text { nombre y decirle «abra los } \\
\text { ojos y míreme» }\end{array}$ \\
\hline-2 & Sedación leve & $\begin{array}{l}\text { Despierta brevemente }(<10 \mathrm{~s}) \text { a la llamada con seguimiento } \\
\text { con la mirada }\end{array}$ & \\
\hline-3 & Sedación moderada & $\begin{array}{l}\text { Movimiento o apertura ocular a la llamada (pero sin } \\
\text { seguimiento con la mirada) }\end{array}$ & \\
\hline-4 & Sedación profunda & $\begin{array}{l}\text { Sin respuesta a la llamada, pero movimiento o apertura } \\
\text { ocular al estimulo físico }\end{array}$ & $\begin{array}{l}\text { Estimular al enfermo } \\
\text { sacudiendo su hombro o } \\
\text { frotando sobre la región } \\
\text { esternal }\end{array}$ \\
\hline-5 & Sin respuesta & Sin respuesta a la voz ni al estímulo físico & \\
\hline
\end{tabular}

Si el valor de la RASS es igual a -4 o -5, deténgase y revalúe al paciente posteriormente.

Si el valor de la RASS es superior a $-4(-3 \mathrm{a}+4)$, entonces proceda, si está indicado, a la valoración del delirium.

Adaptada de Ely et al. ${ }^{17}$.

3. De origen endógeno. Psicosis esquizofrénica, psicosis maniacodepresiva.

¿En qué situaciones está indicada la sedación consciente o cooperativa?

A3. Se recomienda la sedación consciente o cooperativa en aquellos pacientes en los que no sea necesaria una sedación profunda y especialmente en los pacientes que necesiten una valoración periódica de su estado de conciencia debido a una enfermedad crítica o a un procedimiento complejo como durante el acoplamiento a la VM no invasiva, la adaptación a las modalidades espontáneas de VM invasiva, o durante el proceso de retirada del tubo endotraqueal, especialmente en los que puedan complicarse gravemente con síntomas neurológicos.

Grado de recomendación: fuerte. Nivel de evidencia: moderado (1 B).
Justificación: Se puede definir la sedación consciente o cooperativa como la depresión mínima del nivel de conciencia que permite al paciente mantener su vía aérea permeable. Desde un enfoque más operacional (al lado de la cama del enfermo), es aquella en la que el paciente preserva una respuesta apropiada a la estimulación verbal o táctil, con mantenimiento de los reflejos de la vía aérea y ventilación espontánea adecuada. Habitualmente la situación cardiovascular se mantiene estable en-23. $^{23}$.

Se ha utilizado para reducir la duración de la $\mathrm{VM}^{26-31}$ y el tiempo desde el inicio del «destete» a la extubación ${ }^{28}$, acortar la estancia en la $\mathrm{UCl}^{26,28,31,32}$ y en el hospital ${ }^{30}$, disminuir la frecuencia de traqueostomías ${ }^{33}$, y reducir la incidencia de los trastornos psicológicos durante la hospitalización o tras el alta ${ }^{32}$, como el delirium ${ }^{29}$, y el síndrome de estrés postraumático ${ }^{27}$. La menor incidencia del delirium se asocia a una mayor supervivencia ${ }^{29,30}$. 
Se puede administrar durante diferentes procedimientos terapéuticos, diagnósticos o quirúrgicos, cuando se necesite una evaluación neurológica frecuente, durante el acoplamiento a la VM no invasiva, para la adaptación a las modalidades espontáneas de VM invasiva, o durante el proceso de retirada de IT. Su uso debe ser cuidadoso, pues puede asociarse a efectos adversos como riesgo de agitación, especialmente en grupos de pacientes en VM con desórdenes asociados al consumo de alcohol o drogas ${ }^{34}$.

Se han descrito varios métodos para sedar a los pacientes para conseguir la sedación consciente, como son la utilización de protocolos y algoritmos de sedación, con o sin interrupción diaria de los sedantes, despertar todos los días al paciente con o sin ensayos de ventilación espontánea, usar la analgesia-sedación en lugar de sedación hipnótica, administrar nuevos fármacos con menor efecto depresor del centro respiratorio ${ }^{26-31,33}$. La «no sedación» con el uso asociado de analgésicos opioides podía ser considerada como una variedad de sedación consciente ${ }^{30}$.

A4. Se recomienda el uso de dexmedetomidina, fentanilo, remifentanilo, propofol (bolos o infusión), o midazolam (solo bolos de rescate), en dosis titulada según la respuesta, para la sedación consciente en situaciones terapéuticas, diagnósticas o quirúrgicas menores en la UCI.

Grado de recomendación: fuerte. Nivel de evidencia: moderado (1 B).

Justificación: La dexmedetomidina, un agonista $\alpha_{2}$ de acción corta y alta especificidad, produce analgesia, ansiolisis y sedación, que ha sido descrita como consciente, disminuyendo los trastornos del estado mental como el delirium ${ }^{35,36}$. Adicionalmente, la dexmedetomidina no produce depresión respiratoria clínicamente significativa, lo cual facilita el manejo de estos pacientes desde el punto de vista de la respiración y del mantenimiento de la permeabilidad de la vía aérea ${ }^{37-43}$.

El fentanilo, el remifentanilo y el propofol pueden proporcionar sedación consciente en dosis y tiempo variables, supeditada a las características farmacocinéticas de cada fármaco ${ }^{44}$. Al usar infusiones continuas debe tenerse en cuenta la acumulación de metabolitos. Siempre es necesario recordar que el midazolam y el propofol no producen analgesia $20,23-25,37,39-43,45-54$.

A5. El uso de droperidol combinado con opioides para neuroleptoanalgesia debe ser cauteloso, valorando el riesgo-beneficio para cada paciente, por la aparición de síntomas extrapiramidales y el posible riesgo de «torsión de puntas».

Grado de recomendación: fuerte. Nivel de evidencia: moderado (1 B).

Justificación: El droperidol, una butirofenona de inicio rápido de acción y corta duración del efecto es útil para el tratamiento de estados de agitación psicomotriz y agresividad. Las dosis son muy variables (de 0,625 a 1,25 mg en bolo y de 5 a $25 \mathrm{mg}$ en infusión en $24 \mathrm{~h}$ ). Hay que tener en cuenta sus efectos hemodinámicos adversos: vasodilatación, hipotensión y taquicardia. No tiene efecto analgésico significativo, por lo que generalmente se usa asociado a un opiáceo.

Sin embargo, entre sus efectos adversos se han descrito síntomas extrapiramidales y posible alargamiento del QT con el consecuente riesgo de «torsión de puntas», aunque este efecto no está claramente probado con dosis bajas ${ }^{55-57}$.
El remifentanilo se ha utilizado en anestesia. Pese a su rápida terminación de efecto y su nula acumulación, el uso en la sedación consciente de los pacientes críticos necesita de una monitorización y un cuidado extremos, ya que pequeños incrementos de la dosis pueden hacer perder el control de la vía aérea.

\section{B. Monitorización de la sedoanalgesia}

¿Qué beneficios aporta evaluar sistemáticamente la sedoanalgesia en los pacientes críticos?

$B 1$. Se recomienda protocolizar una evaluación sistemática del dolor y la analgesia.

Grado de recomendación: fuerte. Nivel de evidencia: moderado (1 B).

Justificación: La monitorización mejora el manejo efectivo del dolor, permitiendo un mejor ajuste de la medicación sedante y analgésica ${ }^{58}$. Numerosos estudios muestran que una adecuada monitorización de la sedoanalgesia permite reducir el tiempo de $\mathrm{VM}$, la estancia en $\mathrm{UCl}$ o el número de complicaciones infecciosas nosocomiales, especialmente neumonías asociadas a $\mathrm{VM}^{59-65}$. Algunos autores han encontrado incluso reducción de la mortalidad tras implementar una evaluación sistemática de la sedoanalgesia ${ }^{66}$.

¿Cuáles son las herramientas más adecuadas para identificar el dolor en los pacientes críticos?

B2. Se recomienda utilizar una escala validada basada en la cuantificación del dolor por el propio paciente siempre que esto sea posible.

Grado de recomendación: fuerte. Nivel de evidencia: bajo (1 C).

Justificación: El dolor sigue siendo un problema frecuente en los pacientes críticos, originado incluso por técnicas y cuidados rutinarios tales como la realización de cambios posturales ${ }^{67}$. Para identificar el dolor podemos aplicar varias aproximaciones ${ }^{68}$ : intentar que el paciente nos lo comunique, asumir que el enfermo percibe dolor cuando se realizan maniobras que potencialmente pueden causarlo, usar una escala validada de indicadores del comportamiento, valorar la impresión del familiar sobre la posibilidad de dolor de su allegado y valorar la respuesta a analgesia.

Siendo el dolor una experiencia subjetiva, la mejor valoración del dolor es la referida por el propio paciente ${ }^{69}$. Para facilitar la cuantificación del dolor en los pacientes críticos se han diseñado diversas escalas, siendo las más utilizadas las que utilizan un símil numérico o de longitud (escala visual numérica, escala visual analógica) presentado de forma horizontal o vertical, en el que el paciente puede señalar la intensidad del dolor que padece ${ }^{69-71}$. Es importante hacer comprender al paciente qué información queremos obtener, y utilizar instrumentos del tamaño suficiente, especialmente en enfermos con dificultades sensoriales. Un estudio comparativo de estas escalas mostró que la máxima sensibilidad y el mayor valor predictivo negativo para discriminar dolor se obtenía con la escala visual numérica de tamaño ampliado ${ }^{71}$. Por otra parte, la mayoría de los fallos en estas escalas se observaban en los pacientes más graves o con delirium.

B3. Se recomienda utilizar una escala validada basada en indicadores conductuales asociados al dolor en los pacientes que no puedan comunicarse. 
Tabla 6 Behavioral Pain Scale (BPS)

\begin{tabular}{|c|c|c|}
\hline Ítem & Descripción & Puntos \\
\hline \multirow{4}{*}{$\begin{array}{l}\text { Expresión } \\
\text { facial }\end{array}$} & Relajada & 1 \\
\hline & Parcialmente tensa & 2 \\
\hline & Totalmente tensa & 3 \\
\hline & Muecas & 4 \\
\hline \multirow{4}{*}{$\begin{array}{l}\text { Extremidades } \\
\text { superiores }\end{array}$} & No movimientos & 1 \\
\hline & Parcialmente dobladas & 2 \\
\hline & $\begin{array}{l}\text { Totalmente dobladas. Con } \\
\text { flexión de dedos }\end{array}$ & 3 \\
\hline & Permanentemente retraídas & 4 \\
\hline \multirow{4}{*}{$\begin{array}{l}\text { Adaptación al } \\
\text { ventilador }\end{array}$} & Tolera el movimiento & 1 \\
\hline & $\begin{array}{l}\text { Tose, pero tolera la ventilación } \\
\text { la mayor parte del tiempo }\end{array}$ & 2 \\
\hline & «Lucha» contra el ventilador & 3 \\
\hline & $\begin{array}{l}\text { Imposible controlar la } \\
\text { ventilación }\end{array}$ & 4 \\
\hline
\end{tabular}

Fuente: Payen et al. ${ }^{72}$.

Grado de recomendación: fuerte. Nivel de evidencia: bajo (1 C).

Justificación: Cuando el paciente no puede comunicarnos su dolor, la identificación del mismo se complica y requiere herramientas específicas, generalmente basadas en cambios fisiológicos o en comportamientos asociados al dolor. La ausencia de un patrón oro reconocido ha condicionado que muchas de estas herramientas de medición del dolor se hayan desarrollado según criterios clinimétricos, por lo que para su evaluación es fundamental contrastar una adecuada validez (que midan realmente lo que pretenden medir) y una buena reproducibilidad (mismos resultados a lo largo del tiempo y con diferentes observadores).

La escala Behavioral Pain Score (BPS) (tabla 6) se basa en puntuar de 1 a 4 la expresión facial del paciente, la actitud de sus extremidades superiores y la sincronía con la VM, relacionándose mayores puntuaciones con mayor intensidad de dolor ${ }^{72}$. Esta escala ha sido validada por grupos independientes del que la desarrolló ${ }^{73}$ y ha mostrado correlación adecuada con las escalas subjetivas ${ }^{74}$. Incluso se ha desarrollado una versión modificada para su uso en pacientes no intubados, sustituyendo el ítem de adaptación a la VM por el de vocalización ${ }^{75}$.

Otros grupos han desarrollado diferentes instrumentos de identificación del dolor basados en indicadores conductuales, destacando la Critical-Care Pain Observation Tool (CPOT) $)^{76,77}$; la escala Face, Legs, Activity, Cry, Consolability desarrollada a partir de la infantil COMFORT y aplicable también a niños ${ }^{78}$; la escala de Campbell ${ }^{69,79}$ o la reciente modificación de esta última para adaptarla mejor a pacientes ventilados, Escala de Conductas Indicadoras de Dolor $^{80}$. Aunque los instrumentos citados se han desarrollado mediante un proceso de validación de contenido, construcción y criterio adecuados, la escasa experiencia publicada con su uso hace que no se disponga de evidencia suficiente para la recomendación de una escala en particular.
B4. Se recomienda no utilizar aisladamente parámetros fisiológicos para identificar dolor, ya que son inespecíficos.

Grado de recomendación: fuerte. Nivel de evidencia: bajo (1 C).

Justificación: El dolor conlleva cambios en diversos parámetros fisiológicos, pudiendo observarse entre otros aumento de frecuencia cardíaca, incremento de presión arterial o dilatación pupilar. Cuando ocurren de forma súbita y manifiesta pueden suscitar la sospecha de que el paciente presenta dolor, pero frecuentemente estas alteraciones se presentan de manera irregular y dadas las características del paciente crítico resultan inespecíficas $^{81,82}$. En la fase de elaboración de la escala CPOT se incluyeron diversos indicadores fisiológicos que fueron retirados posteriormente al no mejorar la capacidad de discriminación de los componentes conductuales de la escala ${ }^{82}$.

¿Cuáles son las herramientas más adecuadas para controlar el nivel de sedación (y evaluar el grado de agitación) en el paciente crítico?

B5. Se recomienda utilizar una escala validada que mida la profundidad de sedación basándose en la capacidad del paciente de reaccionar a estímulos. Se recomienda elegir una escala que cuantifique tanto el nivel de sedación como el grado de agitación.

Grado de recomendación: fuerte. Nivel de evidencia: moderado (1 B).

Justificación: Se han desarrollado múltiples escalas clínicas para documentar la profundidad de sedación según el tipo e intensidad de estímulo físico necesario para suscitar una respuesta en el paciente, siendo todavía la más utilizada la de Ramsay ${ }^{13}$, publicada hace más de 35 años. Muy sencilla de realizar y bien aceptada por enfermería ${ }^{83}$, valora en 6 niveles la situación del paciente, correspondiendo solamente uno a agitación. Entre otras herramientas diseñadas para evaluar la sedación pueden citarse la Escala de Interacción-Serenidad de Vancouver ${ }^{84}$, la Observer's Assessment of Alertness/Sedation Scale ${ }^{85}$, la Adaptation to the Intensive Care Environment (ATICE) ${ }^{86}$ o la $\mathrm{MAAS}^{14}$, aunque las más utilizadas actualmente son la $\mathrm{SAS}^{15}$, la RASS ${ }^{18}$ o la ATICE.

La escala SAS consta de 7 categorías, comprendiendo desde la ausencia de reactividad hasta la agitación peligrosa. Ha sido validada por varios grupos y es bien aceptada por enfermería ${ }^{87,88}$ para documentar tanto el grado de sedación como el de agitación. La escala ATICE ${ }^{86}$ puntúa 5 categorías, correspondiendo 2 al dominio de conciencia y 3 al dominio de tolerancia. Su uso dentro de un algoritmo de manejo de la sedación en enfermos críticos sin traumatismo cerebral se ha asociado a disminución del tiempo de VM y de la estancia en $\mathrm{UCl}^{60}$. La escala RASS parte del nivel cero en un paciente alerta y calmado, para cuantificar la agitación en 4 grados positivos y la profundidad de sedación en 5 grados negativos. Adecuadamente validada y aceptada ${ }^{17}$, muestra además buena correlación con la escala Ramsay ${ }^{89}$, siendo de fácil implementación y con la ventaja de constituir un componente para la identificación del delirium mediante la escala Confusion Assessment Method for the Intensive Care Unit $(\mathrm{CAM}-\mathrm{ICU})^{90}$ (tabla 7). La escala RASS es considerada de elección por los redactores de las presentes recomendaciones. 
Tabla 7 Escala de delirium en la Unidad de Cuidados Intensivos (CAM-ICU)

Criterios y descripción del CAM-ICU

1. Comienzo agudo o evolución fluctuante

Ausente

Presente

Es positivo si la respuesta es «sí» a $1 \mathrm{~A}$ o $1 \mathrm{~B}$

1A. ¿Hay evidencia de un cambio agudo en el estado mental sobre el estado basal?

0

1B. ¿Ha fluctuado el comportamiento (anormal) en las últimas $24 \mathrm{~h}$ ? Es decir, ¿tiende a aparecer y desaparecer, o aumenta y disminuye en gravedad, evidenciado por la fluctuación de una escala de sedación (p. ej., RASS), o GCS, o en la evaluación previa de delirium?

2. Falta de atención

¿Tuvo el paciente dificultad para fijar la atención, evidenciada por

Ausente Presente puntuaciones $<8$ en cualquiera de los componentes visual o auditivo del ASE?

$2 A$. Comience con el ASE de letras. Si el paciente es capaz de hacer esta prueba y la puntuación es clara, anote esta puntuación y pase al punto 3

$2 B$. Si el paciente no es capaz de hacer esta prueba o la puntuación no está clara, haga el ASE de figuras. Si hace las 2 pruebas use el resultado del ASE de figuras para puntuar

3. Pensamiento desorganizado

¿Hay evidencia de pensamiento desorganizado o incoherente

Ausente Presente constatado por respuestas incorrectas a 2 o más de las 4 preguntas, y/o incapacidad para obedecer órdenes?

$3 A$. Preguntas de «sí» $O$ «no» (alternar grupo A y grupo B):

Grupo A

¿Puede flotar una piedra en el agua

¿Hay peces en el mar?

¿Pesa $1 \mathrm{~kg}$ o más que $2 \mathrm{~kg}$ ?

¿Se puede usar un martillo para clavar un clavo?

\section{Nivel de conciencia alterado}

\section{Grupo B}

¿Puede flotar una hoja

en el agua?

¿Hay elefantes en el

mar?

¿Pesan $2 \mathrm{~kg}$ más que $1 \mathrm{~kg}$ ?

¿Se puede usar un martillo para cortar madera?

Ausente Presente

Ausente Presente

Es positivo si la puntuación RASS es diferente de 0

Puntuación global

Si el 1 y el 2 y cualquiera de los criterios 3 o 4 están presentes, el

enfermo tiene delirium

ASE: Attention Screening Examination; CAM-ICU: Confusion Assessment Method for the Intensive Care Unit; GCS: Glasgow Coma Score; RASS: Richmond Agitation Sedation Scale.

Adaptada de Ely et al. ${ }^{90}$.

¿Cuál es el papel de la monitorización de la profundidad de sedación mediante índice biespectral (BIS) en el paciente crítico?

B6. Se recomienda utilizar el BIS solamente para evitar infra y sobresedación en los pacientes que requieran bloqueo neuromuscular o no sea factible el uso de escalas clínicas.

Grado de recomendación: fuerte. Nivel de evidencia: moderado (1 B).

Justificación: La utilización de sistemas derivados del electroencefalograma (EEG) para asegurar la inconsciencia en quirófano durante el acto quirúrgico ha llevado a evaluar estos dispositivos para manejar la sedación en otros entornos, como las UCl. Entre estos sistemas destacan la entropía y sobre todo el BIS, el más utilizado y evaluado de todos $^{91,92}$. El BIS es un parámetro adimensional derivado del EEG cuyo rango va de 0 , ausencia de actividad cerebral, a 100, completamente alerta. Para una anestesia quirúrgica se considera apropiado el intervalo 40$60^{91}$.

Diversos estudios han abordado la correlación entre el valor de BIS y las escalas clínicas con resultados dispares, aunque han sido considerados aceptables por algunos autores ${ }^{93-98}$. En general, no se han mostrado apropiados para ajustar la sedoanalgesia99-101. La causa principal de esa mala correlación son los artefactos producidos por el electromiograma ${ }^{102-105}$, que desaparecen lógicamente cuando se usan bloqueadores neuromusculares. La depresión profunda de la actividad cerebral es captada por el BIS y no por las escalas clínicas ${ }^{106}$. 
Por las razones comentadas, la opinión mayoritaria es que no se utilice el BIS cuando puedan usarse las escalas clínicas $^{107-110}$, por lo que la mayor ventaja del BIS sería permitir controlar la sedación en los pacientes bajo bloqueo neuromuscular ${ }^{111}$, en los que resultaría apropiada la recomendación de anestesia quirúrgica manteniendo el BIS entre 40 y 60 . Es importante subrayar que la sedación por debajo de 40 y el aumento de la tasa de supresiones (porcentaje de EEG isoeléctrico) se ha asociado con aumento de mortalidad $^{112}$.

El BIS se ha utilizado también como herramienta pronóstica tras parada cardiorrespiratoria, como marcador de muerte encefálica, como monitorización en neurocríticos o como indicador del grado de encefalopatía hepática. Estas indicaciones van más allá de los objetivos de estas recomendaciones, existiendo en general escasa evidencia publicada.

B7. Se recomienda el uso de BIS para la evaluación del estado de conciencia en pacientes con fallo hepático fulminante y encefalopatía en lista activa para trasplante hepático para su seguimiento antes y después del trasplante.

Grado de recomendación: fuerte. Nivel de evidencia: débil (1 C).

Justificación: El uso del BIS en anestesia se ha validado desde hace varios años para la valoración del estado de alerta o despertar. Ha sido recomendado especialmente en técnicas de anestesia total intravenosa por ser un método no invasivo fácil de interpretar. En pacientes con insuficiencia hepática fulminante se observó que el aumento de los valores de BIS se producía ligeramente antes de que se observara la recuperación en la escala de coma Glasgow en el postoperatorio del trasplante hepático ${ }^{113}$.

\section{Paciente con delirium y síndromes de abstinencia}

\section{Delirium}

¿Cuáles son los factores que contribuyen a su aparición?

C1. Se recomienda identificar los factores de riesgo predisponentes para el desarrollo de delirium en el enfermo grave.

Grado de recomendación: fuerte. Nivel de evidencia: moderado $(1 \mathrm{~B})$.

Justificación: El delirium tiene una elevada incidencia en el enfermo grave y es un factor independiente de mortalidad y de estancia prolongada en la $\mathrm{UCl}$.

En 1996 Inouye y Charpentier ${ }^{114}$ identificaron los factores de riesgo precipitantes de delirium en una población de 160 sujetos mayores de 70 años ingresados en un hospital. La incidencia de delirium fue del 18\%. Los factores de riesgo asociados a su aparición fueron: limitación física (odds ratio -OR-4,4; [intervalo de confianza -IC- 95\%: 2,5-7,9]); desnutrición (OR 4,0 [IC 95\%: 2,2 a 7,4]); administración $\geq 3$ fármacos (OR 2,9 [IC 95\%: 1,6 a 5,4]]; uso de sonda vesical (OR 2,4 [IC 95\%: 1,2 a 4,7]); y un evento iatrogénico (OR 1,9 [IC 95\%:1,1 a3,2]). Tomándolos como base desarrolló y validó un modelo predictivo, asignando un punto por cada factor (tabla 8). La tasa de delirium por persona, en los grupos de bajo, intermedio y alto riesgo fue del 3, 20 y $59 \%$ respectivamente $(p<0,001)$.
Tabla 8 Estratificación de riesgo para delirium en pacientes hospitalizados $\geq 70$ años

\begin{tabular}{|c|c|c|}
\hline \multicolumn{3}{|l|}{ Factores de riesgo } \\
\hline \multicolumn{3}{|c|}{ Uso de restricción física } \\
\hline \multicolumn{3}{|c|}{ Malnutrición ${ }^{\mathrm{a}}$} \\
\hline \multicolumn{3}{|c|}{ Administración de $>3$ medicamentos } \\
\hline \multicolumn{3}{|c|}{ Catéter urinario } \\
\hline \multicolumn{3}{|c|}{ Algún episodio iatrogénico } \\
\hline Grupo de riesgo & $\begin{array}{l}\text { Probabilidad de } \\
\text { delirium (\%) }\end{array}$ & $\begin{array}{l}\text { Número de } \\
\text { factores de riesgo }\end{array}$ \\
\hline Bajo & 3 & 0 \\
\hline Intermedio & 20 & $1-2$ \\
\hline Alto & 59 & $\geq 3$ \\
\hline
\end{tabular}

Van Rompaey et al. ${ }^{115}$ evaluaron los factores riesgo para el desarrollo de delirium en una población de 523 enfermos ingresados en $\mathrm{UCl}$, no intubados en el momento de su inclusión en el estudio, agrupándolos en 4 dominios: características del paciente, patología crónica, enfermedad aguda y factores ambientales (tabla 9). La incidencia de delirium fue del $30 \%$, presentándose hasta en un $75 \%$ dentro del primer día y en más del $90 \%$ a partir del tercer día de su inclusión en el estudio.

¿Es posible predecir la aparición de delirium en el paciente crítico?

C2. Se recomienda el uso del modelo predictivo PREdiction of DELIRium in ICU patients (PRE-DELIRIC) para la predicción temprana de delirium y el inicio de medidas preventivas en el paciente crítico.

Grado de recomendación: fuerte. Nivel de evidencia: moderado (1 B).

Justificación: El PRE-DELIRIC (tabla 10) ${ }^{116}$ es un modelo desarrollado y validado para predecir el riesgo de aparición de delirium en pacientes críticos. Integra 10 factores de riesgo: edad, Acute Physiology and Chronic Health Evaluation (APACHE I), compromiso neurológico, tipo de paciente (quirúrgico, médico o traumatizado), infección, acidosis metabólica, uso de opioides, sedantes (benzodiazepinas o propofol), uremia y admisión urgente. El modelo tiene un área bajo la curva ROC de 0,87 , mientras que la curva ROC de la valoración de los médicos y enfermeras fue de 0,59. El modelo permite identificar a pacientes con alto riesgo e iniciar precozmente medidas preventivas dirigidas ${ }^{116}$. La versión on-line puede ser consultada y descargada en la dirección web: www.umcn.nl/Research/Departments/intensive\%20care/ Pages/vandenBoogaard.aspx

¿Cuáles son las escalas y elementos más usados para la monitorización y diagnóstico de delirium?

C3. Se recomienda utilizar la escala CAM-ICU para la monitorización y diagnóstico de delirium.

Grado de recomendación: fuerte. Nivel de evidencia: moderado $(1 \mathrm{~B})$.

C4. Todo paciente que tenga una respuesta con la escala de RASS de -3a+4 debe ser valorado con las escala CAM-ICU. 
Tabla 9 Factores de riesgo de delirium

\begin{tabular}{|c|c|c|}
\hline Factores de riesgo & Análisis univariado (OR) & Análisis multivariado $(\mathrm{OR})$ \\
\hline \multicolumn{3}{|l|}{ No modificables } \\
\hline \multicolumn{3}{|l|}{ Características del paciente } \\
\hline - Vivir solo en casa & $1,94(1,06$ a 3,57$)$ & \\
\hline - Alcohol (> 3 unidades/día) & $3,23(1,29$ a 4,80$)$ & $3,23(1,30$ a 7,98$)$ \\
\hline - Tabaquismo ( $\geq 10$ cigarros/día) & $2,04(1,05$ a 3,95$)$ & \\
\hline - La edad, edad > 65 años y género & NS & \\
\hline \multicolumn{3}{|l|}{ Patología crónica } \\
\hline - Demencia: OR 2,41 & $2,18(1,14$ a 4,14$)$ & $2,41(1,21$ a 4,79$)$ \\
\hline - Insuficiencia cardíaca y enfermedad pulmonar & NS & \\
\hline \multicolumn{3}{|l|}{ Modificables } \\
\hline \multicolumn{3}{|l|}{ Enfermedad aguda } \\
\hline - Estancia en UCI antes de la inclusión & $1,26(1,17$ a 1,35$)$ & \\
\hline - Estancia en UCI > 1 día & $2,78(1,89$ a 4,09$)$ & \\
\hline - Estancia en $\mathrm{UCl}>2$ días & $5,77(3,71$ a 8,97$)$ & \\
\hline - Enfermedad de origen médico & $1,57(1,07$ a 2,29$)$ & \\
\hline - Alto riesgo de muerte: SAPS $\|>40$, APACHE $\|>24$ & $2,5(1,31$ a 4,66$)$ & \\
\hline - TISS- $28 \geq 30$ & $2,81(1,60$ a 5,05$)$ & \\
\hline - Medicamentos psicoactivos & $3,34(1,99$ a 4,99$)$ & $3,34(1,50$ a 11,23$)$ \\
\hline - Sedación & $13,66(7,15$ a 26,1$)$ & \\
\hline - Uso de benzodiazepinas & $2,89(1,44$ a 5,69$)$ & \\
\hline - Presencia de cánula endotraqueal o traqueal & $7,04(4,30$ a 14,16$)$ & $8,07(1,18$ a 55,06$)$ \\
\hline - Presencia de sonda gástrica & $7,80(4,30$ a 14,16$)$ & \\
\hline - Presencia de sonda vesical & $5,37(2,09$ a 13,80$)$ & \\
\hline - Número de infusiones & $1,35(1,20$ a 1,52$)$ & \\
\hline$-\geq 3$ infusiones & $2,87(1,85$ a 4,47$)$ & $2,74(1,07$ a 7,05$)$ \\
\hline - Incapacidad para alimentación regular & $3,83(2,36$ a 6,22$)$ & \\
\hline - Uso de morfina, presencia de fiebre y catéter arterial & NS & \\
\hline \multicolumn{3}{|l|}{ Factores ambientales } \\
\hline - Aislamiento del paciente & $3,74(1,69$ a 8,25$)$ & $2,89(1,0$ a 8,36$)$ \\
\hline - No visualizar la luz del día & $1,75(1,19$ a 2,56$)$ & $2,39(1,28$ a 4,45$)$ \\
\hline - No recibir visitas & $2,83(1,5$ a 5,36$)$ & $3,73(1,75$ a 7,93$)$ \\
\hline - Admisión de otra área (no urgencias) & $1,98(1,20$ a 3,28$)$ & \\
\hline - Restricción física & $33,8(11,1$ a 102,3$)$ & \\
\hline $\begin{array}{l}\text {-La admisión vía urgencias, habitación abierta, ausencia de reloj } \\
\text { visible y número de visitas }\end{array}$ & NS & \\
\hline
\end{tabular}

NS: no significativo; OR: odds ratio. UCl: unidad de cuidados intensivos.

Adaptada de van Rompaey et al. ${ }^{115}$.

Grado de recomendación: fuerte. Nivel de evidencia: moderado (1 B).

C5. Se recomienda utilizar con precaución la escala Intensive Care Delirium Screening Checklist (ICDSC) para la detección de delirium, debido al riesgo de detectar casos falsos positivos.

Grado de recomendación: fuerte. Nivel de evidencia: moderado (1 B).

Justificación: En la práctica clínica se inicia la valoración con la escala de sedación RASS antes de la aplicación de la valoración CAM-ICU ${ }^{90}$ (fig. 1). La segunda etapa es valorar la función cerebral. La herramienta validada para la monitorización del delirium es la CAM-ICU. Wei et al. ${ }^{117}$ llevaron a cabo una evaluación de la escala CAM-ICU, presentando una sensibilidad del 94\% (IC 95\%: 91 a 97\%) y una especificidad del 89\% (IC 95\%: 85 a 94\%). En los pacientes bajo VM, la escala CAM-ICU proporciona una evaluación no verbal de la escala CAM, con una sensibilidad del $95-100 \%$ y una especificidad del $93-98 \%^{117}$.
La escala ICDSC, desarrollada para la detección de delirium en el enfermo grave, también es útil para detectar tipos de delirium subclínicos. Presenta un área bajo la curva ROC de 0,90 . Un punto de corte de $\geq 4$ tiene una sensibilidad del $99 \%$ y una especificidad del $64 \%$. Por tanto, la tasa de falsos positivos es del $36 \%{ }^{118}$.

¿Cuál o cuáles son las mejores opciones terapéuticas?

C6. Se recomienda el abordaje no farmacológico del delirium, previo a la terapia farmacológica.

Grado de recomendación: fuerte. Nivel de evidencia: moderado (1 B).

Justificación: El primer paso en el manejo del delirium en el paciente grave es el diagnóstico temprano. Una vez detectado, deberán tratarse los factores de riesgo ${ }^{119-121}$. Las intervenciones generales recomendadas para ello son: a) adecuar la sedación (evitar sedación excesiva, monitorizarla, interrumpirla diariamente, evitar relajantes neuromusculares, adecuar la dosificación y el tiempo de aplicación de las combinaciones de sedantes), 
1. Comienzo agudo o evolución fluctuante del

estado mental

2. Falta de atención

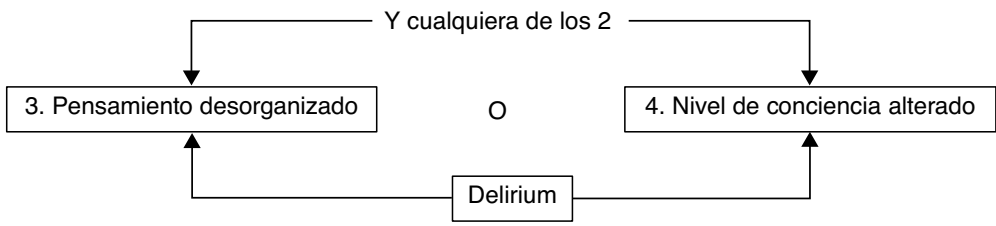

Figura 1 Diagrama de flujo del Confusion Assessment Method for the Intensive Care Unit (CAM-ICU). Adaptada de Ely et al. ${ }^{90}$.

Tabla 10 Fórmula del modelo PREdiction of DELIRium in ICu patients (PRE-DELIRIC)

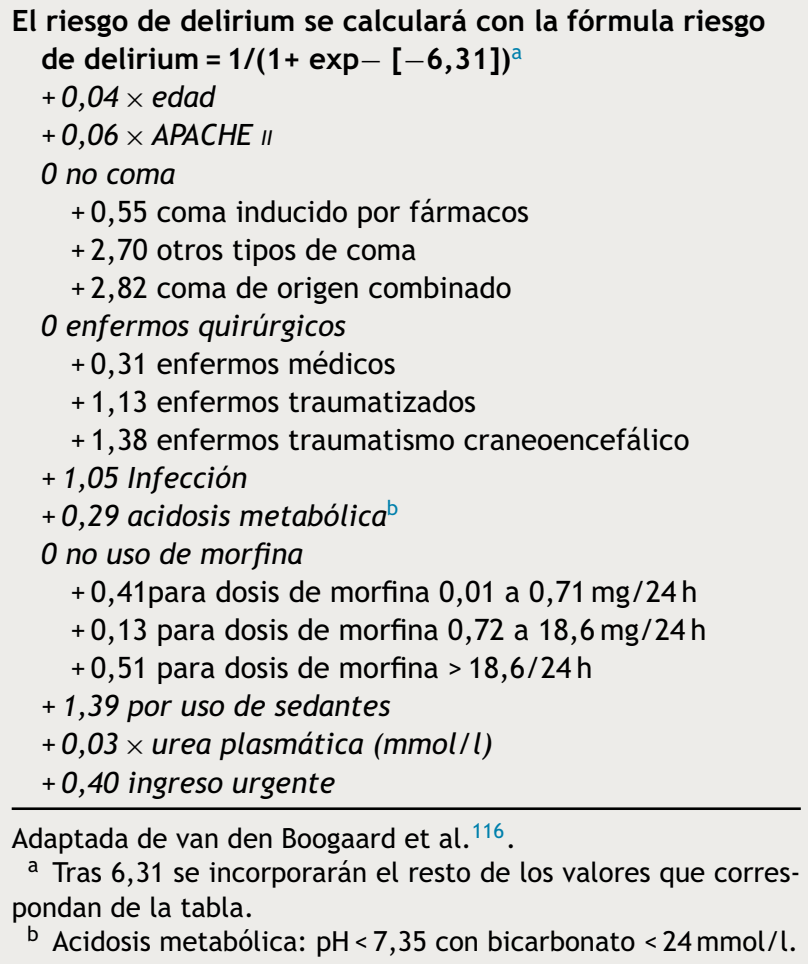

b) realizar traqueostomía temprana (cuando está indicada reduce la necesidad de sedación y mejora la capacidad de comunicación y la movilidad del paciente), c) optimizar el manejo del dolor y d) hacer diagnóstico precoz, profilaxis y tratamiento de los síndromes de abstinencia.

Las estrategias no farmacológicas incluyen reorientación, estimulación cognitiva varias veces al día, adecuación de la relación sueño-vigilia, movilización temprana, retirada precoz de catéteres, estimulación visual y auditiva, manejo adecuado del dolor y minimización del ruido y la luz artificial. Con estas intervenciones se reduce la incidencia del delirium hasta un $40 \%$.

C7. Se recomienda utilizar como terapia farmacológica en el tratamiento del delirium antipsicóticos y/o dexmedetomidina.
Grado de recomendación: fuerte. Nivel de evidencia: moderado (1 B).

C8. El haloperidol es el medicamento recomendado para el manejo del delirium en el enfermo grave, comenzando con dosis de 2,5 a $5 \mathrm{mg}$ intravenosos, con intervalos de 20 a $30 \mathrm{~min}$, hasta el control de los síntomas.

Grado de recomendación: fuerte. Nivel de evidencia: moderado (1 B).

C9. Los antipsicóticos atípicos (olanzapina, risperidona, quetiapina) se recomiendan como alternativa en el manejo del delirium.

Grado de recomendación: fuerte. Nivel de evidencia: moderado $(1 \mathrm{~B})$.

Justificación: Campbell et al. ${ }^{122}$ evaluaron las intervenciones farmacológicas enfocadas a la prevención y tratamiento el delirium. Con relación a las medidas de prevención, el uso de dosis única de risperidona posterior a una cirugía cardiovascular demostró una reducción significativa de delirium vs. placebo. No hubo reducción de la incidencia de delirium con el uso de haloperidol, donepezilo y citicolina. La sedación con dexmedetomidina o lorazepam en pacientes bajo VM y el uso de agentes anestésicos en el intraoperatorio en cirugía no cardíaca no redujo la incidencia de delirium.

El haloperidol es el fármaco de elección, con disminución de la gravedad de los síntomas y la duración del episodio de delirium. Los antipsicóticos de segunda generación son una alternativa en pacientes no candidatos o intolerantes a los de primera generación. Lonergan et al. ${ }^{123}$ compararon el haloperidol vs. risperidona, olanzapina y quetiapina en el tratamiento del delirium. Los resultados no demostraron una diferencia significativa en el efecto global de los antipsicóticos atípicos en el delirium en comparación con el haloperidol (OR 0,63 [IC 95\%: 0,29 a 1,38]). Con relación a los efectos adversos el haloperidol a dosis bajas, no tuvo una incidencia de eventos adversos mayor que los antipsicóticos atípicos. El haloperidol a dosis altas (>4,5 mg/día) se asoció con una incidencia mayor de efectos extrapiramidales, en comparación con la olanzapina.

Devlin et al. ${ }^{124}$ compararon la quetiapina con placebo para el tratamiento del delirium en la $\mathrm{UCl}$ con necesidad de haloperidol. El tiempo de resolución del delirium fue más corto en el grupo de quetiapina (mediana 1 día [intercuartiles -IQR- 0,5 a 3 días]) que en grupo placebo (mediana 4,5 días [IQR 2 a 7 días]), $(\mathrm{p}=0,001)$. El grupo de quetiapina 
recibió haloperidol durante un período más corto (mediana 3 días [IQR 2 a 4 días]) que el grupo placebo (mediana 4 días [IQR 3 a 8 días]), $(p=0,05)$. La duración de los episodios de delirium fueron menores en el grupo de quetiapina (mediana $36=\mathrm{h}$ [IQR 12 a $87 \mathrm{~h}$ ]) que en el grupo placebo (mediana 120 h [IQR 60 a 195 h]), $(\mathrm{p}=0,006)$.

C10. Se recomienda la dexmedetomidina como alternativa en el manejo del delirium.

Grado de recomendación: fuerte. Nivel de evidencia: moderado (1 B).

Justificación: Reade et al. ${ }^{125}$ evaluaron el uso de la dexmedetomidina vs. haloperidol en 20 enfermos con fracaso de «destete» por agitación. Los pacientes asignados al grupo de dexmedetomidina fueron extubados más rápidamente que los del grupo de haloperidol (mediana 20 h [IQR 7 a 24h]) vs. (mediana 42,5 h [IQR 23 a $119 \mathrm{~h}]),(p=0,021 \mathrm{~h})$. La dexmedetomidina disminuyó de manera significativa la estancia en $\mathrm{UCl} 1,5$ vs. 6,5 ( $p=0,004)$.

C11. Las benzodiazepinas no están indicadas para el manejo del delirium, ya que predisponen a la sedación excesiva, depresión respiratoria y empeoramiento de la disfunción cognitiva.

Grado de recomendación: fuerte. Nivel de evidencia: moderado (1 B).

Justificación: Lonergan et al. ${ }^{126}$ evaluaron las benzodiazepinas en el tratamiento del delirium en una revisión sistemática, observando que la duración promedio de días libres de delirium en los pacientes tratados con lorazepam fue de 7 días (5-10) y en el grupo de dexmedetomidina fue de 10 días $(9-12)(p=0,09)$. Los días libres de coma en pacientes tratados con lorazepam fueron $8(5-10)$ y en pacientes tratados con dexmedetomidina $9(9-12)(p=0,001)$. La prevalencia de coma fue del $92 \%$ en el grupo de lorazepam y del $63 \%$ en el grupo de dexmedetomidina $(p=0,001)$. La prevalencia de delirium o coma fue del $98 \%$ en los pacientes con lorazepam vs. $87 \%$ en los pacientes con dexmedetomidina $(p=0,003)$. No obstante, los autores consideran que dada la escasa investigación de calidad sobre este tópico se necesitan estudios controlados adicionales para establecer la función de las benzodiazepinas en el control del delirium no relacionado con el alcohol en pacientes hospitalizados.

C12. No se recomienda el uso de inhibidores de colinesterasa en el manejo del delirium.

Grado de recomendación: fuerte. Nivel de evidencia: moderado (1 B).

Justificación: Overshott et al. ${ }^{127}$ en una revisión sistemática concluyeron que solo existe un ensayo clínico que comparó el donepezilo ( $5 \mathrm{mg} /$ día) con placebo (una tableta/día) en la prevención y tratamiento del delirium en el período postoperatorio de 80 enfermos. Quince pacientes desarrollaron delirium: $8(20,5 \%)$ en el grupo de donepezilo y $7(17,1 \%)$ en el grupo placebo (riesgo relativo [RR] 1,20 [IC 95\%: 0,48 a 3,00]). No hubo diferencia significativa entre el grupo de tratamiento y placebo en la duración del delirium (diferencia promedio -0,3\%; IC 90\%:-7,8 a 7,2).

\section{Síndrome de abstinencia en la unidad de cuidados intensivos}

¿Cuáles son los factores que contribuyen para su aparición?

C13. Se recomienda evaluar el desarrollo de la tolerancia y el síndrome de abstinencia en todos los pacientes graves que se han manejado con sedantes y opioides, sobre todo cuando se utilizaron dosis elevadas, y en forma combinada durante más de $48 \mathrm{~h}$.

Grado de recomendación: fuerte. Nivel de evidencia: bajo (1 C).

Justificación: Una complicación frecuente de la sedación, cuando se utiliza durante más de una semana y en dosis elevadas, es la tolerancia, que puede ser metabólica o funcional. La incidencia del síndrome de abstinencia en las $\mathrm{UCl}$ pediátricas y de adultos puede llegar hasta el $62 \%{ }^{128}$.

Los factores de riesgo asociados al desarrollo del síndrome de abstinencia son: a) dosis elevadas de benzodiazepinas, opioides o propofol, b) infusión durante más de 3 días, c) suspensión brusca de los fármacos, d) combinación de medicamentos y e) administración de barbitúricos ${ }^{129,130}$.

El síndrome de abstinencia por benzodiazepinas se manifiesta con agitación, delirium, convulsiones, alucinaciones, alteraciones cognitivas, insomnio, temblor, fiebre, náuseas, vómitos e hiperactividad simpática (taquicardia, hipertensión, taquipnea) $)^{129,131-139}$.

El síndrome de abstinencia por propofol se asocia a infusiones durante más de $24 \mathrm{~h}$ y a dosis elevadas. Se caracteriza por confusión, temblor, alucinaciones, convulsiones tónico-clónicas, taquicardia, taquipnea y fiebre. El desarrollo de tolerancia al propofol está sujeto a controversia $^{51,140-150}$.

El síndrome de abstinencia por opioides se caracteriza por: irritabilidad, temblor, clonus, delirium, hipertonicidad, movimientos coreoatetósicos, alucinaciones, vómitos, estridor, diarrea, hipertensión arterial, taquicardia, diaforesis y fiebre. Una dosis total de fentanilo de más de $1,5 \mathrm{mg} / \mathrm{kg} 0$ una duración de la infusión de más de 5 días se asocia a una incidencia de síndrome de abstinencia del 50\%, mientras que una dosis total superior a $2,5 \mathrm{mg} / \mathrm{kg}$ durante más de 9 días se asocia a una incidencia del $100 \%$ en niños ${ }^{132,151-155}$.

¿Cuál o cuáles son las mejores opciones terapéuticas?

C14. Se recomienda el uso de protocolos de disminución progresiva de los sedantes y opioides para evitar síndromes de abstinencia.

Grado de recomendación: fuerte. Nivel de evidencia: bajo (1 C).

C15. Se recomienda el empleo de lorazepam durante la retirada de infusiones con dosis altas y por tiempo prolongado de midazolam.

Grado de recomendación: fuerte. Nivel de evidencia: bajo (1 C).

Justificación: Dentro de las estrategias para disminuir la incidencia de los síndromes de abstinencia a sedantes y opioides en el paciente grave se han descrito: a) el uso de escalas para ajustar las dosis a los objetivos terapéuticos de la sedación, b) evitar la sedación excesiva, c) limitar, en lo posible, los días de tratamiento, d) definir en cada caso y para cada sedante la forma de administración, en bolos o en infusión, e) reducir progresiva y gradualmente los sedantes y analgésicos, f) evitar en lo posible la combinación de medicamentos sedantes, sobre todo en dosis elevadas y g) valorar el empleo de la dexmedetomidina para facilitar la reducción de la dosis de opioides y sedantes.

Se han propuesto diferentes esquemas para la retirada de medicamentos: 
1. Para una sedación inferior a 5 días, la reducción debe ser del 10 al $15 \%$ de la dosis cada 6 a $8 \mathrm{~h}$ hasta su suspensión ${ }^{156}$.

2. Para una sedación de 7 días o más, sobre todo cuando se realiza con medicamentos de lenta eliminación, se recomienda la administración oral o subcutánea de dosis bajas del medicamento ${ }^{130}$.

3. Después de infusiones prolongadas de midazolam se recomienda el cambio a lorazepam por vía oral, teniendo en cuenta que la relación potencia y vida media midazolam/lorazepam es de 1,2 y 1,6 respectivamente. Después de la segunda dosis de lorazepam por vía oral se iniciará la reducción a un $50 \%$ de la dosis del midazolam y otro $50 \%$ tras cada dosis por vía oral ${ }^{156,157}$.

4. Para la reducción de los opioides se recomienda disminuir inicialmente de un 20 a un $40 \%$ la dosis y posteriormente el $10 \%$ cada $12-24 h^{157}$.

C16. Se recomienda la metadona por vía oral durante la retirada de los opioides administrados en dosis elevadas y durante un tiempo prolongado.

Grado de recomendación: fuerte. Nivel de evidencia: bajo (1 C).

Justificación: La dosis inicial de metadona será igual a la dosis total de fentanilo intravenoso. Después de la segunda dosis oral de metadona, la infusión de fentanilo se reducirá a un $50 \%$, y así sucesivamente, hasta la cuarta dosis. Las manifestaciones de abstinencia se tratarán con dosis de rescate de morfina. La dosis total de morfina usada para los rescates deberá considerarse para calcular la dosis de metadona del siguiente día. Si se observa una sedación excesiva, la metadona puede ser reducida en un $10-20 \%$ hasta que la sedación se controle. La dosis de metadona será reducida progresivamente en un $20 \%$ cada semana. De esta manera los opioides podrán ser retirados en 5 a 6 semanas $^{156}$.

C17. Se sugiere el uso de la dexmedetomidina o la clonidina para facilitar la retirada de los sedantes y opioides y tratar sus síndromes de abstinencia.

Grado de recomendación: bajo. Nivel de evidencia: moderada (2 B).

Justificación: Se ha sugerido que la clonidina o la dexmedetomidina pueden ser útiles para el tratamiento del síndrome de abstinencia por sedantes y opioides ${ }^{158-162}$.

C18. Se recomienda el uso de buprenorfina en el manejo del síndrome de abstinencia por opioides.

Grado de recomendación: fuerte. Nivel de evidencia: moderado $(1 \mathrm{~B})$.

Justificación: Gowing et al. ${ }^{163}$ en una revisión sistemática mostraron que la buprenorfina y la reducción progresiva de la dosis de metadona tienen la misma eficacia en el manejo del síndrome de abstinencia por opioides, pero los síntomas se resuelven más rápidamente con la buprenorfina. El cumplimiento del tratamiento de la abstinencia parece más probable con buprenorfina en comparación con metadona (RR 1,18 [IC 95\%: 0,93 a 1,49]), ( $p=0,18)$.

\section{Síndrome de abstinencia por alcohol}

¿Cuáles son las medidas de primera elección y alternativas de tratamiento?
C19. Se recomienda el uso de benzodiazepinas como tratamiento de primera línea para el síndrome de abstinencia por alcohol, prevención y manejo de las crisis convulsivas y delirium tremens.

Grado de recomendación: fuerte. Nivel de evidencia: moderado $(1 \mathrm{~B})$.

C20. Se sugiere el uso de dexmedetomidina como coadyuvante al tratamiento con benzodiazepinas en el manejo del síndrome de abstinencia por alcohol. (2C).

Grado de recomendación: débil. Nivel de evidencia: bajo

C21. No se recomienda el uso de etanol para el manejo del síndrome de abstinencia por alcohol.

Grado de recomendación: fuerte. Nivel de evidencia: moderado (1 B).

Justificación: El abuso de alcohol y los desórdenes secundarios a su ingesta son frecuentes en pacientes hospitalizados. Los síntomas de abstinencia por alcohol incluyen insomnio, temblor, ansiedad leve, anorexia asociada con náuseas y vómito, cefalea, diaforesis y palpitaciones (primeras $6 \mathrm{~h}$ ), crisis convulsivas tónico-clónicas (12 a $48 \mathrm{~h}$ ) y alucinaciones $(12 \text { a } 24 \mathrm{~h})^{164}$. El delirium tremens es la manifestación más grave, que pone en riesgo la vida, caracterizado por alucinaciones, desorientación, fiebre, taquicardia, agitación y diaforesis, y está asociado a suspensión aguda o abstinencia por alcohol ${ }^{164}$.

Las benzodiazepinas son el tratamiento de primera línea para el manejo del síndrome de abstinencia por alcohol, prevención y tratamiento de las crisis convulsivas y del delirium tremens $^{164}$.

Amato et al. ${ }^{165}$ compararon las benzodiazepinas con placebo $\mathrm{u}$ otros tratamientos farmacológicos y entre ellos mismos. Los resultados demostraron que las benzodiazepinas son efectivas para controlar los síntomas del síndrome de abstinencia por alcohol vs. placebo (RR 0,16 [IC 95\%: 0,04 a 0,69$])$. No hubo diferencias estadísticamente significativas entre el tratamiento con benzodiazepinas y con otros fármacos.

En un metanálisis se demostró que las benzodiazepinas son más efectivas que el placebo en reducir los signos y síntomas del síndrome de abstinencia por alcohol. Por otra parte, también hubo una reducción significativa de las crisis (-7,7 convulsiones por 100 pacientes [IC 95\%: -12,0 a -3,59]), $(p=0,003)$, y de la incidencia de delirium $(-4,9$ casos por 100 pacientes [IC 95\%: $-9,0$ a 0,7]), $(p=0,04)^{166}$.

En un estudio retrospectivo de 17 enfermos con abstinencia alcohólica, la adición de dexmedetomidina se asoció a una reducción de la dosis de benzodiazepinas en $32 \mathrm{mg} /$ día $(61,5 \%)$ (IC 95\%: 16,7 a 48,1), ( $p<0,001)$, haloperidol en $5,6 \mathrm{mg} /$ día $(46,7 \%)$ (IC 95\%: $-0,03$ a 11,23), $(\mathrm{p}=0,05)$ y la gravedad del síndrome de abstinencia en 1,9 puntos $(21 \%)$ (IC 95\%: 0,44 a 3,36), ( $\mathrm{p}<0,015)$ en las primeras $24 \mathrm{~h}$ de su administración. En cuanto a los parámetros hemodinámicos, la frecuencia cardíaca disminuyó una media de 23 lpm $(22,8 \%)$ (IC 95\%: 18,4 a 28,4), ( $\mathrm{p}<0,001)$ y la presión arterial sistólica se redujo 13,5 mmHg (9,6\%) (IC 95\%, 3,8 a 15,4\%), $(p=0,002)^{167}$.

Weinberg et al. ${ }^{168}$ en un ensayo clínico aleatorizado de 50 enfermos no observaron ninguna ventaja en la administración de etanol frente a la de benzodiazepinas durante 4 días en la profilaxis del síndrome de abstinencia por alcohol. 


\section{Síndrome de abstinencia por estimulantes (cocaína} y metanfetaminas)

\section{¿Cuáles son las medidas de tratamiento?}

C22. La evidencia científica actual no permite hacer recomendaciones sobre el manejo del síndrome de abstinencia por estimulantes. Sin embargo, ante la frecuencia de este síndrome, se sugiere la realización de estudios clínicos aleatorizados para determinar el manejo integral del síndrome de abstinencia por cocaína y anfetaminas.

Justificación: El síndrome de abstinencia por estimulantes produce disforia con sueño, apetito y alteraciones motoras. Dentro de las primeras 8 a $48 \mathrm{~h}$ pueden aparecer síntomas depresivos que pueden persistir hasta 2 semanas $^{169}$.

El tratamiento del síndrome de abstinencia por estimulantes como los agonistas indirectos de dopamina (metilfenidato, amantadita), antidepresivos (desipramina, bupropion) no ha demostrado eficacia en reducir la intensidad de los síntomas ${ }^{169}$.

Kampman et al. ${ }^{170}$ evaluaron la administración de antagonistas adrenérgicos (propranolol) vs. placebo en pacientes con síndrome de abstinencia por cocaína sin demostrar una superioridad con el uso de propranolol, excepto en aquellos pacientes con síndrome grave de abstinencia por cocaína.

En una revisión sistemática, los tratamientos para el síndrome de abstinencia por anfetaminas con amineptina o mirtazapina no mostraron diferencias al compararlos con placebo $^{171}$.

\section{Delirium y déficit cognitivo persistente}

¿Cuáles son los factores de riesgo asociados con déficit cognitivo persistente tras el ingreso en la UCl?

C23. Se recomienda realizar una valoración de los factores de riesgo asociados a la aparición de déficit cognitivo persistente en los pacientes admitidos a la UCI.

Grado de recomendación: fuerte. Nivel de evidencia: moderado (1 B).

Justificación: Hay pocos estudios que evalúan los factores de riesgo para déficit cognitivo persistente. El delirium ha sido encontrado como factor precipitante para la disfunción cognitiva en 2 estudios, en los cuales se halló una correlación positiva entre el delirium durante la estancia en $\mathrm{UCl}$ y el déficit cognitivo que persiste más allá del alta hospitalaria ${ }^{172,173}$. En un estudio observacional multicéntrico, Iwashyna et al. ${ }^{174}$ observaron que la sepsis grave era un factor de riesgo para déficit cognitivo persistente (OR: 3,34 [IC 95\%: 1,53 a 7,25$]$ ). El delirium hiperactivo y mixto han sido los subtipos más asociados al desarrollo de esta disfunción cognitiva, en comparación con el subtipo hipoactivo ${ }^{175}$. La enfermedad crítica aguda, incluso en ausencia de delirium, también puede ser un factor de riesgo para la persistencia de disfunción cognitiva a los 2 meses de la salida de la $\mathrm{UCI}^{176}$. En un estudio retrospectivo de 74 enfermos supervivientes de SDRA se encontró que la hiperglucemia se asoció a disfunción cognitiva ${ }^{177}$. Sin embargo, en dicho estudio no se ajustó el riesgo por algunas covariables como la gravedad de la enfermedad.

En un estudio de casos y controles de 37 pares de enfermos críticos la hipoglucemia se asoció con disfunción cognitiva en cuanto a habilidades visuoespaciales a un año del alta de la UCI. No obstante, estos hallazgos necesitan confirmación en otros estudios ${ }^{178}$. No recordar eventos ocurridos durante la estancia en UCl también parece estar asociado a disfunción cognitiva que persiste al menos un año luego del alta hospitalaria ${ }^{179}$. Al parecer, la enfermedad crítica crónica también se comporta como un factor de riesgo para déficit cognitivo persistente ${ }^{180}$.

¿Cuáles son las escalas más frecuentemente utilizadas para el diagnóstico y monitorización de la disfunción cognitiva?

C24. Se sugiere aplicar las escalas validadas como herramientas para la identificación de déficit cognitivo persistente.

Grado de recomendación: débil. Nivel de evidencia: bajo (2C).

Justificación: Se han usado muchas escalas para diagnosticar y cuantificar la disfunción cognitiva. Las más frecuentemente utilizadas son tests estandarizados que incluyen: Wechsler Adult Intelligence Test Revised ${ }^{181}$, Wechsler Memory Scale-Revised ${ }^{181}$, Rey Auditory-Verbal Learning Test, Rey Osterrieth Complex Figure Test ${ }^{182}$, Trail Making Test Parts $A$ and $B^{183}$ y Verbal Fluency Test ${ }^{184}$. Hay experiencia importante con el uso de estas pruebas neurocognitivas y han sido validadas en diferentes entornos para evaluar el déficit cognitivo persistente.

Otras pruebas que también pueden ser aplicadas son la Mini-Mental State, que está validada y es más fácil de utilizar en la UCI ${ }^{185}$, The Cambridge Neuropsychological Test Automated Battery, que puede ser utilizada en pacientes que no pueden hablar ${ }^{186}$, y el Questionnaire on Cognitive line in the Elderly, que puede ser administrado a los familiares o visitantes del paciente ${ }^{187}$. Según nuestro conocimiento, no hay estudios que comparen la exactitud de dichas escalas.

¿Cuáles son las mejores opciones de manejo?

C25. Se sugiere implementar medidas preventivas para el déficit cognitivo persistente, dada la ausencia de ensayos clínicos que evalúen posibles opciones terapéuticas una vez que esta condición ya se ha manifestado. (2C).

Grado de recomendación: débil. Nivel de evidencia: bajo

Justificación: Hasta el momento no hay estudios diseñados para evaluar el déficit cognitivo persistente como desenlace primario para cualquier intervención terapéutica. Sin embargo, sí ha sido evaluado como desenlace secundario ${ }^{188}$. La movilización temprana y la terapia ocupacional se han asociado con tasas reducidas de ocurrencia de delirium en $\mathrm{UCl}$ y en el hospital, así como también con mejores desenlaces funcionales a largo plazo. Dada la relación directa entre algunos factores de riesgo modificables y la ocurrencia de déficit cognitivo persistente, se podría inferir que la modificación de dichos factores puede tener un impacto significativo en su incidencia. Aun así, no hay suficiente información para apoyar esta suposición.

\section{Prevención no farmacológica del delirium en la unidad de cuidados intensivos}

¿Cuáles son las intervenciones no farmacológicas recomendadas para prevenir el desarrollo de delirium en la UCI? 
C26. Se recomienda utilizar un protocolo de movilización temprana como un componente mayor de las estrategias para la prevención del delirium en los pacientes que se encuentran en UCI.

Grado de recomendación: fuerte. Nivel de evidencia: moderado (1 B).

C27. Se sugiere utilizar múltiples intervenciones en conjunto y el uso de tapones auditivos para prevenir el delirium. (2C).

Grado de recomendación: débil. Nivel de evidencia: bajo

Justificación: El objetivo de las intervenciones no farmacológicas es prevenir o revertir potenciales factores de riesgo. Hasta la fecha solo pocos estudios han evaluado estas estrategias no farmacológicas para la prevención del delirium, y la mayoría de ellos se han realizado fuera del ámbito del cuidado crítico. Schweickert et al. ${ }^{188}$ observaron que un protocolo de movilización temprana y terapia ocupacional puede reducir la duración del delirium en pacientes con VM. Se realizó un estudio de antes-y-después, que evaluó una intervención basada en la reorientación de pacientes, musicoterapia y el uso de un protocolo de sedación y analgesia, en el cual la incidencia de delirium no cambió; sin embargo, la incidencia de delirium subclínico se redujo ${ }^{189}$. Needham y Korupolu evaluaron la movilización temprana en el contexto de un programa de mejoramiento de calidad, encontrando que después de implementar el protocolo de movilización temprana la incidencia de delirium disminuyó (días en $\mathrm{UCl}$ sin delirium: 53 vs. $21 \%$, $\mathrm{p}=0,003)^{190}$. En un estudio reciente que evaluó el uso de tapones auditivos para mejorar la calidad del sueño y reducir la incidencia de delirium, esta no disminuyó; sin embargo, la ocurrencia de confusión leve sí se redujo de manera significativa ${ }^{191}$.

¿Cuáles son los indicadores de calidad que deben ser usados para evaluar las medidas de prevención?

C28. Se sugiere interconsultar a terapia física y ocupacional para la adecuada movilización del paciente en la UCI. La sobresedación, incidencia del delirium, valoración del dolor, eventos de seguridad y movilidad funcional deben ser usados como indicadores de calidad para la prevención del delirium; sin embargo, se necesitan más estudios que aborden este tema. (2C).

Grado de recomendación: débil. Nivel de evidencia: bajo

Justificación: Solo un estudio que evalúa los indicadores de calidad para prevención de delirium ha sido publicado hasta la fecha. En este estudio Needham y Korupolu ${ }^{190}$ usaron como indicadores de calidad para la prevención del delirium los siguientes: 1) interconsultas a terapia física y ocupacional (proporción de pacientes), 2) alerta de sobresedación (proporción de días en $\mathrm{UCl}$ ), 3) incidencia de delirium (proporción de días en $\mathrm{UCl}$ ), 4) escalas de dolor (media de puntajes diarios), 5) inestabilidad fisiológica (medida como cambio en la frecuencia cardíaca, presión sistólica y saturación de oxígeno desde el comienzo hasta el final del procedimiento), 6) eventos inesperados (proporción de tratamientos) y 7) movilidad funcional (proporción de tratamientos con el paciente sentado al borde de la cama o durante intentos de bipedestación).

\section{Pacientes sin intubación traqueal ni asistencia ventilatoria}

¿Cuáles son las recomendaciones para el manejo del paciente con ansiedad y combativo que ingresa a la UCI?

D1. Se recomienda el inicio de la sedación del paciente críticamente enfermo agitado solo después de proporcionar una analgesia adecuada y tratar las causas potencialmente reversibles.

Grado de recomendación: fuerte. Nivel de evidencia: bajo (1C).

D2. Se recomienda establecer y redefinir periódicamente el objetivo de la sedación para cada paciente. La respuesta al tratamiento debe ser evaluada en forma continua y documentada sistemáticamente.

Grado de recomendación: fuerte. Nivel de evidencia: bajo (1 C).

D3. Se recomienda en los pacientes $\sin I T$ y/o sin soporte ventilatorio usar fármacos con bajo riesgo de producir depresión respiratoria y efectos adversos hemodinámicos graves, tales como haloperidol y dexmedetomidina.

Grado de recomendación: fuerte. Nivel de evidencia: bajo (1 C).

¿Es útil el manejo farmacológico en pacientes con VM no invasiva no colaboradores?

D4. Se recomienda sedación con medicamentos que no produzcan depresión respiratoria en pacientes no colaboradores con VM no invasiva.

Grado de recomendación: fuerte. Nivel de evidencia: moderado $(1 \mathrm{~B})$.

Justificación: El tratamiento farmacológico en el paciente críticamente enfermo agitado sin vía aérea artificial puede llevar a una menor cooperación por parte del paciente. Además, los medicamentos por si solos pueden ser la causa de la agitación o de la pérdida de la vía aérea, creando una urgencia aguda. Por tanto, la monitorización del nivel de sedación es más importante que la técnica seleccionada para sedar ${ }^{192}$.

En los enfermos sin IT se usan los mismos fármacos que en los pacientes intubados. La forma de administración en bolo es mejor al inicio, continuando con infusión que será pautada según la respuesta. Si el paciente está muy agitado puede ser inmovilizado mientras se le administran las medicaciones apropiadas por vía intravenosa ${ }^{192}$.

Lo más importante para la sedación en el paciente crítico agitado sin VM es la presencia física de personal adecuadamente entrenado en el manejo de la vía aérea ${ }^{192}$. La elección apropiada de los medicamentos sedantes es a menudo difícil, y depende de las necesidades individuales. Si se requiere un rápido despertar, como en el paciente neurológico, el propofol es el fármaco recomendado. El haloperidol ha sido el fármaco preferido en el delirium. No se recomienda utilizar benzodiazepinas porque empeoran el cuadro de agitación. Las dosis de medicamentos requeridos para la adecuada sedación también varían en el paciente crítico dependiendo de la comorbilidad, de la interacción del sedante con otros fármacos y de la respuesta al tratamiento ${ }^{193}$ (fig. 2).

En los últimos años hemos asistido a un incremento del uso de la VM no invasiva en la UCl. Su uso está indicado 


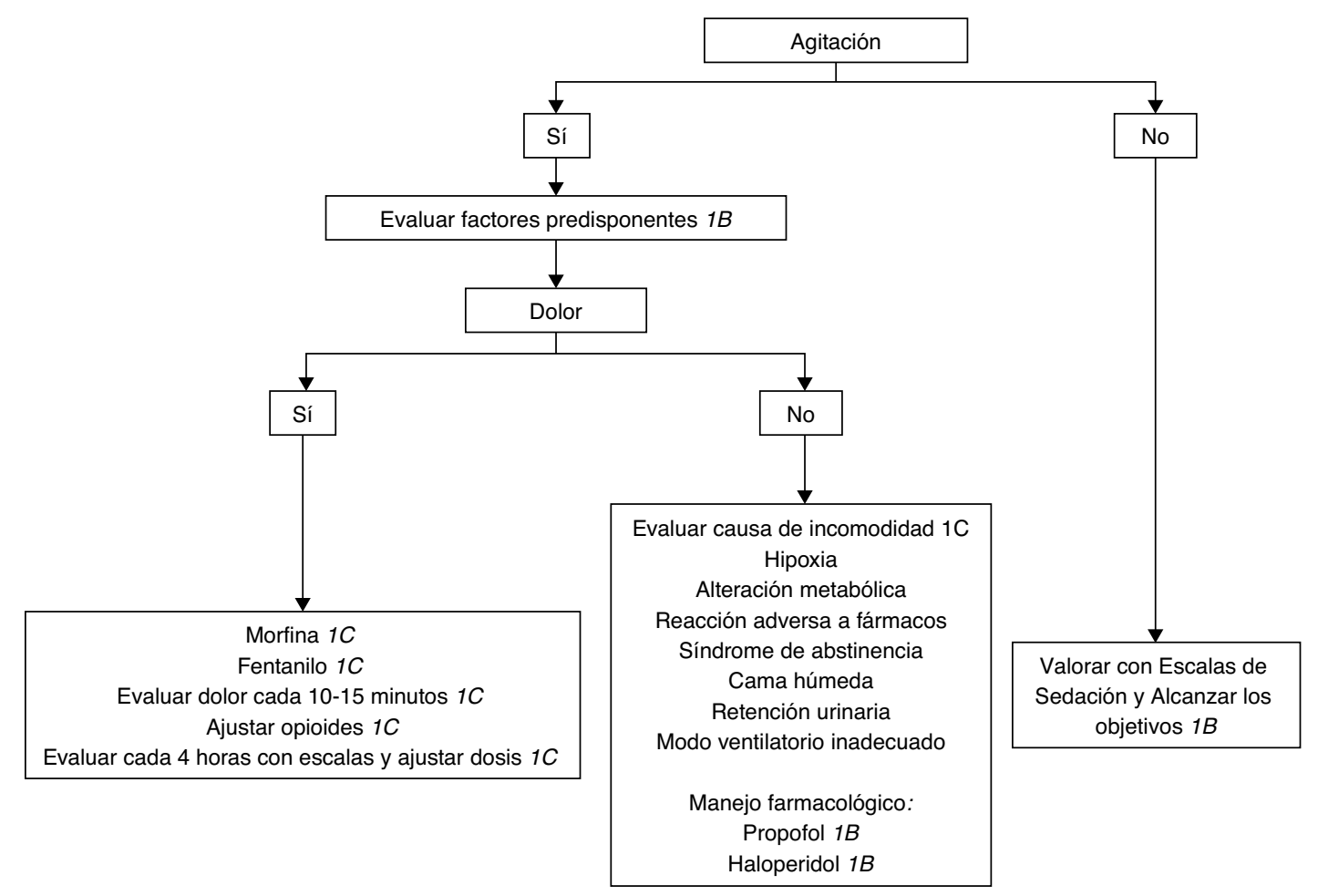

Figura 2 Algoritmo para la sedación y analgesia de los pacientes sin intubación traqueal.

principalmente en casos de insuficiencia respiratoria aguda, con el objetivo de mejorar la oxigenación arterial, aumentar la ventilación alveolar, disminuir el trabajo respiratorio y evitar la IT. La VM no invasiva reduce la mortalidad y la necesidad de intubación en pacientes con EPOC con insuficiencia respiratoria cuando se utiliza tanto en $\mathrm{UCl}$ como en hospitalización. En la UCI la VM no invasiva reduce también los días de estancia ${ }^{194}$. La tolerancia del paciente es importante para asegurar la eficacia de la VM no invasiva. No obstante, esta modalidad de ventilación asistida frecuentemente reduce la comodidad de los enfermos, generando ansiedad, angustia y dificultad para la sincronización entre el paciente y el ventilador.

Los esquemas terapéuticos elegidos son variables, pero no deben utilizarse fármacos que provoquen depresión respiratoria ${ }^{195}$. Entre los medicamentos de los que disponemos actualmente para sedación, el único que no produce depresión respiratoria es la dexmedetomidina ${ }^{195,196}$. El midazolam ${ }^{195}$ o el remifentanilo ${ }^{197,198}$ a bajas dosis y bajo estricta monitorización médica pueden ser utilizados.

En un ensayo clínico de 41 enfermos con VM no invasiva, ambos fármacos fueron eficaces en alcanzar el grado de la escala RASS deseado y mantuvieron la misma frecuencia respiratoria y parámetros de intercambio gaseoso. En el grupo dexmedetomidina 2 enfermos precisaron ajuste de dosis y en el grupo midazolam $3^{195}$. Huang et al. también compararon el efecto de la dexmedetomidina con midazolam en 62 enfermos con edema pulmonar cardiogénico que rechazaron la VM no invasiva. El grupo tratado con dexmedetomidina requirió menos IT (21 vs. 45\%), (RR 0,47 [IC 95\%: 0,22 a $1,02]),(p=0,06)$; menor estancia en $\mathrm{UCl}(4,9$ vs. 8,5 días $)$, $(p=0,04)$; y mortalidad en UCl similar (6 vs. $10 \%)^{199}$.
¿Se deben utilizar elementos para la inmovilización de pacientes? ¿Cuándo?

$D 5$. Se recomienda el uso de sujeción solo en situaciones clínicas apropiadas, y no como un procedimiento de rutina. Cuando la sujeción sea usada, debe ser claro su beneficio y basado en un protocolo del servicio.

Grado de recomendación: fuerte. Nivel de evidencia: bajo (1 C).

D6. Se recomienda que la elección de la terapia de sujeción sea la menos invasiva y capaz de optimizar la seguridad del paciente, su comodidad y su dignidad.

Grado de recomendación: fuerte. Nivel de evidencia: bajo (1 C).

D7. Se recomienda el registro en la historia clínica del uso racional de la sujeción y el tiempo durante el cual se va a utilizar. Requiere órdenes escritas.

Grado de recomendación: fuerte. Nivel de evidencia: bajo (1 C).

D8. Se sugiere revaluar periódicamente la posibilidad de retirar la sujeción.

Grado de recomendación: débil. Nivel de evidencia: bajo (2C).

D9. Se recomienda el uso de los medicamentos analgésicos, sedantes y neurolépticos para el tratamiento del dolor, la ansiedad o los trastornos psiquiátricos del paciente en la $\mathrm{UCl}$, ya que pueden disminuir la necesidad de sujeción. Esos medicamentos no se deben administrar en dosis excesivas como «método de sujeción química».

Grado de recomendación: fuerte. Nivel de evidencia: bajo (1 C).

D10. Se recomienda evaluar el desarrollo de complicaciones de la sujeción, al menos, cada $4 \mathrm{~h}$. 
Grado de recomendación: fuerte. Nivel de evidencia: bajo (1 C).

Justificación: Las sujeciones son usadas comúnmente en $\mathrm{UCl}$ para proteger al paciente de los riesgos asociados con el retiro accidental de dispositivos tales como tubo endotraqueal, sondas nasogástrica, catéteres venosos, arteriales, tubos de drenaje y sondas urinarias, así como impedir la lesión involuntaria al personal de salud debido a la alteración del estado cognoscitivo del paciente $e^{200,201}$. También pueden ser necesarias para limitar los movimientos del paciente cuando estén contraindicados; por ejemplo, en una fractura espinal, para facilitar la realización de procedimientos en los que el paciente no puede colaborar, y finalmente para facilitar el manejo de algunos pacientes psiquiátricos $^{202}$. El método usado más frecuentemente es limitar el movimiento de los miembros superiores mediante la fijación a nivel de las muñecas $(87 \%)^{201}$.

La inmovilización debe ser usada solo cuando las medidas alternativas han sido infructuosas o no puedan ser empleadas sin poner en riesgo al paciente. Entre estas medidas alternativas no farmacológicas está la limitación del ruido, evitar despertar innecesariamente al paciente y la colaboración familiar. Si lo anterior falla, la inmovilización podrá ser necesaria.

A la hora de prescribir la sujeción del paciente hay que considerar el potencial conflicto entre la percepción del equipo médico-enfermera y el mejor interés del paciente. Por un lado, hay que valorar la necesidad de proteger al enfermo de sus acciones involuntarias, pero también hay que tener en cuenta que la inmovilización puede agravar los síntomas de delirium y puede producir lesiones. Por otro lado, hay que proteger al equipo que atiende al enfermo de la agresión involuntaria por parte de un paciente agitado.

La sujeción se debe usar el menor tiempo posible y su indicación debe quedar escrita en la historia clínica. Según las normas de la Joint Commission on Accreditation of Healthcare Organizations ${ }^{203}$, una vez que las alternativas a la sujeción han fracasado y se da la orden de sujetar al paciente, es necesario escribirlo en la historia clínica, explicando el motivo de la misma. En la realidad es el personal de enfermería el que sugiere la decisión de usar la inmovilización de los pacientes. Cada institución debe desarrollar internamente un programa para asegurar la calidad de la atención, en concordancia con los principios y políticas para un adecuado uso de las inmovilizaciones físicas ${ }^{201}$ (fig. 3).

Las políticas de sujeción mecánica en las UCI del mundo son muy variables, aun con tecnologías o relación enfermera-paciente similares ${ }^{204}$, y su prevalencia asimismo es muy variable (del 0 al $100 \%)^{205}$. Algunos estudios han encontrado cierta relación entre la extubación traqueal no planificada con la sujeción mecánica ${ }^{206,207}$. También se ha asociado la sujeción mecánica con un mayor riesgo de padecer delirium ${ }^{115}$ y síndrome de estrés postraumático en pacientes dados de alta de la $\mathrm{UCl}^{208}$, pero por la metodología de los estudios impide llegar certeramente a estas conclusiones.

\section{E. Paciente con ventilación mecánica}

¿Hay beneficios fisiológicos al utilizar sedación y analgesia durante la VM?
E1. Se recomienda el uso rutinario de sedoanalgesia en los pacientes ventilados mecánicamente con IT.

Grado de recomendación: fuerte. Nivel de evidencia: moderado (1 B).

Justificación: La falta de adaptación del paciente con el ventilador genera numerosas complicaciones que pueden agravar la situación de los pacientes críticos y que, por tanto, deben ser evitadas. Entre ellas: acidosis respiratoria secundaria a hipoventilación y aumento de la producción de $\mathrm{CO}_{2}$; hipocapnia por hiperventilación; hipoxemia por asincronía entre el paciente y el ventilador; aumento de la presión intratorácica con disminución del retorno venoso, del volumen minuto cardíaco y de la presión arterial; e incremento del consumo de $\mathrm{O}_{2}$ por el aumento de la actividad muscular $3,59,209-211$.

Es frecuente que el uso de la sedación y la analgesia esté indicado en pacientes muy graves, que requieren al mismo tiempo otras medicaciones o tratamientos considerados prioritarios. La indicación de sedación y analgesia se realiza de manera empírica, con una elección del fármaco y una dosificación que, en la práctica, frecuentemente es inadecuada ${ }^{212}$.

No todos los pacientes ventilados requerirán de todos o algunos de estos medicamentos, como es el caso de los pacientes neuromusculares (por ejemplo, síndrome de Guillain-Barré), los cuales necesitarán una sedación diurna leve y una nocturna necesaria para asegurar el sueño. Un paciente con SDRA grave necesitará probablemente niveles máximos de analgesia, sedación y, a veces, relajación muscular 213,214 .

La analgesia implica ausencia de sensibilidad al dolor o a los estímulos agresivos, como, por ejemplo, la presencia de un tubo endotraqueal o las maniobras de aspiración de secreciones. Es muy frecuente que en la VM se utilicen fármacos sedantes, que «duermen» al paciente pero que no lo protegen del dolor ni de las reacciones sistémicas que este provoca, como son la taquicardia, el aumento del consumo de oxígeno miocárdico, etc. Si tras la administración de analgésicos los signos fisiológicos alterados desaparecen, se confirma la hipótesis de que el dolor era la causa de esas alteraciones ${ }^{3,61,64}$.

La sedación en el paciente crítico se indica como tratamiento básico de la ansiedad y la agitación. Estas 2 sensaciones, junto con la VM, hacen que la indicación de sedación en dichos pacientes sea inevitable, al menos en los primeros períodos ${ }^{3,211}$. Existen diferencias en la modalidad del uso de los agentes sedantes, en situaciones agudas o de corta duración, y la sedación prolongada que acompaña a la VM. Estas diferencias radican no solo en el agente a utilizar, sino en el modo de administración.

¿Cuáles son las recomendaciones para el manejo de la sedación y la analgesia en el paciente con VM?

E2. Se recomienda la utilización de una escala para la evaluación del dolor y la profundidad de la sedación en el paciente con VM.

Grado de recomendación: fuerte. Nivel de evidencia: moderado (1 B).

Justificación: Es importante evaluar de forma reproducible si la analgesia buscada con el tratamiento se ha logrado satisfactoriamente. Como el dolor es predominantemente subjetivo, se tratará, si el estado del paciente lo permite, 


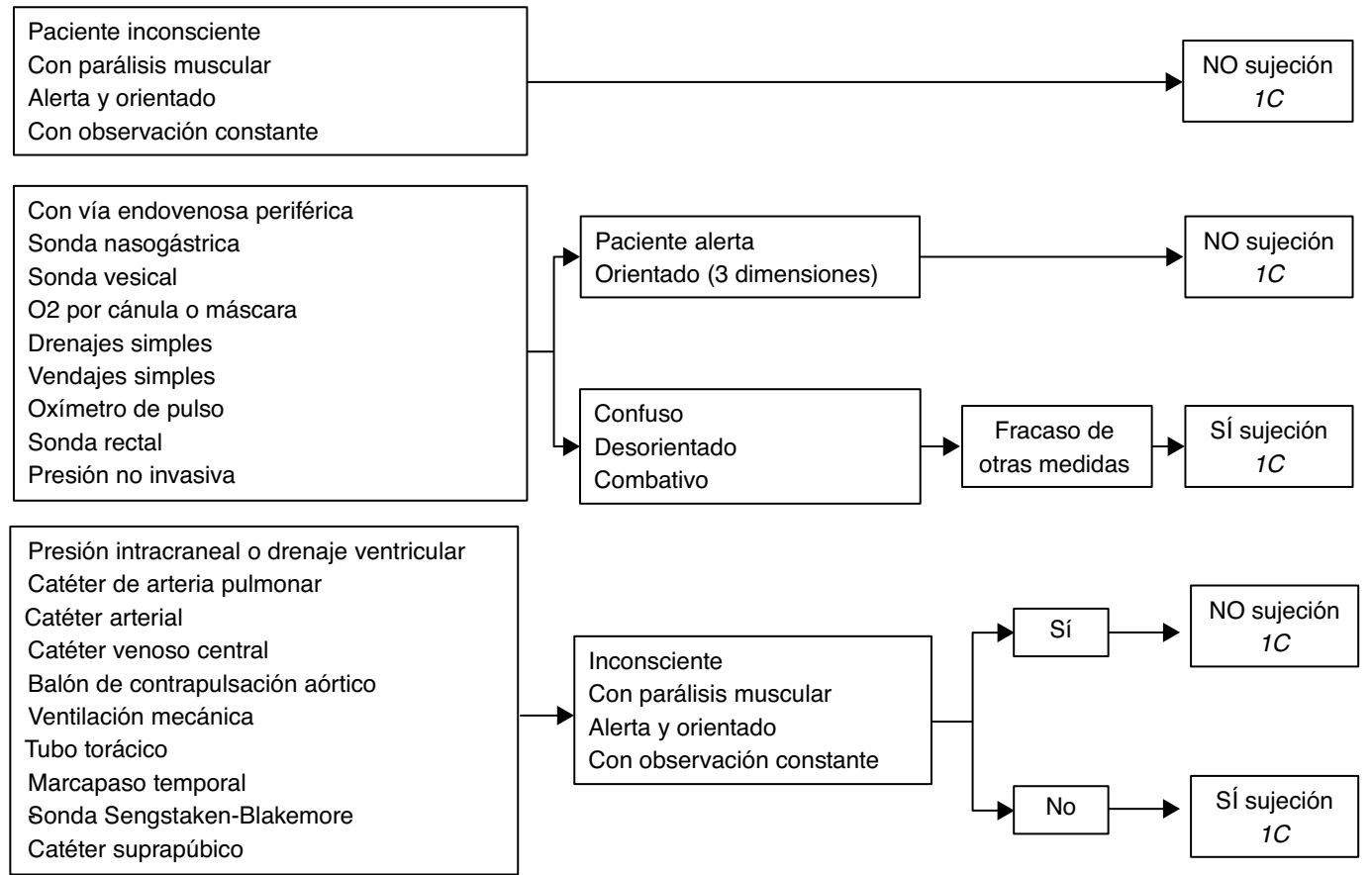

Figura 3 Necesidades de sujeción relacionadas con el tipo de pacientes y el uso de dispositivos para monitorización y/o tratamiento.

de obtener su opinión. Dado que estamos considerando a los pacientes ventilados $y$, por supuesto, con IT, se puede usar una escala gráfica del dolor (escala visual analógica), fácilmente comprensible, que tenga, por ejemplo, una línea de no dolor en uno de sus extremos y otra de dolor máximo en el otro. En el caso de los pacientes sedados, en los que especialmente se tiende a infrautilizar la analgesia, es importante evaluar los equivalentes somáticos y fisiológicos del dolor. Entre los primeros, la expresión facial, los movimientos y la postura pueden ser claros indicadores de dolor como en la escala BPS 215,216 . Entre los signos fisiológicos, la taquicardia, la hipertensión, la taquipnea, la desadaptación al ventilador, incluidos en la escala Non-Verbal Pain Scale $e^{215,216}$, obligarán a considerar la administración de analgésicos, si no se estaban administrando, o a aumentar su dosis $^{3,61,64}$.

Otro problema es la dificultad en la evaluación de la profundidad de la sedación. El uso de escalas para la evaluación de la profundidad de la sedación durante la VM está recomendado en la mayor parte de los consensos realizados sobre el tema. El uso de las escalas de sedación es parte fundamental de los protocolos de adaptación del paciente con $\mathrm{VM}^{60,61,64,106}$ (tabla 3).

E3. Se recomienda que la implementación de los protocolos de sedación y analgesia se realice preferentemente por el equipo de enfermería. Se sugiere no aplicar esta recomendación cuando el número de enfermeros no sea el suficiente.

Grado de recomendación: fuerte. Nivel de evidencia: moderado (1 B).

Justificación: Con algunas excepciones, varios autores han comunicado mejores resultados con la aplicación de protocolos estrictos de sedación y analgesia controlados y aplicados por el personal de enfermería de UCl. Pero es evidente que cuando el número de enfermeros es insuficiente no pueden ser sobrecargados con esta tarea adicional $^{34,65,217-230}$.

E4. Se recomienda no usar sedación profunda (RASS 1 a -3) rutinariamente en los pacientes con VM.

Grado de recomendación: fuerte. Nivel de evidencia: moderado (1 B).

Justificación: Los niveles de sedación serán diferentes para cada tipo de paciente. Los niveles de sedación adecuados para los pacientes ventilados estarían entre 2 y 4 de la escala de Ramsay o RASS 1 y - $3^{13,27,29,32,231-234}$ (tablas 3 y 5). En los pacientes con VM por situaciones respiratorias complejas (por ejemplo, EPOC reagudizada, asma grave, SDRA), se recomiendan niveles Ramsay 3 o 4 o RASS de 4. En estos niveles de sedación se observa frecuentemente amnesia anterógrada, hecho que algunos autores asocian con mayor incidencia de delirium y estrés postraumático.

Debe recordarse que la sedación profunda de nivel 5 o 6 de la escala de Ramsay o RASS - 5 podría ser útil únicamente en la sedación que forma parte del tratamiento de la hipertensión intracraneal o en situaciones como el tétanos o la hipertermia maligna ${ }^{235,236}$.

E5. Se recomienda, siempre que sea posible, utilizar sedación consciente o cooperativa con bajas dosis tituladas en infusión continua de propofol o dexmedetomidina.

Grado de recomendación: fuerte. Nivel de evidencia: moderado (1 B).

Justificación: Se ha demostrado en varios estudios que con este método se acorta el período de VM, los días de internación en $\mathrm{UCl}$, la incidencia y la duración del delirium. También se ha comunicado que esta estrategia no aumenta la incidencia de isquemia miocárdica 29,32,231-234,237,238.

E6. Se recomiendan los opioides como analgésicos de elección en el paciente ventilado, siendo de primera línea el fentanilo y la morfina. Especialmente en los pacientes que requieren ventilación prolongada. 
Grado de recomendación: fuerte. Nivel de evidencia: moderado (1 B).

Justificación: Los efectos secundarios más importantes de los opioides, que se consideran los agentes de elección para la analgesia en el paciente crítico, son depresión respiratoria, hipotensión arterial, retención gástrica e íleo. A pesar de esos efectos adversos, una correcta analgesia es un objetivo primario en el paciente crítico con $\mathrm{VM}^{3,59,61,64,210,239}$.

La morfina, ya sea como sulfato o clorhidrato, constituye el agente analgésico de elección para los pacientes ventilados. Sus ventajas son su potencia analgésica, el bajo coste y el efecto euforizante. La morfina debe administrarse por vía intravenosa, comenzando con una dosis de carga y luego con una infusión venosa continua. La dosis de carga recomendada es de $0,05 \mathrm{mg} / \mathrm{kg}$ administrada en 5 a $15 \mathrm{~min}$. La mayoría de los adultos requieren una infusión continua que oscila desde 2 a $3 \mathrm{mg} / \mathrm{h}$, hasta 4 a $6 \mathrm{mg} / \mathrm{h}$ en algunos pacientes. Es frecuente que, durante la infusión continua de morfina, se requieran uno o más bolos con las mismas dosis que la carga inicial para lograr un efecto analgésico adecuado. En el caso de optar por un esquema de administración en bolos, este debería programarse en dosis repetidas, cada $3 \mathrm{~h}$, tratando de graduar las dosis sobre la base de la respuesta terapéutica ${ }^{3}$.

El fentanilo es el agente analgésico de elección para los pacientes ventilados con inestabilidad hemodinámica o para los pacientes que manifiesten síntomas de liberación histamínica o alergia con el uso de la morfina. No causa liberación de histamina, hecho que puede explicar su menor efecto sobre la presión arterial y el músculo liso bronquial. Tiene una vida media relativamente corta (de 30 a $60 \mathrm{~min}$ ) debido a una rápida distribución. Sin embargo, su administración prolongada lleva a su acumulación en los compartimentos periféricos y al aumento de su vida media (vida media contextual) hasta $16 \mathrm{~h}$. Debe administrarse en infusión continua de 1 a $2 \mu \mathrm{g} / \mathrm{kg} / \mathrm{h}$, tras una o más dosis de carga de 1 a $2 \mu \mathrm{g} / \mathrm{kg}$. El uso rutinario no es recomendable en todos los pacientes, debido a que su efecto analgésico es similar al de la morfina, tiende a acumularse por la prolongación de su vida media y su coste suele ser mayor ${ }^{3}$.

E7. Se recomienda no usar en el paciente crítico meperidina, nalbufina y buprenorfina.

Grado de recomendación: fuerte. Nivel de evidencia: bajo (1 C).

Justificación: La meperidina tiene un metabolito activo, la normeperidina, que puede acumularse y producir excitación del SNC y convulsiones, especialmente en los pacientes con daño neurológico agudo ${ }^{3}$.

La nalbufina y la buprenorfina se prescriben habitualmente para calmar el dolor leve o moderado en el postoperatorio inmediato. Debe recordarse que pueden revertir el efecto de los otros opioides por interacción a nivel de los receptores. Pueden usarse como opción cuando estén contraindicados los opioides tradicionales ${ }^{3}$.

E8. Se recomienda, cuando sea posible, minimizar o suprimir el uso de sedantes en la VM prolongada, usando el esquema de sedación basada en la analgesia.

Grado de recomendación: fuerte. Nivel de evidencia: moderado (1 B).

Justificación: Se han publicado varios estudios que demuestran la disminución de los días con VM y la estancia en
$\mathrm{UCl}$ cuando se suprime o minimiza la utilización de sedantes mediante la administración de analgésicos opioides en infusión continua en pacientes con VM. El fármaco más utilizado en los estudios que proponen estos esquemas es el remifentanilo, cuya mayor ventaja es la rápida desaparición de su efecto y la independencia de la función renal y/o hepática ${ }^{31,36,240-243}$.

El remifentanilo es un opioide sintético que, por ser metabolizado rápidamente por esterasas plasmáticas; prácticamente no se acumula. Tampoco lo hace en pacientes con insuficiencia renal o hepática. Estas propiedades hacen que la recuperación de su efecto se produzca en pocos minutos, aun después de infusiones prolongadas. Las dosis analgésicas habituales son $0,05 \mathrm{a} 0,3 \mu \mathrm{g} / \mathrm{kg} / \mathrm{min}$. Dependiendo de la dosis, produce efectos depresores centrales como otros opioides. Hay estudios que recomiendan su utilización en los esquemas de sedación basada en la analgesia ${ }^{36,240-243}$. También ha sido utilizado en el proceso de destete del ventilador $^{244-246}$.

E9. Se recomiendan midazolam, propofol o lorazepam como sedantes de elección en pacientes con VM que requieren un nivel de sedación profundo RASS -4 a -5 o Ramsay 4 a 6.

Grado de recomendación: fuerte. Nivel de evidencia: bajo (1 C).

Justificación: Existen diferencias en la modalidad del uso de los agentes sedantes en situaciones agudas o de corta duración, y en la sedación profunda que acompaña a la VM de los pacientes con patologías mencionadas previamente (fig. 4). Estas diferencias radican no solo en el agente a utilizar, sino en el modo de administración ${ }^{247-251}$.

Todas las benzodiazepinas parenterales causan amnesia anterógrada y debemos recordar que no tienen actividad analgésica. Aunque el prototipo del sedante intravenoso es el diazepam, ya no se recomienda porque: a) causa con frecuencia dolor y tromboflebitis cuando se administra por una vena periférica; b) la administración en forma de bolos puede llevar a una sedación excesiva; c) la administración en infusión intravenosa continua aumenta su vida media, llegando a ser hasta de 7 días en algunos pacientes; y d) requiere dilución en un volumen grande, lo que implicaría el riesgo de sobrecarga hídrica en el uso prolongado. Sin embargo, en algunos centros se utiliza por su bajo coste y por su rápido mecanismo de acción para maniobras cortas (cardioversión eléctrica, $\mathrm{IT}$ ), indicándose un bolo único ${ }^{3}$. El midazolam y el propofol son los agentes de elección para la sedación de corta duración, como la que es necesaria para realizar maniobras de la IT en el comienzo de la VM. La dosis habitual de midazolam para lograr una sedación efectiva durante las maniobras de la IT $u$ otros procedimientos de corta duración es de $0,2 \mathrm{mg} / \mathrm{kg}$, que puede repetirse en bolos de $0,07 \mathrm{mg} / \mathrm{kg}$ hasta lograr el nivel de sedación deseado ${ }^{3}$.

El propofol es un agente anestésico intravenoso que cuando se usa en dosis subanestésicas tiene propiedades sedantes e hipnóticas, y la capacidad de generar cierto grado de amnesia anterógrada. El propofol y el midazolam han demostrado poseer el mismo efecto sedante en estudios comparativos $^{3,252}$. 

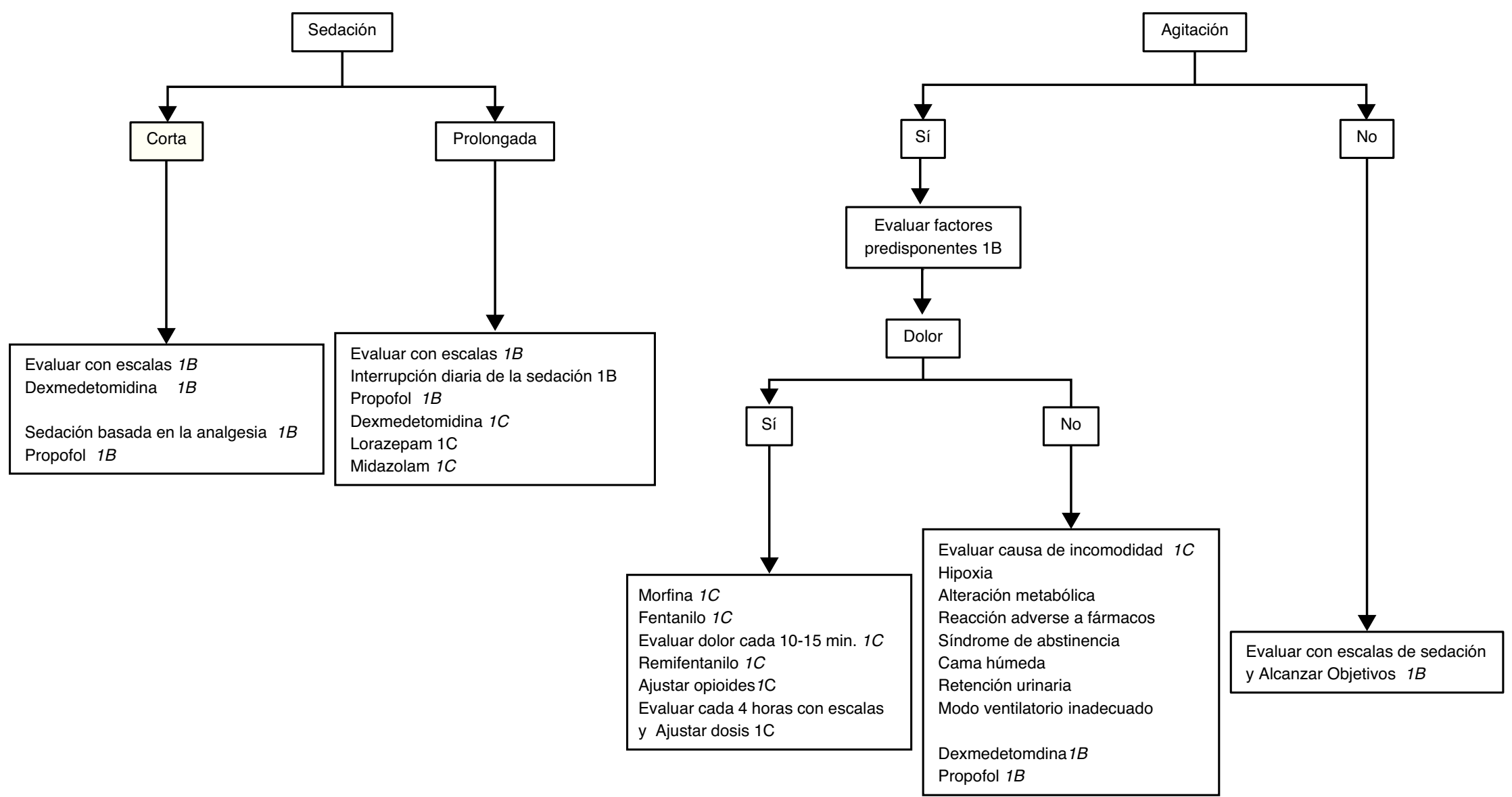

Figura 4 Algoritmo para la sedación y analgesia en los pacientes con intubación traqueal. 
El comienzo de la acción del propofol es rápido tras la administración de un bolo intravenoso (1 a 2 min), dada su rápida entrada en el SNC, y su efecto es breve (10 a $15 \mathrm{~min})$. Cuando se usa en forma prolongada solo debe administrarse por infusión continua con la precaución de usar una vena central y no periférica. También el propofol alarga significativamente su vida media con la administración por períodos prolongados, debido a la acumulación en los depósitos lipídicos, llegando su vida media a ser hasta de 300 a $700 \mathrm{~min}^{252,253}$. Para lograr una sedación rápida, como en el caso de una IT, se utiliza la administración en bolo de 2 a $2,5 \mathrm{mg} / \mathrm{kg}$. Si se quiere mantener al paciente sedado, en el caso de proseguir con VM, se deberá continuar con una infusión continua a un ritmo inicial de $0,5 \mathrm{mg} / \mathrm{kg} / \mathrm{h}$, que se aumentará $0,5 \mathrm{mg} / \mathrm{kg}$ cada 5 a $10 \mathrm{~min}$ de acuerdo con la respuesta clínica. Una dosis habitual de mantenimiento oscila entre 0,5 y $3 \mathrm{mg} / \mathrm{kg} / \mathrm{h}$. La administración en bolo de propofol causa habitualmente un descenso de la presión arterial, que puede ser de hasta el $30 \%$ de la presión basal ${ }^{254,255}$.

En los últimos años se han publicado gran número de estudios que demuestran que las benzodiazepinas (midazolam y lorazepam) se asocian con mayor incidencia de coma y delirium en los pacientes intubados y ventilados. Esto condiciona períodos más prolongados de VM, mayor estancia y mayor morbimortalidad $29,32,35,36,231,233,234,256$.

El lorazepam es uno de los fármacos apropiados para la sedación prolongada en el paciente ventilado. Es una benzodiazepina de acción intermedia que, por ser menos lipofílica que otros agentes del grupo, tiene menor acumulación periférica. El lorazepam, en comparación con el midazolam, tiene una vida media más larga y una capacidad equivalente de provocar amnesia anterógrada. Dada su vida media, el fármaco es apto para la administración en bolos intermitentes, aunque puede usarse por infusión continua. Debido a que el lorazepam tiene un tiempo de latencia mayor que otras benzodiazepinas para el comienzo de su acción farmacológica, se aconseja empezar con una dosis de diazepam o midazolam para inducir una rápida sedación. La dosis de lorazepam aconsejada como bolo inicial o como dosis de «refuerzo» es de $0,05 \mathrm{mg} / \mathrm{kg}$, que deberá repetirse cada 2 a $4 \mathrm{~h}$ según se precise. En la sedación prolongada algunos autores aconsejan la administración en infusión continua de lorazepam en dosis de 0,025 a $0,05 \mathrm{mg} / \mathrm{kg} / \mathrm{h}$. Estas dosis suelen ser insuficientes y llegan a duplicarse o triplicarse en algunos pacientes. Algunos autores reportan niveles elevados de propilenglicol que podrían ser tóxicos en estas circunstancias, aunque no se han comunicado efectos clínicos evidentes ${ }^{251}$. La forma intravenosa del lorazepam no se encuentra disponible en todos los países ${ }^{3}$.

E10. Se recomienda utilizar un sedante de vida media más corta, como la dexmedetomidina, para disminuir el tiempo de VM y la incidencia de delirium, en los pacientes que puedan tolerar un nivel de sedación leve (RASS 1 a -3 o Ramsay 2-3).

Grado de recomendación: fuerte. Nivel de evidencia: moderado (1 B).

E11. Se recomienda la dexmedetomidina como agente útil para la sedación y la analgesia postoperatoria de los pacientes que requieren VM por períodos cortos y especialmente en los pacientes sépticos.

Grado de recomendación: fuerte. Nivel de evidencia: moderado (1 B).
Justificación: La dexmedetomidina es un agonista $\alpha_{2}$ con una afinidad mayor por los receptores $\alpha_{2}$ que por los $\alpha_{1}$. Al inhibir los receptores postsinápticos produce, además de la reducción de la presión arterial y la frecuencia cardíaca, un claro efecto ansiolítico y sedante. Por su efecto a nivel de los receptores espinales, tiene también un efecto analgésico. La administración inicial de carga en los pacientes ventilados es de $1 \mu \mathrm{g} / \mathrm{kg}$ en $10 \mathrm{~min}$. La infusión de mantenimiento es 0,2 a $1,4 \mu \mathrm{g} / \mathrm{kg} / \mathrm{h}$, considerando que los efectos secundarios son mayores con las dosis superiores a $0,7 \mu \mathrm{g} / \mathrm{kg} / \mathrm{h}$. La dosis de mantenimiento debe ser aumentada frecuentemente cuando se usa la dexmedetomidina en forma prolongada. El bolo de carga puede ocasionar bradicardia acompañada de hipotensión, en ocasiones sostenida, lo que suele ser más frecuente en pacientes hipovolémicos y ancianos. Hay autores que recomiendan no usar dosis de carga para evitar estos efectos secundarios.

Este medicamento no produce depresión respiratoria ni alteración del intercambio gaseoso, y puede administrarse con seguridad en pacientes con insuficiencia renal. Tampoco produce alteraciones en la función adrenocortical, ni inflamatoria. Debido a las propiedades mencionadas, algunos autores eligen este fármaco como el sedante más adecuado para el proceso de destete de la VM y para la sedación consciente. En estudios observacionales también parece disminuir la incidencia de delirium y reducir la mortalidad en los enfermos sépticos (hazard ratio 0,3 [IC 95\%: 0,1 a 0,9$])^{29,32,248,253,256-260}$, pero estos hallazgos deben ser confirmados otros estudios posteriores. Las dosis deben ser reducidas en pacientes con insuficiencia hepática $13,35,36,38,42,248,259,261-264$.

E12. Se recomienda no usar el etomidato en la sedoanalgesia del paciente con VM.

Grado de recomendación: fuerte. Nivel de evidencia: bajo (1C).

Justificación: El etomidato debería contraindicarse en el paciente crítico por su capacidad de provocar insuficiencia suprarrenal ${ }^{265,266}$.

E13. Se recomienda la interrupción diaria de la infusión de sedantes y analgésicos con el fin de disminuir la dosis total administrada.

Grado de recomendación: fuerte. Nivel de evidencia: moderado (1 B).

E14. Se recomienda la interrupción diaria de la sedoanalgesia y realizar una prueba de ventilación espontánea, cuando el cuadro respiratorio lo permita, con el fin de disminuir la aparición de complicaciones y el tiempo de VM.

Grado de recomendación: fuerte. Nivel de evidencia: bajo (1C).

Justificación: Kress et al. ${ }^{267}$, en un ensayo clínico con 128 enfermos tratados con el mismo esquema de sedoanalgesia, midazolam o propofol más morfina, para mantener unos valores de la escala de Ramsay de 3 o 4, compararon el efecto de interrumpir diariamente la sedoanalgesia a partir de las $48 \mathrm{~h}$ de su inicio (grupo experimental) con la interrupción de la sedoanalgesia según juicio del médico (grupo control). La duración media de la VM en el grupo experimental fue de 4,9 días y en el grupo control de 7,3 días $(p=0,004)$; la estancia en la $\mathrm{UCl}$ fue de 6,4 y 9,9 días $(p=0,02)$, respectivamente. La incidencia de complicaciones (por ejemplo, la retirada accidental del tubo 
endotraqueal) fue del 4 y $7 \%$, respectivamente. La disminución en la dosis total de sedantes y morfina solo se observó en los enfermos tratados con midazolam ( $40 \%$ menos dosis en el grupo experimental) y no en los tratados con propofol.

Resultados similares se han repetido en un estudio retrospectivo, en el que también se observó una menor incidencia de neumonías, sinusitis, bacteriemia y trombosis venosa profunda en los pacientes manejados con la interrupción diaria de la sedoanalgesia ${ }^{267,268}$. La suspensión diaria de la sedoanalgesia no debe hacerse de rutina en los pacientes con hipertensión intracraneal, VM con modos no convencionales o con inestabilidad hemodinámica, situaciones que deben evaluarse individualmente 267,268 .

Se ha comunicado una mejoría de los patrones de sueño con esta práctica ${ }^{269}$. Algunos autores no han podido reproducir estos datos ${ }^{34}$. Si el paciente está desadaptado del ventilador, tiene ya una analgesia adecuada y un nivel 4 de la escala de Ramsay o RASS menor a -3, se pueden usar relajantes neuromusculares. No se debe progresar a grados más altos de sedación para la adaptación al ventilador. En los pacientes que estén recibiendo una infusión de relajantes musculares, deberá esperarse a la desaparición de sus efectos antes de decidir la suspensión diaria de la sedoanalgesia. Si pasado el plazo que se considere suficiente para la pérdida del efecto paralizante el paciente no presenta desadaptación del ventilador, se procederá a la suspensión del midazolam como se recomienda para el conjunto de los pacientes $^{34,253,267-273}$.

E15. Se recomienda la monitorización de la sedación con BIS para los pacientes en VM con patología neurocrítica aguda o bajo el efecto de relajantes neuromusculares, para evitar la infra o sobresedación.

Grado de recomendación: fuerte. Nivel de evidencia: moderado (1 B).

Justificación: Olson et al. ${ }^{101}$ compararon en un ensayo clínico de 67 enfermos neurocríticos, en VM y sedación continua con propofol, el efecto de 2 protocolos controlados por enfermeras: Ramsay 4 vs. Ramsay 4 más BIS 60-70 durante $12 \mathrm{~h}$. La adición del BIS a la escala de Ramsay se asoció a una reducción de la dosificación de propofol 14,6 vs. $27,9 \mu \mathrm{g} / \mathrm{kg} / \mathrm{min}(\mathrm{p}=0,003)$.

E16. Se recomienda valorar la disminución de la dosis de sedantes y analgésicos en los pacientes con VM tras practicarles traqueostomía.

Grado de recomendación: fuerte. Nivel de evidencia: bajo (1 C).

Justificación: Cuando la VM se prolonga el paciente no debe continuar con el tubo endotraqueal.

No es el propósito de este documento discutir cuál es el momento para realizar la traqueostomía, ni cuál es el mejor método para realizarla. La ausencia de tubo a través de la glotis disminuye sensiblemente el dolor del paciente. Asimismo el nivel de sedación puede disminuirse en estas circunstancias, porque el paciente está más estable tanto desde el punto de vista hemodinámico como neurológico y respiratorio. Nieszkowska et al. encontraron en un estudio observacional retrospectivo de 72 enfermos ventilados mecánicamente que tras la traqueostomía disminuyeron las necesidades de sedantes y analgésicos ${ }^{274}$.

E17. Se sugiere no aumentar rutinariamente las dosis de sedantes, cuando se acompañan de una infusión de morfina, en los pacientes tratados con hipercapnia permisiva.
Grado de recomendación: débil. Nivel de evidencia: bajo (2C).

Justificación: La hipercapnia permisiva es una técnica de VM que puede utilizarse en 2 tipos de situaciones. La primera es la de los pacientes con obstrucción grave del flujo aéreo (asma, EPOC) que requiere una baja frecuencia respiratoria y bajos volúmenes corrientes para evitar las altas presiones en las vías aéreas y el atrapamiento aéreo. La segunda es la de los pacientes con SDRA grave que desarrollan hipercapnia al ser ventilados con una estrategia protectora ${ }^{275}$. Estas situaciones precisan frecuentemente el uso de relajantes musculares ${ }^{276}$. Vinayak et al. ${ }^{277}$ observaron en un estudio retrospectivo de 124 enfermos ventilados mecánicamente que durante los 3 primeros días los pacientes con hipercapnia permisiva tratados con midazolam $(n=13)$ no precisaron más dosis que los que no tuvieron hipercapnia permisiva $(n=51)$. Sin embargo, los pacientes con hipercapnia permisiva tratados con propofol $(n=10)$ sí precisaron una mayor dosis que los que no tuvieron hipercapnia $(n=50)$. Otros estudios han mostrado resultados similares $^{278,279}$.

E18. Se sugiere en los pacientes con SDRA, con $\mathrm{PaO}_{2} / \mathrm{FiO}_{2}<150$, con VM protectora, considerar el uso de bloqueadores neuromusculares no despolarizantes en infusión continua durante las primeras $48 \mathrm{~h}$.

Grado de recomendación: débil. Nivel de evidencia: moderado (2 B).

Justificación: Recientemente Needhamet al. publicaron que los pacientes con SDRA grave tratados con infusión continua de relajantes musculares no despolarizantes (cisatracurio) durante las primeras $48 \mathrm{~h}$ de VM tuvieron menor mortalidad a los 90 días, y disminución de la morbilidad: menor duración de la VM, la estadía en $\mathrm{UCl}$, menor incidencia de falla orgánica y debilidad muscular ${ }^{276}$.

¿Cuáles son las recomendaciones para pacientes con condiciones especiales como paciente con EPOC, SDRA, asma, inestabilidad hemodinámica o fracaso multiorgánico?

E19. Se recomienda el fentanilo como analgésico de elección en los pacientes con inestabilidad hemodinámica, asma bronquial o EPOC.

Grado de recomendación: fuerte. Nivel de evidencia: bajo (1 C).

Justificación: El fentanilo no causa liberación de histamina, hecho que puede explicar su menor efecto sobre la presión arterial y el músculo liso bronquial ${ }^{3}$.

E20. Se recomienda la implementación de un protocolo temprano de terapia física y ocupacional en pacientes intubados y ventilados mecánicamente con el objetivo de disminuir el tiempo de VM.

Grado de recomendación: fuerte. Nivel de evidencia: moderado $(1 \mathrm{~B})$.

Justificación: Schweickert et al. estimaron en 109 enfermos la eficacia de la terapia física y ocupacional comenzada en los primeros 3 días de la VM durante los períodos de despertar diario con el tratamiento estándar prescrito que incluía el despertar diario pero sin fisioterapia hasta su prescripción por el equipo de atención primaria. La terapia precoz se asoció a un mayor porcentaje de independencia funcional al alta (59 vs. 35\%), (OR 2,7 [IC 95\%: 1,2 a 6,1$]),(p=0,02)$ y menor duración del delirium (2 vs. 4 días) $(0,02)^{188}$. Needham et al, encontraron en un estudio 
prospectivo observacional a 6 meses con 57 pacientes en VM por 4 días o más, en quienes se aplicó un protocolo de rehabilitación física temprana y reducción de la sedación profunda, una reducción de la incidencia de delirium, una mejoría de la movilidad funcional y una disminución de la estancia en cuidados intensivos y hospitalaria ${ }^{233}$.

E21. Se recomienda el empleo de musicoterapia como adyuvante no farmacológico de la sedación del paciente en VM especialmente durante el destete.

Grado de recomendación: fuerte. Nivel de evidencia: leve $(1 \mathrm{C})$.

Justificación: En diferentes estudios se ha observado que la musicoterapia disminuye la ansiedad, sus equivalentes fisiológicos y las dosis administradas de sedantes durante

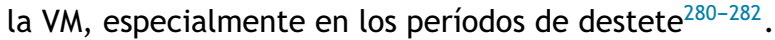

\section{F. Pacientes en proceso de retirada del tubo endotraqueal y de la ventilación mecánica}

¿Cuál debe ser la aproximación farmacológica para el paciente que está en proceso de retirada de la VM y del tubo oro/nasotraqueal?

F1. Se recomienda contar con un protocolo definido de monitorización y ajuste de las dosis de sedación y analgesia cuando se prevea la retirada del ventilador, una vez esté resuelta la causa que llevó al paciente a la VM. Dicho protocolo debe integrar diariamente una evaluación de la sedación, una prueba de despertar y un test de respiración espontánea ${ }^{30}$. (1A).

Grado de recomendación: fuerte. Nivel de evidencia: alto

Justificación: El paciente en proceso de retirada de la VM y del tubo traqueal debe estar despierto. Todo protocolo de sedoanalgesia debe estar dirigido a impedir la acumulación de sedantes y analgésicos, y la prolongación de su efecto.

En este momento, la prioridad número uno es aplicar medidas no farmacológicas para aliviar la ansiedad: explicar al paciente claramente la situación, la colaboración que se espera de él y los pasos a seguir. Igualmente se debe reducir al mínimo los ruidos, la intensidad de la iluminación y permitir un horario de visitas flexible; son medidas que ayudan al paciente en esta fase. Uno de los principios básicos para la extubación es valorar la sedación y establecer si su nivel podría interferir con la respiración espontánea. En el estudio de Girard et al. ${ }^{30}$, en 336 pacientes sedados en VM, se evaluó la combinación de interrupción de la sedación y la prueba de respiración espontánea en el grupo intervención con la prueba de respiración espontánea en el grupo control. En el grupo asignado a la intervención se apreció una clara reducción en los días sin ventilador, en la estancia en $\mathrm{UCl}$ $(9,1$ vs. 12,9 días $),(p=0,01)$. La mortalidad a los 28 días no mostró diferencias significativas ( 28 vs. $35 \%),(p=0,21)$, aunque sí lo fue la diferencia de la mortalidad a un año (44 vs. $58 \%),(p<0,01)$. La interrupción de la sedación y la prueba de respiración espontánea pueden considerarse estándares de cuidado.

F2. Se recomienda contar con un protocolo definido de monitorización y ajuste de las dosis de sedación y analgesia, con suspensión diaria, cuando se prevea la retirada del ventilador, una vez esté resuelta la causa que llevó al paciente a la VM.
Grado de recomendación: fuerte. Nivel de evidencia: alto (1 A).

Justificación: Durante el proceso de retirada de la VM y de la IT es necesario que el paciente esté lúcido y alerta. $\mathrm{Si}$ es preciso, se administrarán fármacos para controlar el dolor y la agitación psicomotora ${ }^{28,283,284}$.

¿Cuáles son los medicamentos que podrían estar contraindicados?

F3. Se recomienda no usar midazolam o lorazepam en el proceso de retirada de la VM.

Grado de recomendación: fuerte. Nivel de evidencia: bajo (1 C).

Justificación: La sedación prolongada, con midazolam o lorazepam, se asocia a un aumento del tiempo de permanencia en VM, del tiempo de retirada de la VM y del tubo orotraqueal, y de la estancia en la $\mathrm{UCl}$, ya que pueden acumularse y prolongar la sedación ${ }^{253,285-288}$.

¿Hay algunos medicamentos que podrían estar indicados?

F4. Se recomienda el remifentanilo en dosis bajas en infusión continua para sedación y analgesia a los pacientes en el destete de VM.

Grado de recomendación: fuerte. Nivel de evidencia: moderado (1 B).

Justificación: La elección de los fármacos depende de factores relacionados con el paciente (comorbilidades, causa o indicación para VM, tiempo de VM), con la farmacología de los medicamentos, con sus efectos adversos y costes $^{289}$. El dolor puede ser una de las causas del fracaso de la retirada. Para garantizar la analgesia constante, se prefiere la infusión continua a las dosis en bolos, por permitir una titulación más efectiva, una dosis total más baja de fármacos y menos tiempo de VM. Las dosis en bolos se pueden utilizar en forma intravenosa como dosis de rescate $253,285,286$.

Rozendaal et al. compararon el efecto de 2 protocolos de analgesia y sedación en 205 enfermos en VM en un ensayo clínico abierto cross-over. En un grupo se administró remifentanilo y solo se administró propofol si no se alcanzaba la sedación a dosis máximas $12 \mu \mathrm{g} / \mathrm{kg} / \mathrm{h}$. En el grupo convencional se realizó analgesia con morfina o fentanilo y sedación con propofol o midazolam o lorazepam. El tiempo medio de destete fue $6 \mathrm{~h}$ en el grupo tratado con remifentanilo y $25 \mathrm{~h}$ en el grupo tratado convencionalmente $(p=0,0001)$; la estancia en UCI 6 vs. $8(p>0,05)$ respectivamente ${ }^{240}$. En opinión de algunos autores estos resultados sostienen la recomendación del remifentanilo en el proceso de destete $e^{290}$.

F5. Se sugiere el uso de metadona por vía enteral en pacientes que reciban opioides durante más de 5 días y que se encuentren en VM.

Grado de recomendación: débil. Nivel de evidencia: moderado (2B).

Justificación: En un grupo de 28 enfermos en VM, el 32\% (IC 95\%: 13 a 51\%) desarrollaron síndrome de abstinencia luego de recibir opioides durante 7 días o más ${ }^{291}$. Un reciente estudio clínico controlado aleatorizado doble ciego en 68 pacientes mostró que entre los 54 supervivientes el uso de metadona enteral en pacientes que habían recibido opioides durante más de 5 días redujo el tiempo de destete de 7 días (IC 95\%: 2,5 a 11,5) a 4 (IC 95\%: 1,99 a $6,01)^{292}$.

F6. Se recomienda el uso de la dexmedetomidina en pacientes posquirúrgicos. 
Grado de recomendación: fuerte. Nivel de evidencia: bajo (1 C).

F7. Se recomienda el uso de la dexmedetomidina en los pacientes con destete difícil de la VM y en pacientes con síndrome de abstinencia.

Grado de recomendación: fuerte. Nivel de evidencia: bajo (1 C).

F8. Se recomienda la dexmedetomidina en pacientes con intentos previos no exitosos de destete de la VM secundarios a agitación y delirium.

Grado de recomendación: fuerte. Nivel de evidencia: bajo (1C).

Justificación: La dexmedetomidina es un sedante eficaz y seguro para la mayoría de los pacientes posquirúrgicos en la UCl. Las ventajas de la dexmedetomidina son: el efecto agonista $\alpha$, la sedación consciente, la reducción de las necesidades de opioides y la estabilidad respiratoria. No obstante, se asocia a hipotensión y a bradicardia, que generalmente se resuelven espontáneamente o con una mínima intervención: reposición de volumen y a veces, atropina y dosis bajas de fármacos vasoactivos ${ }^{287,293-295}$.

Cuando el paciente se agita, presenta delirium, se torna ansioso o desarrolla un síndrome de abstinencia, es útil mantener un nivel de sedación mínimo, con fármacos de corta vida media ${ }^{1}$.

El delirium, la agitación y la abstinencia se han asociado con desenlaces adversos en el paciente en VM, especialmente durante la retirada de la VM. En este proceso la dexmedetomidina ha sido usada para garantizar el éxito del destete del ventilador en pacientes que fracasaron en este proceso por agitación. Es posible que los beneficios de la dexmedetomidina sean más significativos cuando se usa con interrupción diaria de la sedación, protocolo de destete y movilidad temprana ${ }^{125,296-299}$.

F9. Se recomienda el propofol en pacientes posquirúrgicos.

Grado de recomendación: fuerte. Nivel de evidencia: bajo (1 C).

Justificación: El propofol es el sedante de elección cuando se requiere que el paciente despierte rápidamente, debido al menor tiempo requerido para despertar. Esta diferencia es más acusada cuando el objetivo terapéutico es 40 5 en la escala de Ramsay. Además, el tiempo de despertar es más predecible en los que reciben propofol que en los que reciben midazolam ${ }^{253,285-287}$.

\section{G. Poblaciones especiales: pacientes traumatizados, ancianos, embarazadas y quemados}

¿Qué consideraciones especiales deben tenerse en cuenta y cuáles son las recomendaciones farmacológicas para el manejo de la sedación y analgesia en cada uno de estos pacientes?

\section{Pacientes traumatizados}

G1. Se recomienda el propofol para la sedación de pacientes traumatizados que requieren evaluaciones neurológicas frecuentes (fig. 5).

Grado de recomendación: fuerte. Nivel de evidencia: bajo (1 C).

Justificación: Las propiedades farmacocinéticas del propofol, en las que se observa una recuperación rápida del
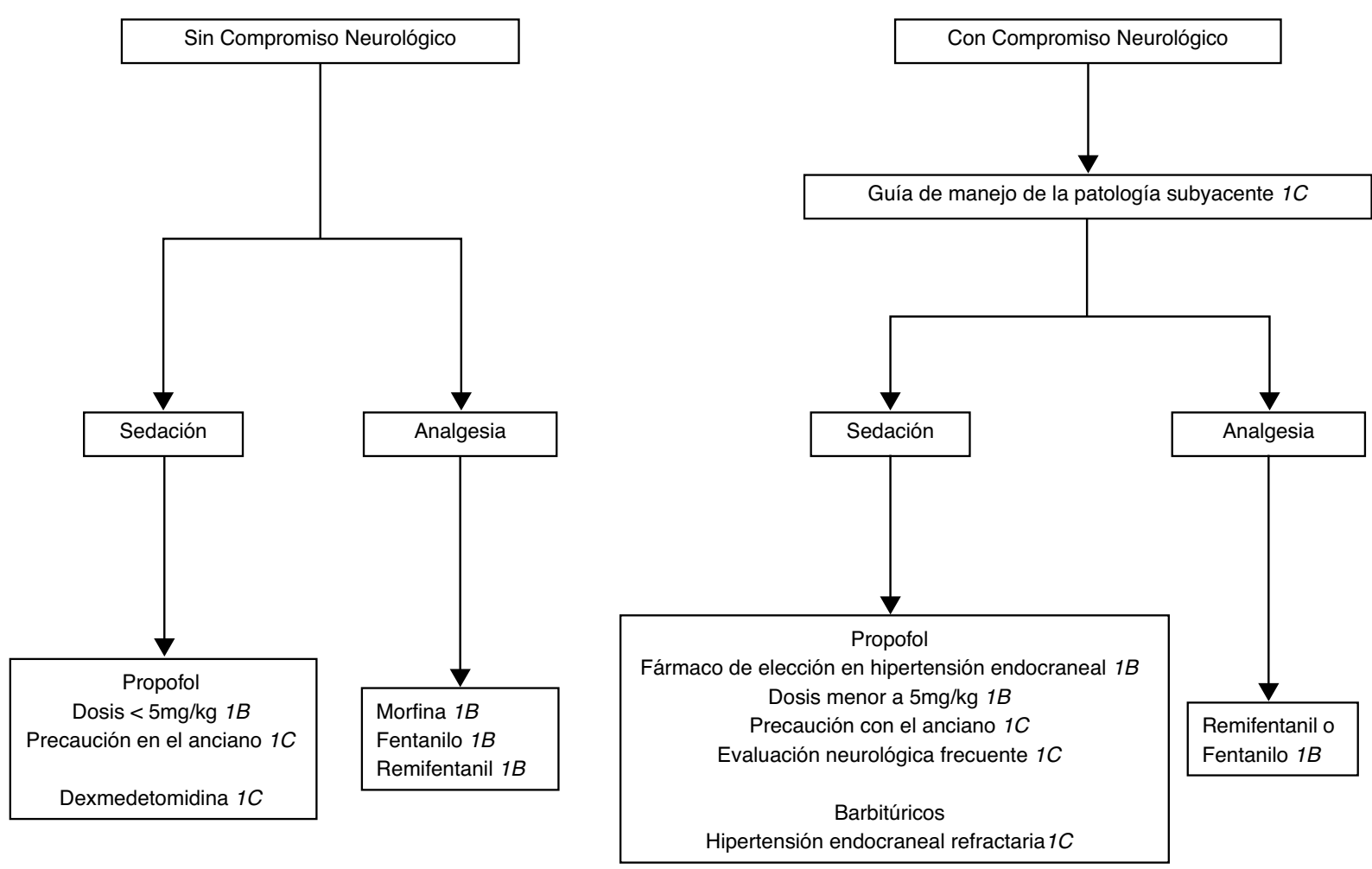

Figura 5 Algoritmo de sedación y analgesia en los pacientes traumatizados con y sin compromiso neurológico. 
estado de conciencia del paciente en 10-15 min luego de descontinuar su infusión, han sido mencionadas en varias publicaciones $^{300-302}$. Esta característica es de gran utilidad en pacientes que requieren de evaluaciones frecuentes de la función del SNC.

G2. Se recomienda usar el propofol a dosis menores de $5 \mathrm{mg} / \mathrm{kg} / \mathrm{h}$ para evitar el «síndrome de infusión de propofol».

Grado de recomendación: fuerte. Nivel de evidencia: moderado (1 B).

Justificación: El «síndrome de infusión de propofol»se define como la presencia de insuficiencia cardíaca, acidosis metabólica y rabdomiolisis ${ }^{303}$. En este estudio los síntomas se evidenciaron después de 24 a $48 \mathrm{~h}$ de iniciada la infusión. La mortalidad secundaria a este síndrome en los pacientes que recibían propofol para el control de la hipertensión intracraneal fue del 10\%. La probabilidad de aparición del fenómeno es de 1,93 por cada $\mathrm{mg} / \mathrm{kg}$ de aumento sobre la dosis promedio de $5 \mathrm{mg} / \mathrm{kg} / \mathrm{h}$ (equivalente a $83 \mu \mathrm{g} / \mathrm{kg} / \mathrm{min}$ ). Ninguno de los pacientes que recibieron menos de esta dosis promedio desarrolló el síndrome ${ }^{303}$. La recomendación subraya el evitar dosis de propofol mayores de $5 \mathrm{mg} / \mathrm{kg} / \mathrm{h}$ hasta que se valore la seguridad de otras dosis.

G3. Se recomienda la utilización de protocolos de sedoanalgesia y detección de delirium en pacientes traumatizados críticos.

Grado de recomendación: fuerte. Nivel de evidencia: bajo (1 C).

Justificación: En un estudio prospectivo, controlado en pacientes que no pueden tener interrupciones diarias de la infusión de sedantes, se vio que la evaluación objetiva utilizando protocolos de analgesia, sedación consciente y detección del delirium disminuye los días en VM y la estancia hospitalaria en pacientes traumatizados $\operatorname{críticos}^{62}$.

G4. Se recomienda la utilización del CAM-ICU en la detección de delirium en pacientes traumatizados.

Grado de recomendación: fuerte. Nivel de evidencia: bajo (1 C).

Justificación: En un estudio retrospectivo se compararon 59 enfermos traumatizados tratados con protocolo de sedación (RASS), analgesia (escala visual analógica) y estimación de delirium (CAM-ICU) con 61 enfermos tratados sin ese protocolo 2 años antes. Durante el período en el que se usó el protocolo, la duración de la VM se redujo de una mediana de 3,2 a 1,2 días $(p=0,03)$, y la mediana de la duración de la estancia en $\mathrm{UCl}$ fue 5,9 vs. 4,1 ( $p=0,21)$ respectivamente ${ }^{304}$.

\section{Pacientes ancianos}

G5. Se recomienda tener precaución durante la utilización de propofol en pacientes ancianos.

Grado de recomendación: fuerte. Nivel de evidencia: bajo (1 C).

Justificación: Los tiempos de recuperación inicial en pacientes sedados con propofol son similares en personas jóvenes (20 a 50 años) y ancianos (65 a 85 años). Sin embargo, la recuperación total psicomotora es más lenta en el segundo grupo, y puede tardar hasta 120 min luego de mantener a los pacientes sedados con BIS de 60 a $70^{305}$. Los tiempos de recuperación de la estabilidad postural en ancianos respecto a personas jóvenes son más lentos y pueden tardar hasta $120 \mathrm{~min}^{306}$.
G6. Se recomienda tener precaución con la utilización de benzodiazepinas en ancianos.

Grado de recomendación: fuerte. Nivel de evidencia: moderado (1 B).

Justificación: Existe correlación en pacientes mayores de 65 años con el aumento en la aparición de delirium y su consecuente asociación a incrementos de la morbimortalidad y costes de atención. La probabilidad de desarrollar delirium en este grupo aumenta un $2 \%$ en términos relativos (OR 1,02 [IC 95\%: 1,01 a 1,03]) por año después de los 65 años. Además, otros factores asociados independientemente a la aparición de delirium son la escala de APACHE ॥ y la utilización de lorazepam ${ }^{307}$.

G7 . Se sugiere el uso profiláctico de haloperidol en dosis bajas en el postoperatorio de pacientes ancianos.

Grado de recomendación: débil. Nivel de evidencia: moderado (2 B).

Justificación: En un ensayo clínico aleatorizado y controlado en 457 enfermos, se observó que la profilaxis con haloperidol a dosis baja $(0,5 \mathrm{mg}$ bolo inicial intravenoso e infusión intravenosa $0,1 \mathrm{mg} / \mathrm{h}$ ) y de corta duración $(12 \mathrm{~h}$ ) puede disminuir la incidencia de delirium en pacientes ancianos en los 7 días después de cirugía no cardíaca del 23 al $15 \%(p=0,03)$ y la estancia en UCl de 23 a $21 \mathrm{~h}$. Otro efecto observado fue la mejoría en los días sin delirium ${ }^{308}$.

\section{Pacientes embarazadas}

G8. Para evaluar la administración de analgésicos y sedantes durante el embarazo, se recomienda seguir la clasificación de la Food and Drug Administration (FDA) de EE. UU.

Grado de recomendación: fuerte. Nivel de evidencia: bajo (1C).

Justificación: En el manejo de la analgesia y sedación de pacientes embarazadas deben tenerse en cuenta 2 factores: 1. la capacidad del fármaco de producir lesiones embrionarias y fetales; 2 los posibles efectos fisiológicos reversibles del fármaco en el recién nacido (sedación, depresión respiratoria, síndrome de abstinencia) cuando se utiliza en situaciones periparto.

La clasificación de la FDA figura en la tabla $11^{309}$.

Los riesgos potenciales de la sedoanalgesia en las embarazadas son los siguientes:

Propofol. Categoría B.

Produce efectos fetales reversibles. Sobre todo en el período de periparto puede producir depresión neonatal ${ }^{309}$. Puede utilizarse en dosis subhipnóticas para el control de la emesis asociado a cesáreas ${ }^{310}$. No hay diferencia en el metabolismo o respuesta en el embarazo ${ }^{311,312}$.

Fentanilo y remifentanilo. Categoría $\mathrm{C}$.

Pueden producir depresión neonatal y deben usarse con precaución. El uso crónico en el embarazo se ha visto asociado a síndrome de abstinencia en el neonato ${ }^{309}$.

Benzodiazepinas. Categoría D.

Producen efectos fetales reversibles, depresión neonatal e hipotonía ${ }^{309}$. Se ha evidenciado, estadísticamente, una posible asociación a malformaciones de tubo digestivo. En particular, el uso de lorazepam durante la embriogénesis se ha asociado a atresia anal ${ }^{313,314}$.

Dexmedetomidina. Categoría C.

Se han observado efectos adversos fetales en estudios animales, como bajo peso y muerte fetal, pero no existen 
Tabla 11 Clasificación de fármacos en el embarazo de la US Food and Drug Administration

A Estudios controlados en humanos muestran que no hay riesgo

B No hay evidencia de riesgos en estudios

Estudios en animales en los que no se aprecia riesgo, sin controles en embarazadas. Estudios en animales con riesgo, pero sin riesgo en estudios controlados en embarazadas

C No se pueden descartar riesgos

No hay estudios controlados en embarazadas, y hay riesgo en estudios animales

Solo deben usarse si el beneficio potencial sobrepasa al riesgo potencial en el feto

D Evidencia de riesgo para el feto Solo usar cuando el beneficio en la embarazada en situación grave puede ser aceptable a pesar del riesgo para el feto

$x \quad$ Contraindicada tanto en mujeres embarazadas como en mujeres que pueden quedar embarazadas

Adaptada de Drugs at FDA: FDA approved drug products. Disponible en: http://www.accessdata.fda.gov/ scripts/cder/drugsatfda/index. $\mathrm{cfm}^{309}$.

estudios controlados o reportes de teratogenicidad en humanos ${ }^{309}$.

Haloperidol. Categoría C.

Se han observado efectos adversos fetales en estudios animales, como aborto, muerte fetal y paladar hendido, pero no existen estudios controlados en humanos ${ }^{309}$.

Lurasidona. Categoría B.

Los estudios animales no han mostrado efectos fetales; además, estudios en pacientes embarazadas no han demostrado riesgo fetal $^{309}$.

Ketamina. Categoría B.

Los estudios animales no han mostrado efectos fetales. No existen estudios en humanos o informes sobre una posible teratogenicidad $^{309}$.

G9. Se recomienda el uso concomitante de paracetamol intravenoso en situaciones que requieran analgesia inmediata, para disminuir los requerimientos de opioides y sus potenciales efectos adversos.

Grado de recomendación: fuerte. Nivel de evidencia: moderado (1 B).

Justificación: La administración intravenosa de paracetamol aumenta su biodisponibilidad y eficacia, comparado con las presentaciones enterales, al evitar el metabolismo hepático directo del primer paso. Este fármaco tiene un efecto sinérgico con otros analgésicos parenterales más potentes, por lo que reduce la dosis requerida de estos últimos al disminuir los requerimientos de analgésicos. Además, en dosis usuales, es un fármaco con alto índice de seguridad ${ }^{315}$.

\section{Sedación y Analgesia: procedimientos especiales (quemados)}

¿Qué consideraciones especiales deben tenerse en cuenta para el manejo de la sedación y analgesia en el paciente quemado?
G10. Se recomienda la ketamina como medicamento de primera línea para la sedoanalgesia en procedimientos rutinarios dolorosos en el paciente quemado y el uso de opioides como medicamentos de segunda línea.

Grado de recomendación: fuerte. Nivel de evidencia: moderado (1 B).

G11. Se recomienda que la ketamina no se utilice sola. Debe ir acompañada de midazolam, propofol o con dexmedetomidina.

Grado de recomendación: fuerte. Nivel de evidencia: moderado (1 B).

Justificación: El manejo de procedimientos dolorosos en los pacientes quemados como son los cambios de vendajes, curaciones etc. debe hacerse con analgésicos con grados altos de hipnosis, siendo el más reconocido la ketamina dados su rápida acción, no compromiso de la función respiratoria y estabilidad hemodinámica. Los estudios actuales están encaminados a evaluar el medicamento ideal que acompañe a la ketamina para disminuir sus efectos secundarios $^{316-318}$.

\section{H. Sedoanalgesia en el postoperatorio inmediato de cirugía cardiovascular}

¿Hay beneficios al utilizar sedación y analgesia en el paciente en postoperatorio de cirugía cardíaca?

H1. Se recomienda que todos los pacientes en postoperatorio inmediato de cirugía cardíaca reciban analgesia y sedación adecuadas para disminuir la aparición de posibles complicaciones.

Grado de recomendación: fuerte. Nivel de evidencia: moderado $(1 \mathrm{~B})$.

Justificación: La ausencia de dolor es un derecho fundamental del paciente, al igual que la ausencia de ansiedad; además disminuye la incidencia de complicaciones ${ }^{67,319}$. La sedoanalgesia postoperatoria reduce la morbilidad en cirugía cardíaca. La taquicardia y la liberación de catecolaminas contribuyen a la presentación de hipertensión arterial, isquemia miocárdica y rotura de la placa aterosclerótica. En el momento del ingreso en la $\mathrm{UCl}$, los pacientes se encuentran bajo efectos residuales de anestésicos, siendo la técnica anestésica empleada un factor importante para definir el grado de sedoanalgesia necesario.

Durante el postoperatorio inmediato, hay un lapso en el que se requiere de VM y, por lo tanto, es necesario el uso de sedoanalgesia mientras se logra la homeostasis térmica y la estabilidad hemodinámica. La sedación óptima en este período minimiza la respuesta cardiovascular a la estimulación, disminuye el tiempo necesario para despertar y, por ende, permite la retirada del tubo endotraqueal sin incrementar la incidencia de complicaciones cardiovasculares ${ }^{320}$. Actualmente, debido al uso de sistemas de anestesia de fasttrack, la elección de fármacos de acción corta permite una rápida recuperación postanestésica ${ }^{321}$.

$H 2$. Se sugiere una sedación consciente postoperatoria que controle la respuesta al estrés adecuadamente. Se debe usar una escala de medición de sedación para controlar este objetivo (RASS con un nivel de -1 y -2).

Grado de recomendación: débil. Nivel de evidencia: moderado (2 B). 
Justificación: Tradicionalmente se creía que los pacientes en postoperatorio de cirugía cardíaca requerían una sedación profunda para reducir la respuesta endocrina al estrés y prevenir la isquemia miocárdica ${ }^{320}$. Sin embargo, no existe diferencia estadísticamente significativa en los indicadores de la respuesta al estrés, como los niveles de catecolaminas y cortisol, entre la sedación superficial y la profunda. Por el contrario, aquellos pacientes con sedación profunda experimentan un mayor grado de isquemia miocárdica, niveles de dolor más elevados y prolongación del tiempo de asistencia ventilatoria respecto a aquellos con sedación leve ${ }^{322}$.

H3. Se recomienda el uso de remifentanilo en primera instancia u otros opioides y PCA en el manejo de la analgesia postoperatoria cardiovascular.

Grado de recomendación: fuerte. Nivel de evidencia: moderado (1 B).

Justificación: El uso de remifentanilo/propofol en comparación con fentanilo/midazolam en pacientes durante el postoperatorio de cirugía cardiovascular mientras permanecen en VM mantuvo mejores niveles de analgesia, disminuyendo el tiempo en VM $(20,7$ vs. $24,2 \mathrm{~h}$, [p $<0,05])$ y la duración de estancia en $\mathrm{UCl}(46,4 \text { vs. } 64,7 \mathrm{~h},[\mathrm{p}<0,05])^{323}$. Una vez se le retira la VM al paciente, la analgesia con morfina o sus análogos sigue siendo el tratamiento de elección en el manejo del dolor del paciente debido a su potencia, variando su forma de administración, ya sea en bolo, infusión continua o PCA.

No se han encontrado diferencias significativas cuando se compara el uso de la PCA con la suministrada por el personal de enfermería, debido a que se suele estar muy atento a la presencia de dolor en estos pacientes y a proporcionar el analgésico oportunamente ${ }^{324}$. Al comparar el uso de la PCA con la analgesia peridural, tampoco se encontraron diferencias en el nivel de sedoanalgesia alcanzado ${ }^{325,326}$.

H4. Se sugiere considerar el uso de la analgesia subaracnoidea y/o peridural para el manejo del dolor postoperatorio.

Grado de recomendación: débil. Nivel de evidencia: moderado (2 B).

Justificación: La combinación de anestesia general con anestesia regional ha mostrado una reducción del tiempo de retirada del tubo endotraqueal y un mejor control del dolor en los pacientes sometidos a cirugía cardíaca. La administración de sufentanilo, clonidina o morfina intratecales reduce la necesidad de analgesia postoperatoria y proporciona un mejor control del dolor. El uso de morfina intratecal es seguro, en comparación con los métodos de administración convencionales ${ }^{327-332}$. Sin embargo, la administración de morfina intratecal no reduce los tiempos de retirada de IT en comparación con el placebo ${ }^{333}$. Por otro lado, la asociación de opioides epi o subdurales con los que se administran por vía intravenosa durante la cirugía puede producir depresión respiratoria y retardar la retirada del tubo endotraqueal ${ }^{334}$.

En los protocolos de fast-track en cirugía cardíaca la administración de dosis bajas de morfina intratecal se asocia a una disminución del consumo de morfina intravenosa en un $40 \%$ durante las primeras $24 \mathrm{~h}$ posteriores a la retirada del tubo endotraqueal ${ }^{335}$.

La analgesia peridural con dosis bajas de bupivacaína al $0,125 \%$ mejora la relación aporte/demanda de oxígeno del miocardio, aumenta el flujo sanguíneo subendocárdico y reduce la hipercoagulabilidad postoperatoria, por lo que su empleo, en combinación con la anestesia general inhalada, se ha asociado a una reducción de la respuesta al estrés en los pacientes sometidos a cirugía coronaria $^{336}$.

No se han comunicado hematomas secundarios al bloqueo neuroaxial. Sin embargo, el riesgo, aunque bajo, existe y debe ser considerado (1:150.000 para el bloqueo peridural y 1: 220.000 para el subdural $)^{337}$.

En conjunto, por tanto, los riesgos y los beneficios del empleo de técnicas regionales de anestesia deben valorarse en cada paciente, considerando que no existe una literatura que apoye definitivamente su empleo para conseguir una retirada más rápida del tubo endotraqueal, al compararlas con la administración tradicional de opioides y AINE intravenosos.

Se ha sugerido que otras técnicas como el bloqueo paraesternal, la infiltración de la herida quirúrgica, el uso de bloqueos paravertebrales y el de infusiones continuas de anestésicos locales pueden ser de utilidad como analgésicos en los pacientes sometidos a cirugía cardíaca ${ }^{338-341}$.

H5. Se sugiere el uso de AINE para el manejo de dolor postoperatorio.

Grado de recomendación: débil. Nivel de evidencia: moderado (2 B).

Justificación: Los AINE permiten reducir la dosis de opioides, mantener o mejorar la analgesia y disminuir los efectos secundarios indeseables de los opioides ${ }^{342,343}$.

El diclofenaco, la indometacina y el ketoprofeno han demostrado ser eficaces para el manejo del dolor postoperatorio ${ }^{343}$. Sin embargo, están contraindicados en enfermedad coronaria, insuficiencia renal, sangrado digestivo y broncoespasmo.

H6. Se recomienda el uso de dexmedetomidina, remifentanilo o su combinación, la combinación de dosis bajas de propofol y midazolam, o la de propofol y fentanilo para la sedación y analgesia postoperatoria.

Grado de recomendación: fuerte. Nivel de evidencia: moderado $(1 \mathrm{~B})$.

Justificación: El uso de dexmedetomidina reduce significativamente la incidencia y la duración de delirium en pacientes en postoperatorio de cirugía cardiovascular que requieren sedación cuando se compara con midazolam y propofol, y cuando se compara con pacientes que son manejados solo con morfina, a la vez que disminuye la estancia en $\mathrm{UCl}$ y en el hospital ${ }^{344,345}$. El remifentanilo ha demostrado reducir los niveles de marcadores bioquímicos de daño miocárdico después de cirugía coronaria, el tiempo en VM y la duración de la hospitalización ${ }^{346,347}$.

Actualmente se sabe que la combinación adecuada de agentes sedantes de corta acción puede reducir los requerimientos analgésicos y los efectos adversos de los opioides de larga duración ${ }^{322}$.

Existen diversos protocolos que evalúan la eficacia en la combinación de propofol con midazolam, así como de propofol y fentanilo.

La combinación de dosis bajas de propofol y midazolam ha tenido gran aceptación, ya que poseen un efecto sinérgico al actuar sobre el mismo receptor ácido $\gamma$-amino butírico (GABA), lo que proporciona mayor estabilidad hemodinámica que el uso de propofol como agente único ${ }^{321}$. Además, 
la combinación de estos fármacos ha demostrado ser una alternativa eficaz y segura en los pacientes que se encuentran en el postoperatorio de cirugía cardíaca, ya que tiene unos mínimos efectos sobre la presión arterial ${ }^{348}$.

No se ha demostrado la superioridad del propofol como agente único para la sedación en comparación con el midazolam, ya que no se asocia a una disminución significativa del tiempo de retirada del tubo endotraqueal, de la incidencia de reintubación, de la hipertensión y la hipotensión postoperatorias ni de los requerimientos ${ }^{349}$. No obstante, en la fase de retirada de IT, cuando el paciente aun se encuentra sedado, la administración de propofol es segura y disminuye la incidencia de alteraciones hemodinámicas y de isquemia miocárdica.

No se han encontrado diferencias en la duración del período de despertar o del tiempo de sedación al comparar el uso de propofol como agente único frente a la combinación propofol-fentanilo. Sin embargo, la concentración de propofol, la tasa de infusión y la dosis total fue superior en el grupo donde se utilizó como agente único. Dentro de los parámetros hemodinámicos, la caída de la presión arterial media (superior al 20\%) es mayor en el grupo de propofol como agente único que en el de propofol-fentanilo. Por lo tanto, la combinación de propofol-fentanilo es superior en términos de sedación, sobre todo para prevenir períodos de hipotensión en pacientes en postoperatorio ${ }^{210,343}$.

H7. Se recomienda la dexmedetomidina en los pacientes en postoperatorio de cirugía cardiovascular, como agente único o asociado a analgésicos opioides.

Grado de recomendación: fuerte. Nivel de evidencia: moderado $(1 \mathrm{~B})$.

Justificación: Las características de la dexmedetomidina, ya comentadas anteriormente, le hacen un fármaco apropiado para la sedoanalgesia de corta duración. En los enfermos que se recuperan de cirugía cardíaca, la dexmedetomidina proporciona una sedoanalgesia efectiva. En un ensayo clínico realizado con 89 pacientes de cirugía coronaria prolongada, la dexmedetomidina en dosis de $1 \mu \mathrm{g} / \mathrm{kg}$ en dosis de carga, seguida de $0,4 \mu \mathrm{g} / \mathrm{kg} / \mathrm{h}$ y propofol en dosis de $5 \mu \mathrm{g} / \mathrm{kg} /$ hora, mostró una eficacia similar en la sedoanalgesia ${ }^{41,344,345,350-353}$. La prevención del temblor postoperatorio es un beneficio adicional de la dexmedetomidina ${ }^{354,355}$.

H8 . Se sugiere el uso de pregabalina en pacientes ancianos, ya que disminuye los requerimientos de opioides.

Grado de recomendación: débil. Nivel de evidencia: moderado (2 B)

Justificación: En un ensayo clínico controlado, aleatorizado, doble ciego, en el que se evaluó el efecto de la pregabalina en el consumo de oxicodona, la confusión postoperatoria y el dolor en 60 pacientes con edad $\geq 75$ años que fueron sometidos a cirugía cardíaca, se encontró que el uso de pregabalina redujo el consumo postoperatorio de oxicodona antes de la extubación en las primeras $24 \mathrm{hs}$ tras la extubación de 16 a $9 \mathrm{mg}(\mathrm{p}<0,001)$ y la incidencia de confusión solo en el primer día postoperatorio (CAM-ICU en el grupo pregabalina 21 vs. 24 en el grupo placebo [ $=0,04]$ ), aunque aumentó el tiempo de extubación $(10,6 \mathrm{~h})$ comparado con los pacientes a los que se les administró placebo $(8,3 \mathrm{~h})^{356}$.

La figura 6 detalla el manejo de los pacientes en el postoperatorio de cirugía cardiovascular.

\section{El paciente neurológico y neurocrítico}

¿Cuáles son las consideraciones médicas que hay que evaluar antes de iniciar algún tipo de sedación y analgesia?

11. Se recomienda realizar una evaluación neurológica inicial basada en la clínica, descartar la presencia de lesiones de ocupación de espacio, hematomas que puedan ser resueltos quirúrgicamente y contar con un protocolo o guía local para el manejo de estos pacientes.

Grado de recomendación: fuerte. Nivel de evidencia: bajo (1 C).

Justificación: Como en otros enfermos ingresados en la $\mathrm{UCl}$, en los enfermos neurocríticos la sedoanalgesia debe estar dirigida a controlar o disminuir la respuesta metabólica al estrés (taquicardia, hipertensión, aumento del catabolismo proteico, etc.), mantener la sincronización del paciente con el ventilador, y disminuir el dolor, la ansiedad, y la agitación ${ }^{357-359}$.

No obstante, algunos objetivos específicos deben valorarse en el paciente neurocrítico con alteraciones del SNC, bien sea por un traumatismo craneal bien sea por otras lesiones del SNC: prevenir situaciones que produzcan aumentos de la presión intracraneal (PIC), disminuir y mantener los requerimientos metabólicos cerebrales, aumentar la captación de oxígeno, optimizando la hemodinámica sistémica y reduciendo las demandas metabólicas cerebrales de oxígeno ${ }^{358-361}$. Para ello se precisará: a) capacidad de monitorización del paciente en relación con los efectos hemodinámicos sistémicos y cerebrales como la presión arterial sistémica, la presión venosa central y la PIC; b) capacidad de seguimiento de la sedación con escalas adecuadas, fáciles de utilizar en la práctica clínica, reproducibles y ampliamente aceptadas; y c) protocolización y estandarización de los cuidados médicos.

En la sedoanalgesia de los pacientes neurocríticos debe tenerse en cuenta que: a) no debe interferir con la valoración neurológica continua en las primeras horas, para poder detectar complicaciones intracraneales tratables que precisen una pronta intervención, las cuales pueden expresarse como agitación o incomodidad; b) se debe prevenir la lesión neurológica secundaria, asociada a hipoxemia e hipotensión, que deben ser corregidas sin pérdida de tiempo ${ }^{358,360,362}$.

Algunos factores deletéreos sistémicos deben ser corregidos o prevenidos antes de iniciar la sedación: la hipotensión arterial sistémica (manteniendo una presión arterial sistólica superior a $90 \mathrm{mmHg}$, con una PIC a $70 \mathrm{mmHg}$ ), la hipoxemia; la fiebre o hipotermia y la hiperglucemia ${ }^{358-360}$.

¿Cuáles son los medicamentos indicados en caso de necesitar evaluaciones frecuentes del estado neurológico?

12. Se recomienda utilizar medicamentos de vida media corta y de poca acumulación (propofol, dexmedetomidina y remifentanilo) que permitan evaluaciones neurológicas frecuentes. Un régimen de sedación basado en analgesia con opioides de acción corta, como el remifentanilo, está indicado, ya que permite una evaluación adecuada del estado neurológico y un despertar rápido una vez suspendida la medicación.

Grado de recomendación: fuerte. Nivel de evidencia: moderado (1 B).

Justificación: El sedante ideal en el paciente neurocrítico es aquel que evite o prevenga elevaciones de la PIC, permita mantener estable hemodinámicamente al paciente $\mathrm{y}$ 


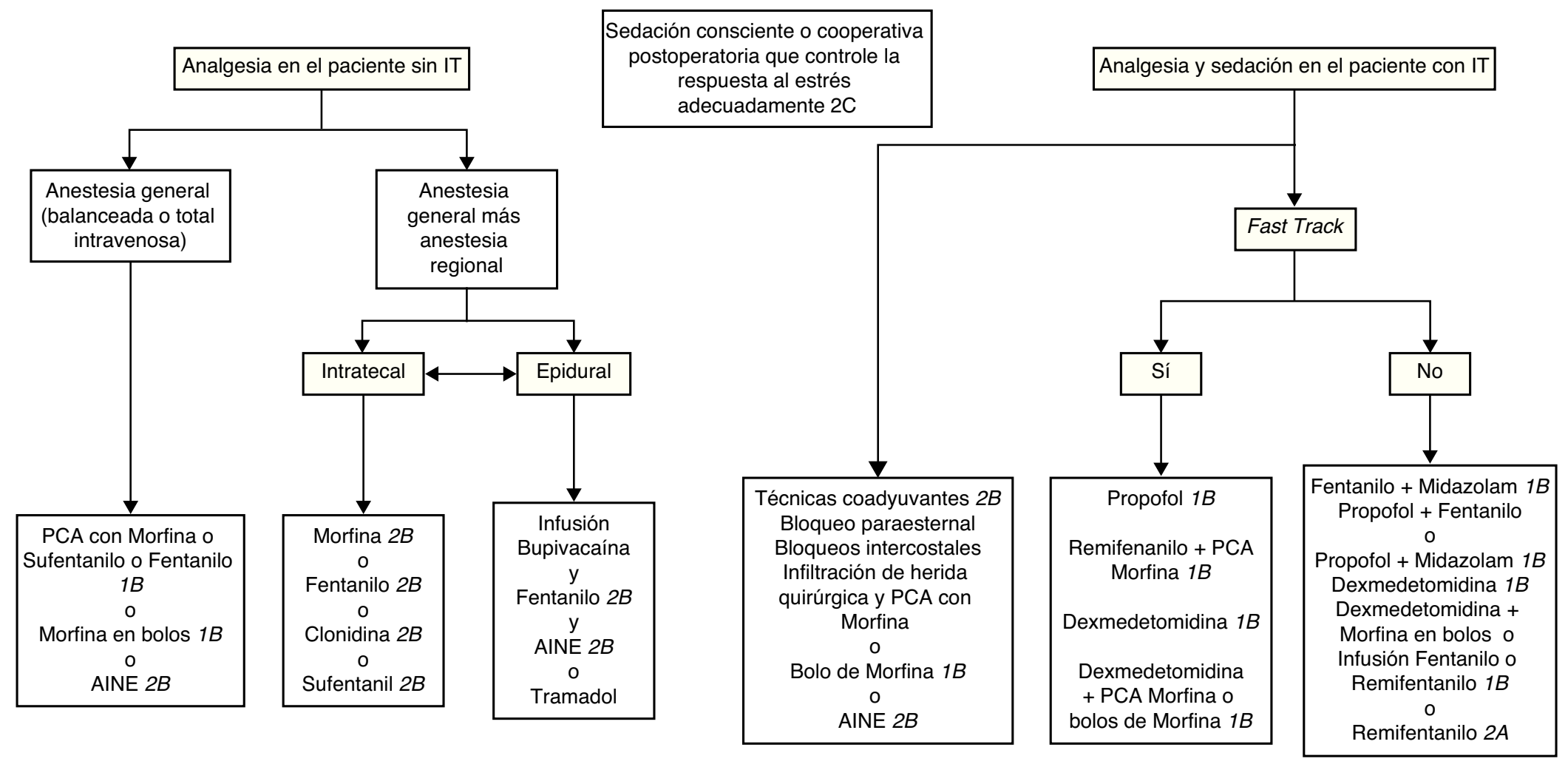

Figura 6 Algoritmo de analgesia y sedación en los pacientes de postoperatorio de cirugía cardiovascular. AINE: antiinflamatorios no esteroideos; IT: intubación traqueal; PCA: analgesia controlada por el paciente. 
evite la sedación profunda (efecto rápido y acción corta). El agente ideal único con estas propiedades no existe, por lo que se debe utilizar una combinación de diferentes fármacos para acercarnos a este objetivo. Las benzodiazepinas siguen siendo utilizadas asociadas a analgésicos, entre los cuales los derivados morfínicos ocupan el primer lugar ${ }^{357}$. El uso de hipnóticos como el propofol en combinación con un opioide como el remifentanilo se considera adecuado para estos pacientes, en los que la necesidad de interrupción diaria o con mayor frecuencia de la sedación es indispensable $e^{284,363}$.

El propofol, al igual que otros barbitúricos, disminuye el flujo sanguíneo cerebral y el consumo de oxígeno, de un modo proporcional a la dosis administrada, hasta un 40 o $60 \%$. Además, tiene un efecto vasoconstrictor sobre el sistema vascular cerebral. Cuando se administra en dosis suficientes para producir el coma, su actividad antiepiléptica es comparable a los barbitúricos, disminuye la PIC y, como efecto adverso, reduce la presión de perfusión cerebral por hipotensión sistémica, en especial en pacientes hipovolémicos. Sus propiedades farmacocinéticas, por lo tanto, permiten recomendarlo como agente hipnótico ideal tanto en la inducción como en el mantenimiento de la sedación en los pacientes neurocríticos, inclusive en el tratamiento de la hipertensión intracraneal, debido a su fácil titulación y rápida reversibilidad una vez descontinuada la infusión, propiedades que permiten proporcionar una sedación predecible. Otras propiedades potencialmente beneficiosas en pacientes con traumatismo craneoencefálico son la inhibición del sistema GABA y de los receptores N-metil-D-aspartato (NMDA), y el efecto antioxidante ${ }^{303,364}$.

La analgesia con opioides es la primera elección. Deben ser utilizados para disminuir la ansiedad, el dolor y la angustia. Este grupo de fármacos, en general, no modifica en forma importante el consumo cerebral de 02. En dosis analgésicas, los efectos hemodinámicos, respiratorios y neurológicos de los 4 derivados (fentanilo, alfentanilo, sufentanilo y remifentanilo) son comparables. La elección entre ellos debe hacerse en función de las características farmacodinámicas. En los pacientes con traumatismo craneoencefálico se ha observado que la administración de opioides puede disminuir la presión de perfusión cerebral, debido a una reducción de la presión arterial media y a un aumento de la PIC. Este efecto se ha descrito cuando se administran en bolos; no así en infusión continua ${ }^{46}$.

La sedación basada en analgesia (remifentanilo con la adición de bolos de propofol y midazolam) permite una evaluación diaria y un despertar más rápido comparada con el régimen clásico (fentanilo o morfina, con la combinación de propofol o midazolam) ${ }^{242,284}$. El remifentanilo ofrece una ventaja puntual en el paciente neurocrítico, puesto que debido a su perfil farmacocinético presenta un despertar rápido una vez suspendida la medicación, lo cual favorece la evaluación del estado neurológico ${ }^{242}$. La morfina fue uno de los analgésicos más utilizados. Sin embargo, su uso está limitado por su inicio de acción largo (promedio de $20 \mathrm{~min}$ ), por el riesgo de acumularse en presencia de insuficiencia renal y por la liberación de histamina, por lo que actualmente se prefiere el uso de opioides de acción corta tipo remifentanilo 284,365 .

No hay trabajos que demuestren la superioridad del remifentanilo frente a otros opioides en función de la disminución de la mortalidad, pero sí en el tiempo de estancia hospitalaria, disminución del tiempo de VM y en el tiempo de extubación. Una desventaja que debemos tener en cuenta en relación con el remifentanilo es la hiperalgesia que produce una vez descontinuado el fármaco, por lo que debe utilizarse analgésicos de transición.

En la tabla 12 se detallan las propiedades de los medicamentos mencionados previamente.

¿Cuál sería el sedante para el paciente con hipertensión intracraneal y con VM?

13. Se recomienda el uso de propofol en infusión, sin exceder los $5 \mathrm{mg} / \mathrm{kg} / \mathrm{h}$ y los 5 días. El midazolam debe considerarse en pacientes en los que el propofol esté contraindicado.

Grado de recomendación: fuerte. Nivel de evidencia: moderado (1 B).

Justificación: Como se mencionó previamente, el propofol y el midazolam son igualmente efectivos en la sedación del paciente neurocrítico en función de sus efectos hemodinámicos sistémicos y cerebrales ${ }^{284,364,366}$.

14. Se recomienda el tiopental sódico como una medida terapéutica reservada para los pacientes con traumatismo craneoencefálico grave con hipertensión intracraneal refractaria al tratamiento médico y en los que no coexistan limitaciones hemodinámicas importantes.

Grado de recomendación: fuerte. Nivel de evidencia: bajo (1 C).

Justificación: Los barbitúricos disminuyen el flujo sanguíneo cerebral y el metabolismo cerebral en una cuantía directamente proporcional a la dosis administrada, hasta lograr una abolición de la actividad cerebral. La disminución de la PIC es secundaria a su efecto sobre el flujo sanguíneo cerebral, la cual, a su vez, se produce por una reducción del metabolismo cerebral, siempre y cuando la hemodinámica cerebral y el acoplamiento flujo sanguíneo cerebral/consumo de $\mathrm{O}_{2}$ se mantenga. Si el consumo de $\mathrm{O}_{2}$ disminuye por alteraciones isquémicas o por daño neurológico secundario, los barbitúricos aumentan el flujo sanguíneo por un mecanismo compensatorio, siempre que la presión arterial sistémica se mantenga por encima de los valores determinados para la autorregulación (presión arterial media superior a $90 \mathrm{mmHg}$ ). Sin embargo, es importante recordar que los barbitúricos, además de comprometer la situación hemodinámica, causan inmunosupresión y prolongación del coma tras suspenderse su administración, debido a su redistribución en los compartimientos adiposos ${ }^{367-371}$.

15. Se recomienda no utilizar sistemáticamente la ketamina en pacientes con traumatismo craneal y en otras patologías neurocríticas.

Grado de recomendación: fuerte. Nivel de evidencia: bajo (1 C).

Justificación: La ketamina es un antagonista no competitivo de los receptores NMDA, cuyo sitio de acción primario es la región neotalámica cortical. La ketamina ha sido relacionada con un aumento de la presión parcial de $\mathrm{CO}_{2}$ en sangre arterial y de la PIC en pacientes sin VM. Sin embargo, recientemente se ha comunicado que en los pacientes con hipertensión intracraneal y VM controlada el uso de ketamina en infusión continua y de midazolam mantiene la hemodinámica cerebral y logra un control de la presión de perfusión cerebral comparable a los opioides ${ }^{372}$. Algunos efectos adversos como el aumento de la frecuencia cardíaca 
Tabla 12 Características de los medicamentos usados en los pacientes neurológicos y neuroquirúrgicos

\begin{tabular}{llllll}
\hline Característica & Propofol & Midazolam & Lorazepam & Fentanilo & Remifentanilo \\
\hline Inicio rápido & +++ & +++ & + & +++ & ++ \\
Recuperación fácil & +++ & ++ & + & ++ & ++ \\
Titulación fácil & +++ & ++ & + & ++ & ++ \\
Presión intracraneal & $\downarrow \downarrow$ & $\downarrow \downarrow$ & $\downarrow$ & $=$ & $=$ \\
Flujo sanguíneo cerebral & $\downarrow \downarrow$ & $\downarrow \downarrow$ & $\downarrow$ & $\downarrow$ & $=$ \\
Consumo cerebral de $\mathrm{O}_{2}$ & $\downarrow \downarrow$ & $\downarrow \downarrow$ & $\downarrow$ & $\downarrow$ & $\downarrow$ \\
Presión arterial media & $\downarrow \downarrow$ & $\downarrow$ & $\downarrow$ & $\downarrow$ & $\downarrow$ \\
\hline
\end{tabular}

y el mayor tiempo de recuperación neurológica al ser suspendida (relacionado con la presencia de un metabolito activo, la norketamina), la hacen no recomendada en pacientes neurocríticos cuando las evaluaciones neurológicas frecuentes sean necesarias.

\section{J. Paciente con insuficiencia renal o hepática}

¿Cuáles son las condiciones médicas a evaluar antes de iniciar algún tipo de sedación y analgesia?

J1. Se recomienda evaluar la situación hepatorrenal de todo paciente que requiera sedoanalgesia en la $\mathrm{UCl}$.

Grado de recomendación: fuerte. Nivel de evidencia: moderado (1 B).

Justificación: La utilidad clínica de la mayoría de los hipnóticos, sedantes y analgésicos se ve afectada negativamente en los pacientes con insuficiencia hepática o renal 0 , en el peor de los casos, en ambas situaciones ${ }^{3}$. Estas alteraciones plantean un verdadero desafío a los clínicos que tienen que manejar a dichos pacientes, balanceando constantemente la relación riesgo-beneficio de la intervención terapéutica, muchas veces sin el respaldo científico adecuado ${ }^{373}$. La insuficiencia hepática o renal produce cambios, no solamente en el aclaramiento, volumen de distribución, fracción libre o eliminación del medicamento original, sino también en la potencial acumulación de metabolitos activos, ya sean estos tóxicos o no.

En presencia de disfunción hepática, la mayoría de los medicamentos están sujetos a un aclaramiento disminuido, vida media aumentada y acumulación de metabolitos potencialmente tóxicos o con actividad metabólica, cuya repercusión clínica es poco conocida. Estudios experimentales han demostrado que en pacientes cirróticos la transmisión opiodérgica puede alterarse, aumentando la afinidad de los receptores por los opioides. Además, estos pacientes tienen aumentada la sensibilidad al GABA, potenciando los efectos de las benzodiazepinas. Algunos cuadros de encefalopatía subclínica pueden precipitarse con la administración de sedantes y opioides. En pacientes con insuficiencia hepática la clasificación de Child-Pugh ${ }^{374,375}$ se utiliza como guía para la elección de fármaco y para establecer la dosis 3 373,376-379 (tabla 13).

J2. Se recomienda evaluar el riesgo-beneficio del uso de la sedoanalgesia en los pacientes con insuficiencia renal crónica.

Grado de recomendación: fuerte. Nivel de evidencia: moderado $(1 \mathrm{~B})$.
Justificación: En los pacientes con insuficiencia renal crónica, estén en diálisis o no, la predicción de los perfiles farmacocinéticos con fórmulas para calcular el filtrado glomerular (FG) no está bien establecida para la mayoría de los medicamentos. La mayoría de los fármacos no han sido extensamente estudiados antes de su introducción en la práctica clínica en los enfermos críticos ${ }^{373,380-382}$. Debido a los cambios en el aclaramiento de los medicamentos y en la potencial acumulación de metabolitos activos, el clínico debe evaluar el balance riesgo-beneficio tomando en consideración otros factores de interacción farmacocinética y farmacodinámica, así como los efectos potencialmente adversos.

¿Qué medicamentos analgésicos y sedantes están contraindicados, y por qué, en este tipo de pacientes?

\section{Insuficiencia renal}

\section{J3. Se recomienda no usar morfina en el paciente crítico con insuficiencia renal y en diálisis.}

Grado de recomendación: fuerte. Nivel de evidencia: moderado $(1 \mathrm{~B})$.

Justificación: La morfina sufre una biotransformación hepática por glucoronidación a productos activos, morfina6-glucurónido y morfina-3-glucurónido, dializables que se excretan por el riñón. El metabolito morfina-6-glucurónido que se acumula durante la insuficiencia renal es el causante de la depresión respiratoria que se ha observado en pacientes con insuficiencia renal. A pesar de la diálisis, el efecto es prolongado, probablemente por la disminución de la difusión desde el SNC. En pacientes crónicos se ha demostrado que la morfina es menos tolerada que la hidromorfona $373,376,378,379$.

Dependiendo del grado de la insuficiencia renal se pueden ajustar las dosis según el FG: entre $20-50 \mathrm{ml} / \mathrm{min}, 75 \%$ de la dosis; entre $10-20 \mathrm{ml} / \mathrm{min}, 50 \%$ de la dosis.

\section{Insuficiencia hepática}

\section{J4. Se recomienda no usar midazolam en pacientes cirróti- cos.}

Grado de recomendación: fuerte. Nivel de evidencia: moderado $(1 \mathrm{~B})$.

Justificación: En los pacientes con insuficiencia hepática, la vida media de eliminación del midazolam aumenta entre 2 y 3 veces, y el aclaramiento disminuye en un $50 \%$. Se ha demostrado encefalopatía hasta $6 \mathrm{~h}$ después de su administración en pacientes cirróticos Child A o $\mathrm{B}$, en infusión para la sedación en la endoscopia digestiva. Sin embargo, puede 
Tabla 13 Clasificación de Child-Pugh modificada para enfermos hepáticos

\begin{tabular}{llll}
\hline Ítem & & Puntuación \\
\cline { 2 - 4 } & 1 & 2 & 3 \\
\hline Ascitis & Ausente & Leve & Moderada \\
Encefalopatía & No & Grado 1 a 2 & Grado 3 a 4 \\
Albúmina $(\mathrm{g} / \mathrm{l})$ & $>3,5$ & $2,8-3,5$ & $<2,8$ \\
Bilirrubina $(\mathrm{mg} / \mathrm{dl})$ & $<2$ & $2-3$ & $>3$ \\
(Para enfermedades colestásicas) & $(<4)$ & $(4-10)$ & $(>10)$ \\
Tiempo de protrombina & $>50(<1,7)$ & $30-50(1,8-2,3)$ & $<30(>2,3)$ \\
& Clase A: $5-6$ puntos & & \\
& Clase B: $7-9$ puntos & & \\
\hline
\end{tabular}

Adaptada de Child y Turcotte T $^{374}$ y Pugh et al. ${ }^{375}$.

utilizarse como sedante en pacientes cirróticos, para endoscopia de vías digestivas altas, en dosis de 30 a $50 \mu \mathrm{g} / \mathrm{kg}$ en pacientes Child A o B 3,380,381,383-385.

¿Cuáles son los medicamentos que se pueden utilizar?

\section{Insuficiencia renal}

J5. Se sugiere el uso de remifentanilo durante VM por más de $48 \mathrm{~h}$ con régimen de interrupción diaria en pacientes con insuficiencia renal que no estén en terapia dialítica.

Grado de recomendación: fuerte. Nivel de evidencia: moderado (1 B).

Justificación: El remifentanilo se metaboliza rápidamente a través de esterasas plasmáticas inespecíficas. No se acumula. Tiene un producto metabólico activo que se elimina en un $90 \%$ por la orina, el ácido remifentanílico, pero que en la práctica carece de efecto por su baja potencia. En comparación con los enfermos sin insuficiencia renal, la concentración plasmática del remifentanilo es un 30\% mayor después de una dosis de carga pero el tiempo de recuperación es similar después de suspendida la infusión cuando esta se ha suministrado durante de $72 \mathrm{~h}^{373,386,387}$.

En un estudio doble ciego aleatorizado y controlado de 19 pacientes comparando el esquema fentanilo-midazolam vs. el esquema remifentanilo-midazolam, en pacientes en VM, el uso de remifentanilo se asoció con disminución del tiempo hasta la extubación en pacientes con insuficiencia renal $(24,7$ vs. $48 \mathrm{~h}[\mathrm{p}=0,04])$, y el tiempo de proceso de destete. El grupo tratado con remifentanilo requirió mayor dosis de morfina tras la extubación. La incidencia de agitación fue similar en los 2 grupos No se evaluó el impacto de estas estrategias sobre la incidencia de complicaciones pulmonares ${ }^{272}$.

J6. Se recomienda el uso de hidromorfona, reduciendo su dosis y monitorizando los signos de excitación del SNC y los estados confusionales.

Grado de recomendación: fuerte. Nivel de evidencia: bajo (1 C).

Justificación: La hidromorfona se glucoroniza en el hígado a un metabolito activo de eliminación renal, que aumenta sus niveles plasmáticos hasta 4 veces durante insuficiencia renal. Muy probablemente este metabolito es el responsable de los efectos adversos excitatorios sobre el SNC (mioclonías, agitación y confusión) que se han comunicado. Durante la diálisis se disminuye la concentración plasmática hasta en un 40\%. La hidromorfona no se acumula sustancialmente porque rápidamente se convierte a 3G-hidromorfona, la cual parece ser efectivamente removida durante la hemodiálisis. La 3G-hidromorfona se acumula entre diálisis, y esta acumulación se asocia a un incremento en la percepción del dolor y reduce la duración de la analgesia ${ }^{3,373,388,389}$.

J7. Se recomienda el uso de fentanilo, comenzando con una dosis de carga más baja en pacientes con filtración glomerular inferior a $50 \mathrm{ml} / \mathrm{min}$.

Grado de recomendación: fuerte. Nivel de evidencia: bajo (1 C).

Justificación: El fentanilo sufre biotransformación hepática por oxidación a metabolitos inactivos. No se sabe si es dializable. En la insuficiencia renal disminuye su aclaramiento en relación con el FG, exhibiendo un perfil farmacológico más seguro que la morfina o la hidromorfona. Se han descrito casos de sedación prolongada y depresión respiratoria en pacientes con infusión continua de fentanilo $3,373,388$.

J8. Se recomienda el uso de dexmedetomidina, disminuyendo la dosis de carga y ajustando la infusión según la respuesta clínica.

Grado de recomendación: fuerte. Nivel de evidencia: bajo $(1 \mathrm{C})$.

Justificación: La dexmedetomidina tiene metabolismo hepático por glucoronidación y por el sistema p450, con eliminación renal de sus metabolitos inactivos, los cuales son excretados por la orina (90\%) y por las heces(10\%). Hay solo una descripción de un caso de un paciente en hemofiltración donde se documento que la dexmedetomidina no es hemofiltrable ${ }^{390}$. Su vida media de eliminación es menor en la insuficiencia renal crónica. A pesar de esto, el tiempo de recuperación es mayor quizá por el pico de concentración plasmática que ocurre con la dosis de carga o por la disminución de la difusión desde el SNC hacia el compartimento central. El aclaramiento y el volumen de distribución son similares entre pacientes sanos y pacientes con insuficiencia renal crónica. Faltan estudios que confirmen si la

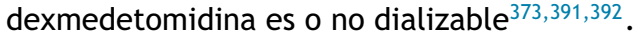

J9. Se sugiere el uso de midazolam solo para períodos inferiores de 48 a $72 \mathrm{~h}$, reduciendo la dosis a un $50 \%$. 

(2C).

Grado de recomendación: débil. Nivel de evidencia: bajo

Justificación: El midazolam tiene metabolismo hepático por oxidación a hidroximidazolam (equipotente), cuya eliminación es renal. Se acumula en pacientes con insuficiencia renal crónica e induce una sedación prolongada. El midazolam no es dializable pero sus metabolitos sí lo son. La depuración extrarrenal continua previene la acumulación de su metabolito activo. Puede usarse en pacientes con insuficiencia renal crónica disminuyendo la dosis ${ }^{3,379}$.

J10. Se sugiere no usar lorazepam en este grupo de pacientes. Si fuese necesario utilizarlo, se recomienda la monitorización de la concentración de propilenglicol, ácido láctico, osmolaridad sérica y la brecha osmolar (anión gap), especialmente en infusiones de más de $72 \mathrm{~h}$.

Grado de recomendación: débil. Nivel de evidencia: bajo (2C).

Justificación: El lorazepam tiene un metabolismo hepático por conjugación a metabolito inactivo, el cual es eliminado por el riñón. En la insuficiencia renal crónica la vida media de eliminación se prolonga, pero el aclaramiento es semejante al de los pacientes sanos. No es dializable ni ultrafiltrable. El propilenglicol (dializable), excipiente del vial del lorazepam, es responsable de la acidosis metabólica y del empeoramiento de la función renal que se ha observado en pacientes con $\mathrm{FG}<50 \mathrm{ml} / \mathrm{min}^{3,150,379,393}$.

J11. Se recomienda el uso del propofol, aumentando su dosis al inicio de la diálisis y monitorizando los niveles séricos de triglicéridos después de $12 \mathrm{~h}$ de infusión continua.

Grado de recomendación: fuerte. Nivel de evidencia: moderado (1 B).

Justificación: El propofol tiene un metabolismo hepático y extrahepático por glucoronidación y sulfuronización a metabolitos inactivos, se ha demostrado también trasformación metabólica a través de metabolismo de fase 1 por el sistema p450. No es dializable y su farmacocinética y farmacodinamia no se alteran significativamente en pacientes con insuficiencia renal crónica. Durante la diálisis se debe aumentar la dosis, debido a la disminución de la concentración plasmática por hemodilución y unión de la albúmina a los filtros. Igualmente, se requiere menos dosis en la infusión continua para sedación, la cual, si es superior a $12 \mathrm{~h}$, ocasiona un aumento significativo de triglicéridos, por lo que se recomienda una monitorización estrecha ${ }^{3,394-396}$.

J12. Se recomienda el uso de haloperidol en pacientes con delirium, disminuyendo su dosis en un $30 \%$.

Grado de recomendación: fuerte. Nivel de evidencia: bajo (1 C).

Justificación: El haloperidol tiene un metabolismo hepático por oxidación. Su metabolito activo es responsable del extrapiramidalismo. Su vida media en sujetos sanos es de 18 a $54 \mathrm{~h}$, pero no se conoce su valor en pacientes con insuficiencia renal crónica, ya que no hay estudios de farmacocinética y farmacodinamia en esos pacientes. La hipomagnesemia y la hipopotasemia resultantes después de la diálisis pueden aumentar el riesgo teórico de taquicardia ventricular polimorfa 3 379,397,398.

\section{Insuficiencia hepática}

J13. Se recomienda el uso de remifentanilo, disminuyendo su dosis y con vigilancia de la ventilación.
Grado de recomendación: fuerte. Nivel de evidencia: bajo (1 C).

Justificación: Debido a su metabolismo y eliminación, el remifentanilo es el opioide de elección en el paciente con disfunción hepática. Sin embargo, la ventana terapéutica entre la analgesia y la depresión respiratoria es estrecha, por lo cual se debe realizar un control estricto de la respiración, en los pacientes que no estén con $\mathrm{VM}^{3,386,399,400}$.

J14. Se recomienda el uso de fentanilo, reduciendo su dosis de mantenimiento.

Grado de recomendación: fuerte. Nivel de evidencia: bajo (1C).

Justificación: El aclaramiento y la vida media de eliminación del fentanilo están prolongados, acumulándose, por lo que se debe disminuir su dosis. No tiene metabolitos activos. Está indicado su uso en pacientes con insuficiencia hepática reduciendo su dosis, aunque no existen datos que guíen su dosificación en la insuficiencia hepática. Se ha utilizado en pacientes con varices esofágicas sangrantes, disminuyendo la respuesta hemodinámica a la $\mathrm{IT}^{3,401}$.

J15. Se sugiere el uso de morfina e hidromorfona en dosis reducidas y fraccionadas, con observación clínica estrecha.

Grado de recomendación: débil. Nivel de evidencia: bajo (2C).

Justificación: Estudios farmacológicos sobre la morfina en pacientes cirróticos han demostrado que su aclaramiento está disminuido. Su vida media de eliminación y el volumen de distribución están aumentados. Este medicamento puede precipitar una encefalopatía hepática. Existen algunas comunicaciones de su uso por vía epidural única en pacientes cirróticos Child $\mathrm{A}$ sin coagulopatía (3-5 mg) para el control del dolor postoperatorio. También se han descrito algunos casos de infusión continua de $2 \mathrm{mg} / \mathrm{h}$ para el tratamiento del dolor postoperatorio $3,377,382,385,402,403$. No hay una clara recomendación para su uso, ya que no tiene un perfil farmacológico seguro y requiere de una vigilancia estrecha para su administración ${ }^{378}$.

La hidromorfona, por su gran metabolismo hepático, puede aumentar la biodisponibilidad en presencia de disfunción hepática, precipitar la aparición de encefalopatía hepática y de depresión respiratoria. Su perfil de seguridad no ha sido evaluado en pacientes con disfunción hepática $^{3,388}$.

J16. Se sugiere el uso de dexmedetomidina, como terapia coadyuvante, en pacientes cirróticos con síndrome de abstinencia alcohólica, cuando el manejo convencional fracasa. Se debe reducir la dosis.

Grado de recomendación: débil. Nivel de evidencia: moderado (2 B).

Justificación: Un estudio en pacientes cirróticos demostró un aumento de la vida media y del volumen de distribución de la dexmedetomidina, con prolongación de su aclaramiento, en comparación con los sujetos sin insuficiencia hepática. Se ha comunicado su utilidad en los pacientes alcohólicos con síndrome de abstinencia que no han respondido adecuadamente al tratamiento convencional ${ }^{3,392,404,405}$.

J17. Se sugiere el uso de lorazepam en pacientes con síndrome de abstinencia alcohólica. 
Grado de recomendación: débil. Nivel de evidencia: bajo (2C).

Justificación: El lorazepam, como todas la benzodiazepinas, puede precipitar la aparición de encefalopatía hepática. Su aclaramiento está disminuido en pacientes cirróticos. Puede utilizarse en pacientes con síndrome de abstinencia alcohólica, como benzodiazepina de primera línea para la prevención de las convulsiones ${ }^{406-408}$.

J18. Se recomienda el propofol como hipnótico de elección en el manejo de pacientes con insuficiencia hepática fulminante que requieren IT y control de la hipertensión intracraneal hasta una dosis de $50 \mu \mathrm{g} / \mathrm{kg} / \mathrm{min}(3 \mathrm{mg} / \mathrm{kg} / \mathrm{h})$.

Grado de recomendación: fuerte. Nivel de evidencia: bajo (1 C).

Justificación: La vida media de eliminación del propofol y su aclaramiento se ven poco afectados en la insuficiencia hepática, pero su volumen de distribución se incrementa al doble. Comparado con sujetos sanos, su tiempo de recuperación es más prolongado. Proporciona una mejor calidad de sedación que el midazolam y un despertar más rápido con menor disfunción psicomotora cuando se ha usado para sedación en la endoscopia digestiva alta ${ }^{3,383,385}$. También se ha demostrado que disminuye la PIC en los pacientes con insuficiencia hepática fulminante ${ }^{409-411}$.

J19. Se recomienda el uso del haloperidol en los pacientes cirróticos con delirium. Se debe iniciar con dosis menores de las recomendadas en pacientes sin insuficiencia hepática, y se deben monitorizar las alteraciones electrolíticas y electrocardiográficas (específicamente el intervalo $Q T)$.

Grado de recomendación: fuerte. Nivel de evidencia: bajo (1C).

Justificación: No se conocen estudios farmacocinéticos del haloperidol en la insuficiencia hepática. Se ha utilizado en pacientes alcohólicos con delirium, administrando dosis menores que en pacientes sin lesión hepática. Se han comunicado casos de taquicardia polimorfa en enfermos cirróticos, asociada a hipopotasemia o hipomagnesemia ${ }^{398,412-414}$.

En la tabla 14 se detallan las dosis de medicamentos ajustadas al tratamiento de la insuficiencia renal o hepática ${ }^{415}$.

J20. Se sugiere el uso de propofol en pacientes Child $A$ o $B$ programados para endoscopia de vía digestiva alta sin sangrado activo. (2C).

Grado de recomendación: débil. Nivel de evidencia: bajo

Justificación: Los pacientes cirróticos son más susceptibles a la presentación de complicaciones relacionadas con la sedación que los pacientes no cirróticos. El propofol comparado con midazolam para este procedimiento tiene un tiempo de recuperación más rápido, es más efectivo y no provoca deterioro agudo en pacientes con encefalopatía mínima analizados con tests psicomotores. Aunque los estudios de este procedimiento han sido realizados en unidades de gastroenterología, en donde la administración de la sedación ha sido confiada exclusivamente a gastroenterólogos o a intensivistas, la sedación moderada con propofol sin necesidad de IT es efectiva y segura. Dosis sugeridas de fentanilo: $50 \mu \mathrm{g}$ seguida de propofol $0,25 \mathrm{mg} / \mathrm{kg}$ con dosis fraccionadas entre $20-30 \mathrm{mg} / \mathrm{min}$ cuando sea necesario sin pasar de $400 \mathrm{mg}$ como dosis $\operatorname{total}^{416,417}$.
Paciente que requiere procedimientos especiales (traqueostomía, tubos o sondas torácicas, lavado peritoneal, curas y desbridamiento de heridas o quemaduras)

\section{¿Cuáles son los medicamentos indicados para efectuar estos procedimientos?}

K1. Se sugiere un analgésico opioide, fentanilo o remifentanilo, asociado a un agente sedante (propofol, midazolam) para la realización de procedimientos especiales. Las dosis deben modificarse teniendo en cuenta el uso previo de otros sedantes y analgésicos.

Grado de recomendación: débil. Nivel de evidencia: bajo (2C).

K2. Se recomienda protocolizar el uso de opioides en caso de procedimientos rutinarios dolorosos o displacenteros (succión endotraqueal y cambios de posición).

Grado de recomendación: fuerte. Nivel de evidencia: bajo (1 C).

Justificación: Ningún medicamento, o combinación de ellos, ha sido evaluado apropiadamente para la anestesia o analgesia en procedimientos especiales en la población de pacientes de $\mathrm{UCl}$. Para los procedimientos menores realizados en la $\mathrm{UCl}$ hay que tener en cuenta qué sedantes, hipnóticos o analgésicos está recibiendo el paciente antes de practicar el procedimiento. Entre las alternativas se pueden considerar los bloqueos nerviosos o las infiltraciones de anestésicos locales, o administrar bolos del 25 al 50\% de la dosis basal de opioide que el enfermo esté recibiendo. Cuando se prevea una sedación corta (menos de $24 \mathrm{~h}$ ) se usará propofol en bolo. Si se prevé que la sedación posterior al procedimiento será $\geq 48$ h se utilizará como primera elección midazolam o lorazepam ${ }^{418-421}$.

K3. Se sugiere no usar de forma rutinaria relajantes neuromusculares en la realización de procedimientos especiales en la UCI. (2C).

Grado de recomendación: débil. Nivel de evidencia: bajo

Justificación: Los relajantes neuromusculares solo deben ser usados en casos especiales en los que el procedimiento lo precise para su ejecución correcta y segura (procedimientos abdominales, algunas traqueostomías, fibrobroncoscopia) o cuando los pacientes requieran protección cerebral como en la hipertensión intracraneal.

¿Cuándo están indicadas las técnicas de anestesia regional para el manejo del dolor en la UCI?

K4. Se recomienda el uso de la analgesia regional en el postoperatorio de la toracotomía y de la cirugía toracoabdominal mayor y en el traumatismo torácico.

Grado de recomendación: fuerte. Nivel de evidencia: alto (1 A).

Justificación: La analgesia regional puede ser de utilidad en algunos pacientes seleccionados de la UCI para el manejo del traumatismo de tórax (fracturas costales múltiples, fracturas de esternón y contusión pulmonar), del dolor postoperatorio de la cirugía torácica y de las intervenciones toracoabdominales mayores ${ }^{422,423}$.

¿Qué técnica de analgesia regional se recomienda para el manejo de dolor en la UCI?

K5. Se recomienda el abordaje peridural continuo como la técnica de elección de analgesia regional en el 
Tabla 14 Ajuste de dosis de sedantes y opioides en la insuficiencia renal y hepática

\begin{tabular}{|c|c|c|c|c|}
\hline Medicamento & $\begin{array}{l}\text { Metabolitos } \\
\text { activos }\end{array}$ & Vía metabólica & $\begin{array}{l}\text { Dosis insuficiencia renal } \\
\text { (observaciones) }\end{array}$ & $\begin{array}{l}\text { Dosis insuficiencia hepática } \\
\text { (observaciones) }\end{array}$ \\
\hline Dexmedetomidina & No & Glucoronidación & $\begin{array}{l}\text { Dosis de impregnación } \\
0,5 \mu \mathrm{g} / \mathrm{kg} \text { en } 10 \mathrm{~min} \\
\text { Infusión } 0,2-0,7 \mu \mathrm{g} / \mathrm{kg} / \mathrm{h}\end{array}$ & $\begin{array}{l}\text { En abstinencia alcohólica: } 1 \mu \mathrm{g} / \mathrm{kg} \\
\text { en } 10 \mathrm{~min} \text {. Continuar } \\
0,2-0,7 \mu \mathrm{g} / \mathrm{kg} / \mathrm{h}\end{array}$ \\
\hline Fentanilo & No & Oxidación & $\begin{array}{l}0,7-10 \mu \mathrm{g} / \mathrm{kg} / \mathrm{h} \text {. Comenzar con } \\
50 \% \text { de la dosis si el FG es } \\
\text { menor de } 50 \mathrm{ml} / \mathrm{min} \\
\text { (Puede producir sedación } \\
\text { prolongada) }\end{array}$ & $\begin{array}{l}1-2 \mu \mathrm{g} / \mathrm{kg} \text { iv para procedimientos } \\
\text { cortos } \\
\text { Child A } 0,7-10 \mu \mathrm{g} / \mathrm{kg} / \mathrm{h} \\
\text { Child } \mathrm{B}-\mathrm{C} \text { disminuir dosis según } \\
\text { respuesta } \\
\text { (Puede precipitar encefalopatía } \\
\text { hepática) }\end{array}$ \\
\hline Hidromorfona & Sí (H3G) & Glucoronidación & $\begin{array}{l}10-30 \mu \mathrm{g} / \mathrm{kg} \text { iv cada } 2-4 \mathrm{~h} \\
\text { (Puede producir mioclonías, } \\
\text { alucinaciones y/o confusión) }\end{array}$ & $\begin{array}{l}\text { Child A: } 10-30 \mu \mathrm{g} / \mathrm{kg} \text { iv cada } 2-4 \mathrm{~h} \\
\text { Child B-C: no se recomienda su } \\
\text { uso en infusión continua } \\
\text { (Puede precipitar encefalopatía } \\
\text { hepática) }\end{array}$ \\
\hline Morfina & $\begin{array}{l}\text { Sí (M3G y } \\
\text { M6G) }\end{array}$ & Glucoronidación & $\begin{array}{l}\text { FG > } 50 \mathrm{ml} / \mathrm{min}: \\
0,02-0,15 \mathrm{mg} / \mathrm{kg} \text { iv cada } 4 \mathrm{~h} \\
\text { FG } 20-50 \mathrm{ml} / \mathrm{min}: 75 \% \text { de la } \\
\text { dosis } \\
\text { FG } 10-20 \mathrm{ml} / \mathrm{min}: 50 \% \text { de la } \\
\text { dosis } \\
\text { (No se recomienda su uso en el } \\
\text { paciente en diálisis) }\end{array}$ & $\begin{array}{l}\text { Child A 0,02-0,1 mg/kg. iv cada } 4 \mathrm{~h} \\
\text { Child B-C 0,02-0,04 mg/kg cada } \\
4-6 \mathrm{~h} \\
\text { (No se recomienda su uso en } \\
\text { infusión continua. Puede } \\
\text { precipitar encefalopatía hepática) }\end{array}$ \\
\hline Remifentanilo & $\begin{array}{l}\text { Sí (ácido } \\
\text { remifentaní- } \\
\text { lico) }\end{array}$ & Hidrolisis (esterasas) & $\begin{array}{l}0,05-0,3 \mu \mathrm{g} / \mathrm{kg} / \mathrm{min} \\
\text { (Opioide de elección en } \\
\text { insuficiencia renal) }\end{array}$ & $\begin{array}{l}0,05-0,3 \mu \mathrm{g} / \mathrm{kg} / \mathrm{min} \text {. Ajustar dosis } \\
\text { según respuesta } \\
\text { (Probablemente es el opioide de } \\
\text { elección) }\end{array}$ \\
\hline Midazolam & Sí (OH) & Oxidación & $\begin{array}{l}\text { Disminuir dosis de carga en un } \\
50 \% \\
\text { Infusión } 0,02-0,1 \mathrm{mg} / \mathrm{kg} / \mathrm{h} \text { no } \\
\text { más de } 48 \mathrm{~h} \\
\text { (OH-midazolam es dializable) }\end{array}$ & $\begin{array}{l}\text { Child A: } 20-50 \mu \mathrm{g} / \mathrm{kg} \text { para } \\
\text { procedimientos cortos } \\
\text { Child B-C: no se recomienda su } \\
\text { uso en infusión continua } \\
\text { (Puede precipitar encefalopatía } \\
\text { hepática) }\end{array}$ \\
\hline Lorazepam & $\begin{array}{l}\text { Sí }(\mathrm{OH}- \\
\text { midazolam) }\end{array}$ & Glucoronidación & $\begin{array}{l}0,01-0,1 \mathrm{mg} / \mathrm{kg} / \mathrm{h} \\
\text { (Posible toxicidad por solvente } \\
\text { propilenglicol) }\end{array}$ & $\begin{array}{l}\text { Dosis } 0,01 \mathrm{a} 0,1 \mathrm{mg} / \mathrm{kg} / \mathrm{h} \\
\text { (En la abstinencia alcohólica es la } \\
\text { primera elección para profilaxis } \\
\text { de convulsiones. Puede precipitar } \\
\text { encefalopatía hepática) }\end{array}$ \\
\hline Propofol & No & Oxidación & $\begin{array}{l}\text { Aumentar dosis de carga al } \\
\text { comenzar diálisis } 2-3 \mathrm{mg} / \mathrm{kg} \text {. } \\
\text { Continuar dosis de infusión } \\
5-40 \mu \mathrm{g} / \mathrm{kg} / \mathrm{min} \\
\text { (Medición de triglicéridos en } \\
\text { infusiones mayores de } 12 \mathrm{~h} \text { ) }\end{array}$ & $\begin{array}{l}5-40 \mu \mathrm{g} / \mathrm{kg} / \mathrm{min} \\
\text { (En la insuficiencia hepática } \\
\text { fulminante es útil para el control } \\
\text { de la presión intracraneal }\end{array}$ \\
\hline Haloperidol & No & Oxidación & $\begin{array}{l}2 \text { mg iv cada } 20 \text { min hasta } \\
\text { control de síntomas } \\
\text { (No se recomienda en } \\
\text { pacientes con hipopotasemia o } \\
\text { hipomagnesemia, o con } Q T \\
\text { prolongado) }\end{array}$ & $\begin{array}{l}2 \mathrm{mg} \text { iv cada } 20 \text { min hasta control } \\
\text { de síntomas } \\
2-4 \mathrm{mg} \text { iv cada } 6 \mathrm{~h} \\
\text { (No se recomienda en pacientes } \\
\text { con hipopotasemia o } \\
\text { hipomagnesemia, o con } Q T \\
\text { prolongado o simultáneamente } \\
\text { con vasopresina) }\end{array}$ \\
\hline
\end{tabular}

FG: filtrado glomerular; iv: vía intravenosa; M3G: morfina-3-glucurónido; M6G: morfina-6-glucurónido. 
postoperatorio de la toracotomía, cirugía toracoabdominal y traumatismo de tórax. El abordaje paravertebral con infusión continua es una alternativa a la vía peridural en los pacientes en postoperatorio de toracotomía.

Grado de recomendación: fuerte. Nivel de evidencia: alto (1 A).

Justificación: La técnica más antigua y difundida es la analgesia peridural, que, en comparación con la analgesia intravenosa con opioides en bolos o PCA, proporciona un adecuado control analgésico, facilidad para realizar fisioterapia respiratoria, y disminución del tiempo de VM y de la incidencia de neumonía nosocomial ${ }^{422-424}$.

Los resultados de los ensayos que han comparado la técnica paravertebral con la peridural muestran la equipotencia analgésica de los 2 procedimientos, pero con menores tasas de efectos adversos como hipotensión, náuseas, vómito y retención urinaria en el abordaje paravertebral ${ }^{425-428}$.

K6. Se sugiere el bloqueo intercostal en el postoperatorio de toracotomía.

Grado de recomendación: débil. Nivel de evidencia: moderado (2B).

Justificación: Al comparar el bloqueo intercostal con la analgesia peridural, se observa una disminución del consumo de opioides (PCA) y de la incidencia de retención urinaria cuando se utiliza la técnica intercostal en toracotomía programada $^{429}$.

\section{Estrategias no farmacológicas o terapias complementarias}

¿Qué usar para modular las condiciones externas que pueden afectar la tranquilidad del paciente: ruido, vigilia-sueño, visitas, conversaciones inadecuadas?

L1. Se debe promover el sueño en la UCI, para lo que se tomarán todas las medidas necesarias, en especial las medidas no farmacológicas.

Grado de recomendación: fuerte. Nivel de evidencia: moderado (1 B).

Justificación: El sueño es importante para la recuperación de los pacientes. Medidas objetivas y subjetivas de la calidad del sueño en la UCI muestran una importante alteración del sueño. Esta privación es un estrés adicional, que puede acarrear consecuencias adversas como el compromiso del sistema inmune, humoral y celular, el incremento del consumo de oxígeno y la producción de $\mathrm{CO}_{2}$ y la alteración de la termorregulación ${ }^{430,431}$.

Entre las causas que pueden producir la alteración del sueño en los pacientes que se encuentran en la UCl están las evaluaciones médico-enfermería, las pruebas diagnósticas, el ruido, la luz nocturna, el dolor, la incomodidad y los procedimientos invasivos ${ }^{432-434}$.

Se puede recurrir a medidas complementarias para promover el sueño ${ }^{435}$, como: control de la luz ambiental, masaje, musicoterapia ${ }^{436}$, sincronización de las actividades con ciclo circadiano, disminución de ruido ${ }^{437}$. Es importante la valoración de la enfermera o el uso de una escala para el control del sueño ${ }^{438}$.

L2. Se recomienda tomar todas las medidas necesarias para la disminución del ruido en la UCI. Una medida complementaria puede ser el uso de tapones auriculares, para así disminuir la percepción del mismo.
Grado de recomendación: fuerte. Nivel de evidencia: moderado (1 B).

Justificación: El ruido en la UCI proporciona un ambiente hostil para el paciente, con la consecuente alteración del sueño y la aparición de ansiedad ${ }^{431-434,437,439-441}$. El ruido en la $\mathrm{UCl}$ es producido por alarmas, ventiladores mecánicos, teléfonos y conversaciones del personal. Los niveles por encima de los 80 decibelios deben ser evitados y los niveles por debajo de 35 decibelios favorecen el sueño ${ }^{442}$. Una medida complementaria puede ser el uso de tapones auriculares para disminuir la percepción de ruido por parte del

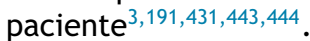

L3. Se recomienda respetar, en la medida de lo posible, el ritmo vigilia-sueño, disminuyendo la intensidad de la luz por la noche, así como las intervenciones de enfermería o los procedimientos.

Grado de recomendación: fuerte. Nivel de evidencia: fuerte (1B).

Justificación: El ritmo vigilia-sueño debe ser respetado en la medida de lo posible, tratando de tener durante la noche la menor cantidad de alteraciones del sueño por procedimientos, así como brindar un ambiente con la menor cantidad de luz posible. El uso de una guía que promueva el control del ruido y de la luz nocturna en la UCI debería ser implementado 445,446 .

¿Cuándo y qué técnicas de relajación y masaje se pueden usar?

L4. Los masajes pueden ser usados como una alternativa o adyuvante de la terapia farmacológica.

Grado de recomendación: fuerte. Nivel de evidencia: débil (1 C).

Justificación: Masajes en la espalda por un promedio de 5 a 10 min promueven la relajación y mejora del sueño ${ }^{447}$, al igual que los masajes en los pies durante $5 \mathrm{~min}^{448}$. La combinación de masajes con acupresión ha mostrado los mismos beneficios $^{449}$.

¿Cuándo usar la musicoterapia?

L5. Se recomienda la musicoterapia en los pacientes admitidos en la $\mathrm{UCl}$, en especial en los que reciben VM.

Grado de recomendación: fuerte. Nivel de evidencia: moderado (1 $\mathrm{B})$.

Justificación: La musicoterapia puede contribuir a la relajación y disminución del dolor de los pacientes en la $\mathrm{UCl}$. La música puede enmascarar el ruido. En el postoperatorio de cirugía cardíaca la audición de música durante el primer día se asoció a una disminución de la sensación de molestia por el ruido, de la frecuencia cardíaca y de la presión arterial sistólica ${ }^{450}$. Un efecto similar se ha obtenido en pacientes oncológicos admitidos en la $\mathrm{UCl}^{451}$. En los pacientes con VM, la musicoterapia se asocia a una disminución de la ansiedad, de la presión arterial sistólica y diastólica, y de la frecuencia cardíaca ${ }^{281,452-457}$. No obstante, se requieren mayores estudios para concluir que la musicoterapia es efectiva en todos los grupos de pacientes. Dado que la musicoterapia es una intervención sin efectos adversos, y tiene un bajo coste, debería ser considerada en las medidas de control de la ansiedad y el ruido en la $\mathrm{UCl}^{280-282,458-461}$

L6. Se recomienda informar al paciente sobre su enfermedad y los procedimientos que se le realizarán.

Grado de recomendación: fuerte. Nivel de evidencia: bajo (1 C). 
Justificación: La falta de información o el manejo inadecuado de la información que recibe el paciente favorecen el incremento de la ansiedad ${ }^{462}$. No hay estudios apropiados sobre cómo informar a los enfermos en la UCl. Un mejor entendimiento de su enfermedad y de las intervenciones que se realizan puede mejorar su colaboración y disminuir la ansiedad. Asimismo, parece razonable evitar las conversaciones médicas o de enfermería inadecuadas que pueda escuchar el paciente ${ }^{463,464}$.

L7. Se recomienda establecer un medio de comunicación efectivo con los pacientes que se encuentren en VM.

Grado de recomendación: fuerte. Nivel de evidencia: bajo (1 C).

Justificación: Los pacientes que se encuentran en VM y no están sedados o están en sedación cooperativa, al tener una mejor comunicación tanto con el personal que le atiende como con los familiares, pueden juzgar mejor su condición y tienen una mayor autonomía y sensación de bienestar. Algunos métodos recomendados pueden ser: gestos, movimientos de la cabeza, escritura, tarjetas de letras, palabras, frases o imágenes y hasta dispositivos electrónicos. En los pacientes con traqueostomía se debe valorar la posibilidad de desinflar el manguito para permitir el uso de la voz ${ }^{465,466}$.

L8. Se recomienda promover el uso de dispositivos que permitan la orientación de los pacientes en los ambientes de cuidados intensivos: como relojes de pared, calendarios, ventanas con luz natural, fotos de familiares en lugares visibles del ambiente de cuidados intensivos, así como objetos de uso diario por parte del paciente.

Grado de recomendación: fuerte. Nivel de evidencia: bajo (1 C).

Justificación: La presencia de un reloj, calendario, tableros y similares que permitan a pacientes y familiares personalizar la habitación, así como tarjetas de felicitación, fotos y otros efectos personales, crean un ambiente cómodo para la recuperación del paciente. Inclusive la habitación puede equiparse con un televisor y un sistema de educación $\mathrm{y} / \mathrm{o}$ entretenimiento, que puede ser utilizado para apoyar las metas de educación y para proporcionar entretenimiento ${ }^{467}$.

A modo de síntesis, en el anexo 3 se sugiere un paquete de medidas 0 «bundle» para el manejo de la analgesia, sedación y delirium en el paciente adulto crítico.

\section{Conflicto de intereses}

Los miembros del grupo Consenso declaran los siguientes conflictos de intereses: G. Castorena, conferencista de MSD para Sugamadex; J.C. Díaz, conferencista para Hospira; A. Hernández, organizador de reuniones académicas para Hospira y Boehringer Ingelheim; T. Muñoz, consultor (Advisory Board) para Orion Pharma S.L.; F. Pálizas, conferencista para Bayer para rivaroxaban y apoyo para asistir a congresos sobre sepsis; J.M. Pardo, apoyo para asistir a congresos por MSD y Sanofi_Aventis; C. Righy, conferencista para Hospira; M. Suárez, conferencista para Hospira, apoyo para asistencia a congresos por Laboratorios Victus y Laboratorios Abbot. Los demás no refieren conflictos de interés.

\section{Agradecimientos}

A la Asociación Colombiana de Medicina Crítica y Cuidado Intensivo $(\mathrm{AMCl})$, por su gestión ante Laboratorios Hospira en la consecución del grant irrestricto necesario para la elaboración de la guía y por la administración de los recursos.

A la doctora Sandra Rubiano, MD, por su apoyo en la redacción y ayuda metodológica en la elaboración de las guías.

A la doctora Olga Lucia Quintero, MD, por su ayuda en la organización de la bibliografía y en la traducción al inglés de las guías.

Al doctor Carlos Eduardo Pinzón, MD, de la Colaboración Cochrane Colombia, por realizar la búsqueda de la bibliografía, además de brindar asesoría en la metodología.

A Alexandra Suárez por su ayuda en la organización de la logística y trabajo de secretaria para la elaboración del escrito de las guías.

\section{Anexo 1. Autores y composición del grupo de trabajo}

\section{Coordinador (chairman):}

Edgar Celis-Rodríguez, MD (Colombia).

Profesor de Anestesia y Medicina Crítica.

Jefe de Departamento de Medicina Crítica y Cuidado

Intensivo.

Hospital Universitario Fundación Santa Fe de Bogotá.

Universidad de Los Andes.

Bogotá, Colombia

Tesorero WFSICCM.

edgarcelis.md@gmail.com

Miembros

Sociedad Argentina de Terapia Intensiva (SATI)

Fernando Pálizas, MD

Director del Servicio de Terapia Intensiva de las Clínicas

Bazterrica y Santa Isabel.

Director de la Carrera de Médico Especialista en Terapia

Intensiva, sede Bazterrica, Universidad de Buenos Aires.

Buenos Aires, Argentina.

palizasfernando@gmail.com

Daniel Ceraso MD, FCCM

Especialista en Terapia Intensiva SATI-FCCM.

Jefe de Unidad de Terapia Intensiva, Hospital Juan A.

Fernández, Buenos Aires.

Jefe de Unidad de Terapia Intensiva, Sanatorio San Lucas,

San Isidro, Argentina.

Director Carrera Medicina Crítica y Terapia Intensiva, Uni-

versidad de Buenos Aires.

dceraso@gmail.com

Néstor Raimondi, MD, FCCM

Coordinador clínico, Terapia Intensiva A. Hospital Juan A. Fernández.

Presidente electo, Sociedad Argentina de Terapia Intensiva.

Vicepresidente de la FEPIMCTI.

Buenos Aires, Argentina

nestor.raimondi@gmail.com

Associação de Medicina Intensiva Brasileira-AMIB

Cássia Righy Shinotsuka

Coordenadora da Unidade Neurointensiva, Hospital Copa

D’Or, Rio de Janeiro, Brasil

Pesquisadora Associada do Instituto D'Or de Pesquisa e Ensino. 


\section{Sociedad Chilena de Medicina Intensiva}

Sebastián Ugarte, MD

Profesor de la Universidad Andrés Bello,

Director Servicio de Paciente Crítico, Clínica INDISA,

Director de la Red de Medicina Intensiva, Santiago de

Chile, Chile.

Presidente Federación Panamericana e Ibérica de Medi-

cina Crítica y Terapia Intensiva.

Council World Federation of Societies of Intensive and

Critical Care Medicine.

sugarteu@gmail.com

Antonio Hernández

Especialista en Medicina Intensiva y Enfermedades Res-

piratorias.

Jefe del Departamento de Paciente Crítico, Hospital Mili-

tar de Santiago.

Profesor de la Universidad de Los Andes.

Profesor de la Universidad de Valparaíso.

antoniohzd@gmail.com

Asociación Colombiana de Medicina Crítica y Cuidado

Intensivo-AMCI

Fernando Raffán-Sanabria M.D.

Anestesiólogo-intensivista, especialista en anestesia para

trasplantes.

Departamento de Anestesiología y Departamento de

Medicina Crítica.

Hospital Universitario Fundación Santa Fe de Bogotá.

Profesor clínico, Facultad de Medicina, Universidad de los

Andes, Bogotá.

Profesor de Anestesiología Universidad El Bosque.

Bogotá.

raffanmago@gmail.com

Carmelo Dueñas Castell

Profesor Universidad de Cartagena.

UCI Gestión Salud, UCI Santa Cruz de Bocagrande.

Secretario de la Federación Panamericana e Ibérica de

Medicina crítica y Terapia Intensiva.

Asesor científico de Linde Healthcare.

crdc2001@gmail.com

Dario I. Pinilla

Gestor de Medicina Crítica, Corporación Mederi.

Profesor Mederi de la Universidad del Rosario en el Área

de Medicina Critica.

darioipinilla@gmail.com

Claudia Birchenall, MD

Médico Internista-intensivista.

Estadística-epidemiologia clínica.

Clínica Universiraria de Colombia.

Hospital Universitario Mayor-Mederi

cibirchenall@yahoo.com

Juan Carlos Díaz Cortés

Anestesiólogo, intensivista, epidemiólogo.

UCI, Hospital Universitario Fundación Santa Fe de Bogotá.

Instructor Anestesia y Medicina Crítica, Universidad del

Bosque, Universidad del Rosario y Universidad de los Andes.

judiazco@gmail.com

Juan Mauricio Pardo Oviedo

Médico especialista en Medicina Interna y en Medicina

Critica y Cuidados Intensivos de la Universidad del Rosario.

Especialista en Filosofía de la Ciencia, Universidad del

Bosque.
Jefe de Educación Médica en Hospital Universitario Mayor-Mederi.

Médico de la Unidad de Cuidados Intensivos, Fundación Cardio-infantil.

Profesor principal de Medicina de la Universidad del Rosario.

Juan.pardo@urosario.edu.co

Society of Critical Care Medicine-SCCM

Edgar J. Jimenez, MD, FCCM

Presidente Federación Mundial de Sociedades de Medicina Crítica y Cuidados Intensivos.

Chairman, Sección de Medicina Critica Orlando Health Corporation y Orlando Health Physicians Group Director, Unidades de Cuidados Intensivos Orlando Regional Medical Center.

Profesor de Medicina University of Central Florida.

Profesor Asociado de Medicina University of Florida y Flo-

rida State University. edgar.Jimenez@orlandohealth.com

edgar.Jimenez@orhs.org

Asociación Mexicana de Medicina Crítica y Terapia Intensiva-AMMCTI

Guillermo Castorena Arellano

Subdirector de Anestesia y Áreas Críticas, Hospital General Manuel Gea González, Ciudad de México

Profesor titular de Anestesiología, UNAM, Fundación Clínica Médica Sur.

Ciudad de México, México

drmicky@prodigy.net.mx

Jesús Ojino Sosa García

Especialista en Medicina Interna y Medicina del Enfermo

en Estado Crítico.

Médico adscrito a la Unidad de Terapia Intensiva, Hospital Médica Sur

Asesor metodológico de Guías de Práctica Clínica. Centro Nacional de Excelencia Tecnológica en Salud. Secretaría de Salud (CENETEC-SALUD).

drintervista@gmail.com

Sociedad Peruana de Medicina Intensiva-SOPEMI

Juan Carlos Meza, MD

Médico internista e intensivista.

Jefe del Departamento de Medicina Crítica y de la Oficina de Educación Médica Continua del Centro Médico Naval «C.M.S.T.».

Docente de la Universidad Nacional Mayor de San Marcos y de la Universidad San Martín de Porres.

jcmezagarcia@gmail.com

Mario Suárez, MD

Médico internista e intensivista.

Director del Hospital Nacional Hipólito Unanue, Lima, Perú.

Tutor de residentes de medicina intensiva Hospital Nacional Hipólito Unanue

mariosuarez125@yahoo.com

Sociedad Venezolana de Medicina Crítica-SVMC

Clara Pacheco Tovar

Medicina interna-médico intensivista.

Jefe de Servicio de Terapia Intensiva del Hospital universitario de Caracas. Universidad Central de Venezuela.

Médico intensivista del centro médico docente La Trinidad. 
Presidenta de la Sociedad Venezolana de Medicina Crítica.

pacheco.clara@gmail.com

Sociedad Española de Medicina Intensiva, Crítica y Unidades Coronarias (SEMICYUC)

Tomás Muñoz Martínez, MD, PhD

Doctor en Medicina y Cirugía por la Universidad del País Vasco.

Especialista en Medicina Intensiva Estudios Avanzados en Epidemiología y Salud Pública (Univ. País Vasco).

Facultativo especialista de área en el Servicio de Medicina Intensiva del Hospital de Cruces (Vizcaya)

Coordinador del Grupo de Trabajo de Analgesia y Sedación de la SEMICYUC.

tomas.munozmartinez@osakidetza.net

tomas@arconte.jazztel.es

Miguel Ángel de la Cal, MD

Jefe de Sección de Medicina Intensiva.

Hospital Universitario de Getafe.

Centro de Investigación Biomédica en Red (CIBER) de

Enfermedades Respiratorias. Instituto de Salud Carlos III.

Madrid, España.

mcal@ucigetafe.com

Metodología y apoyo logístico

Miguel Ángel de la Cal, MD (España)

Claudia Birchenall, MD (Colombia)

Juan Carlos Díaz, MD (Colombia)

\section{Anexo 2. Estrategias de búsqueda en PUBMED}

¿Cuáles son las recomendaciones para pacientes con condiciones especiales como paciente con EPOC, paciente con asma, paciente con inestabilidad hemodinámica y paciente con falla multiorgánica?

(«Conscious Sedation»[MeSH] OR «Deep Sedation»[MeSH] OR «Anesthetics, Dissociative»[MeSH] OR SEDATION[All Fields] OR «Conscious Sedation»[tw] OR «Deep Sedation»[tw] OR «Anesthetics, Dissociative»[tw] OR «sedation»[All Fields] OR «sedation, conscious»[All Fields] OR «sedation, deep»[All Fields] OR «sedation, moderate» [All Fields] OR «sedations»[All Fields] OR «sedations, deep»[All Fields] OR «sedative»[All Fields] OR «sedative action»[All Fields] OR «sedative and hypnotic»[All Fields] OR «sedative effect»[All Fields] OR «sedative effects»[All Fields]) AND (comparative study [mh] OR placebos [mh] OR clinical trial [pt] OR random* [tiab] OR controlled clinical trial [pt] OR randomized controlled trial [pt] OR double blind method) AND («Intensive Care»[MeSH] OR «Intensive Care Units»[MeSH] OR «Critical Care» $[\mathrm{MeSH}]$ OR Intensive Care [tw] OR Intensive Unit* [tw] OR Critical Care [tw] OR ICU [tw] OR Coronary Care Units [MeSH] OR Burn Units [MeSH] OR Respiratory Care Units [MeSH] OR UTI [TW] OR Neurointensive care) AND («sepsis»[MeSH Terms] OR sepsis[Text Word])

¿Cuáles son los factores que contribuyen para la aparición de la agitación?

Search (Cohort studies [mh] OR Risk [mh] OR (Odds [tw] AND ratio* [tw]) OR (Relative [tw] AND risk [tw]) OR Case control* [tw] OR Case-control studies [mh] OR «clinical indicators» [tw] OR forecasting [tw]) AND (Psychomotor Agitation [mh] OR Excitement [tw] OR
Psychomotor Hyperactivity [tw] OR Agitation [tw] OR Psychomotor Restlessness [tw] OR Akathisia [tw] OR Dyskinesias [tw] OR Delirium [MeSH] OR «Alcohol Withdrawal Delirium»[MeSH] OR «Delirium, Dementia, Amnestic, Cognitive Disorders»[MeSH] OR Delirium of Mixed Origin OR Delirium* [tw] OR Confusion [mh] OR bewilderment [tw] OR emotional disturbance [tw] OR perceptual disorientation [tw] OR Confusional State* [tw] OR Bewilderment [tw] OR Confusion [tw] OR Disorientation [tw] OR Neurobehavioral Manifestations [mh] OR Cognitive Symptoms [tw] OR Cognitive Manifestation* [tw] OR Alcohol Withdrawal Delirium [mh] OR DELUSIONS [tw] OR hallucination* [tw] OR tremor [tw] OR agitation [tw] OR insomnia [tw] OR autonomic hyperactivity [tw] OR Hallucinosis [tw]) AND («Intensive Care»[MeSH] OR «Intensive Care Units»[MeSH] OR «Critical Care» [MeSH] OR Intensive Care [tw] OR Intensive Unit* [tw] OR Critical Care [tw] OR ICU [tw] OR Coronary Care Units [MeSH] OR Burn Units [MeSH] OR Respiratory Care Units [MeSH] OR UTI [TW] OR Neurointensive care [tw])Limits:Publication Date from 2006/01/01 to 2011/12/31.

¿Cuáles son los instrumentos de medición (escalas, listas de chequeo, sistemas de medición) más usados para su monitorización y diagnóstico?

( $(\ll$ Intensive Care»[MeSH] OR «Intensive Care Units»[MeSH] OR «Critical Care» $[\mathrm{MeSH}]$ OR (Intensive Care [tw]) OR Intensive Unit* [tw] OR Critical Care [TW] OR ICU [tw] OR Coronary Care Units [MeSH] OR Burn Units [MeSH] OR Respiratory Care Units [MeSH] OR UTI [TW] OR Neurointensive care [tw]) AND («Delirium»[MeSH] OR «Delirium, Dementia, Amnestic, Cognitive Disorders»[MeSH] OR «delirium»[All Fields]) AND (sensitiv*[Title/Abstract] OR sensitivity and specificity[MeSH Terms] OR diagnos*[Title/Abstract] OR diagnosis[MeSH:noexp] OR diagnostic * [MeSH:noexp] OR diagnosis, differential[MeSH:noexp] OR diagnosis[Subheading:noexp] OR Scales [tw] OR «weights and measures»[MeSH Terms] OR SCALE[Text Word]) OR measurement[All Fields] OR «scale»[All Fields]

¿Cuáles son las escalas y elementos más usados para la monitorización y diagnóstico de la agitación?

Search(Scales [tw] OR Pain Measurement [tw] OR Analgesia test* [tw] OR pain score [tw] OR pain scale [tw] OR sedation score [tw] OR Apache [tw] OR glasgow coma scale [tw] OR point scoring systems [tw] OR ramsay sedation score [tw] OR addenbrooke* sedation score* [tw] OR sedation item* [tw] OR «Psychiatric Status Rating Scales» $[\mathrm{MeSH}] \mathrm{OR}$ «Pain Measurement» $[\mathrm{MeSH}] \mathrm{OR}$ «Manifest Anxiety Scale»[MeSH] OR «Test Anxiety Scale»[MeSH] OR pain questionnaire [tw]) AND («Intensive Care»[MeSH] OR «Intensive Care Units»[MeSH] OR «Critical Care» [MeSH] OR (Intensive Care [tw]) OR Intensive Unit* [tw] OR Critical Care [TW] OR ICU [tw] OR Coronary Care Units [MeSH] OR Burn Units [MeSH] OR Respiratory Care Units [MeSH] OR UTI [TW] OR Neurointensive care [tw])Limits:Publication Date from 2006/01/01 to $2011 / 12 / 31$.

¿Cuáles son los factores de riesgo que contribuyen para su aparición?

( («Intensive Care»[MeSH] OR «Intensive Care Units» $[\mathrm{MeSH}]$ OR «Critical Care» $[\mathrm{MeSH}]$ OR (Intensive Care [tw]) OR Intensive Unit* [tw] OR Critical Care [TW] OR ICU [tw] OR Coronary Care Units [MeSH] OR Burn Units [MeSH] 
OR Respiratory Care Units [MeSH] OR UTI [TW] OR Neurointensive care $[\mathrm{tw}]$ )AND («Delirium»[MeSH] OR «Delirium, Dementia, Amnestic, Cognitive Disorders»[MeSH] OR «delirium»[All Fields]) AND (random*[tiab] OR cohort*[tiab] OR risk*[tiab] OR causa*[tiab] OR predispos*[tiab] OR odds ratio[mh] OR case control* OR odds ratio* OR controlled clinical trial [pt] OR randomized controlled trial [pt] OR risk[mh] OR practice guideline[pt] OR epidemiologic studies[mh] OR case contol studies[mh] OR cohort studies[mh] OR age factors[mh] OR comorbidity[mh] OR epidemiologic factors[mh])

¿Cuáles son las recomendaciones específicas en las pacientes embarazadas?

«pregnancy»[MeSH Terms] OR pregnancy[Text Word] OR «pregnancy»[All Fields]

AND («Conscious Sedation»[MeSH] OR «Deep Sedation» $[\mathrm{MeSH}] \quad$ OR «Anesthetics, Dissociative»[MeSH] OR SEDATION[All Fields] OR «Conscious Sedation»[tw] OR «Deep Sedation»[tw] OR «Anesthetics, Dissociative»[tw] OR «sedation»[All Fields] OR «sedation, conscious»[All Fields] $\mathrm{OR}$ «sedation, deep»[All Fields] OR «sedation, moderate»[All Fields] OR «sedations»[All Fields] OR «sedations, deep»[All Fields] OR «sedative»[All Fields] OR «sedative action»[All Fields] OR «sedative and hypnotic»[All Fields] OR «sedative effect»[All Fields] OR «sedative effects»[All Fields]) AND («Intensive Care»[MeSH] OR «Intensive Care Units»[MeSH] OR «Critical Care» [MeSH] OR Intensive Care [tw] OR Intensive Unit* [tw] OR Critical Care [tw] OR ICU [tw] OR Coronary Care Units [MeSH] OR Burn Units [MeSH] OR Respiratory Care Units [MeSH] OR UTI [TW] OR Neurointensive care)

¿Cuáles son las recomendaciones específicas en los pacientes con hipertensión intracraneal

«intracranial hypertension»[MeSH Terms] OR intracranial hypertension[Text Word] OR «pseudotumor cerebri»[MeSH Terms] OR idiopathic intracranial hypertension[Text Word] AND («Conscious Sedation»[MeSH] OR «Deep Sedation» $[\mathrm{MeSH}]$ OR «Anesthetics, Dissociative»[MeSH] OR SEDATION[All Fields] OR «Conscious Sedation»[tw] OR «Deep Sedation»[tw] OR «Anesthetics, Dissociative»[tw] OR «sedation»[All Fields] OR «sedation, conscious»[All Fields] $\mathrm{OR}$ «sedation, deep»[All Fields] OR «sedation, moderate»[All Fields] OR «sedations»[All Fields] OR «sedations, deep»[All Fields] OR «sedative»[All Fields] OR «sedative action»[All Fields] OR «sedative and hypnotic»[All Fields] OR «sedative effect»[All Fields] OR «sedative effects»[All Fields]) AND («Intensive Care»[MeSH] OR «Intensive Care Units»[MeSH] OR «Critical Care» [MeSH] OR Intensive Care [tw] OR Intensive Unit* [tw] OR Critical Care [tw] OR ICU [tw] OR Coronary Care Units [MeSH] OR Burn Units [MeSH] OR Respiratory Care Units [MeSH] OR UTI [TW] OR Neurointensive care)

¿Cuáles son las recomendaciones específicas en los enfermos con traqueostomía?

(«Conscious Sedation»[MeSH] OR «Deep Sedation»[MeSH] OR «Anesthetics, Dissociative»[MeSH] OR SEDATION[All Fields] OR «Conscious Sedation»[tw] OR «Deep Sedation»[tw] OR «Anesthetics, Dissociative»[tw] OR «sedation»[All Fields] OR «sedation, conscious»[All Fields] $\mathrm{OR}$ «sedation, deep»[All Fields] OR «sedation, moderate»[All Fields] OR «sedations»[All Fields] OR «sedations, deep»[All Fields] OR «sedative»[All Fields] OR «sedative action»[All
Fields] OR «sedative and hypnotic»[All Fields] OR «sedative effect»[All Fields] OR «sedative effects»[All Fields]) AND («tracheostomy»[MeSH Terms] OR tracheostomy[Text Word] OR «tracheostomy»[All Fields]) OR «tracheotomies»[All Fields] OR «tracheotomy»[All Fields]) AND («Intensive Care» $\mathrm{MeSH}]$ OR «Intensive Care Units» $[\mathrm{MeSH}] \mathrm{OR}$ «Critical Care» [MeSH] OR Intensive Care [tw] OR Intensive Unit* [tw] OR Critical Care [tw] OR ICU [tw] OR Coronary Care Units [MeSH] OR Burn Units [MeSH] OR Respiratory Care Units [MeSH] OR UTI [TW] OR Neurointensive care)

¿Cuáles son las recomendaciones específicas en los enfermos quemados?

(«Conscious Sedation»[MeSH] OR «Deep Sedation»[MeSH] OR «Anesthetics, Dissociative»[MeSH] OR SEDATION[All Fields] OR «Conscious Sedation»[tw] OR «Deep Sedation»[tw] OR «Anesthetics, Dissociative»[tw] OR «sedation»[All Fields] OR «sedation, conscious»[All Fields] $\mathrm{OR}$ «sedation, deep»[All Fields] OR «sedation, moderate»[All Fields] OR «sedations»[All Fields] OR «sedations, deep»[All Fields] OR «sedative»[All Fields] OR «sedative action»[All Fields] OR «sedative and hypnotic»[All Fields] OR «sedative effect»[All Fields] OR «sedative effects»[All Fields]) AND («Intensive Care»[MeSH] OR «Intensive Care Units»[MeSH] OR «Critical Care» [MeSH] OR Intensive Care [tw] OR Intensive Unit* [tw] OR Critical Care [tw] OR ICU [tw] OR Coronary Care Units [MeSH] OR Burn Units [MeSH] OR Respiratory Care Units [MeSH] OR UTI [TW] OR Neurointensive care) AND («burn injury»[All Fields] OR «burned patients»[All Fields] OR «burn, eye»[All Fields] OR «burn, electric»[All Fields] OR «burn, chemical»[All Fields] OR «burn wounds»[All Fields] OR «burn wound»[All Fields] OR «Burns»[MeSH] OR «Burns, Inhalation» $[\mathrm{MeSH}]$ OR «Eye Burns»[MeSH] OR «Burns, Electric»[MeSH] OR «Burns, Chemical»[MeSH] OR «Burns»[tw] OR «Burns, Inhalation»[tw] OR «Eye Burns»[tw] OR «Burns, Electric»[tw] OR «Burns, Chemical»[tw])

¿Cuál o cuáles son las mejores opciones terapéuticas?

( $($ Intensive Care»[MeSH] OR «Intensive Care Units» $[\mathrm{MeSH}]$ OR «Critical Care» [MeSH] OR (Intensive Care [tw]) OR Intensive Unit* [tw] OR Critical Care [TW] OR ICU [tw] OR Coronary Care Units [MeSH] OR Burn Units [MeSH] OR Respiratory Care Units [MeSH] OR UTI [TW] OR Neurointensive care [tw])AND («Delirium»[MeSH] OR «Delirium, Dementia, Amnestic, Cognitive Disorders» $[\mathrm{MeSH}] \mathrm{OR}$ «delirium»[All Fields]) AND «antipsychotic agents»[MeSH Terms] OR «antipsychotic agents»[All Fields] OR antipsychotic drugs[Text Word] OR «haloperidol»[MeSH Terms] OR haloperidol[Text Word] OR «olanzapine»[Supplementary Concept] OR olanzapine[Text Word] OR «quetiapine»[Supplementary Concept] OR quetiapine[Text Word] OR «risperidone»[MeSH Terms] OR RISPERIDONE[Text Word]

\section{Anexo 3. Manejo de la analgesia, sedación y delirium en el paciente adulto crítico. Paquete de medidas o «bundle»}

\section{C.1. Introducción}

Como producto derivado de esta guía se ha querido destacar un conjunto de medidas que van dirigidas al paciente adulto crítico, esté o no en VM, para ser aplicadas a ser posible desde el mismo momento del ingreso del paciente en la $\mathrm{UCI}$. 


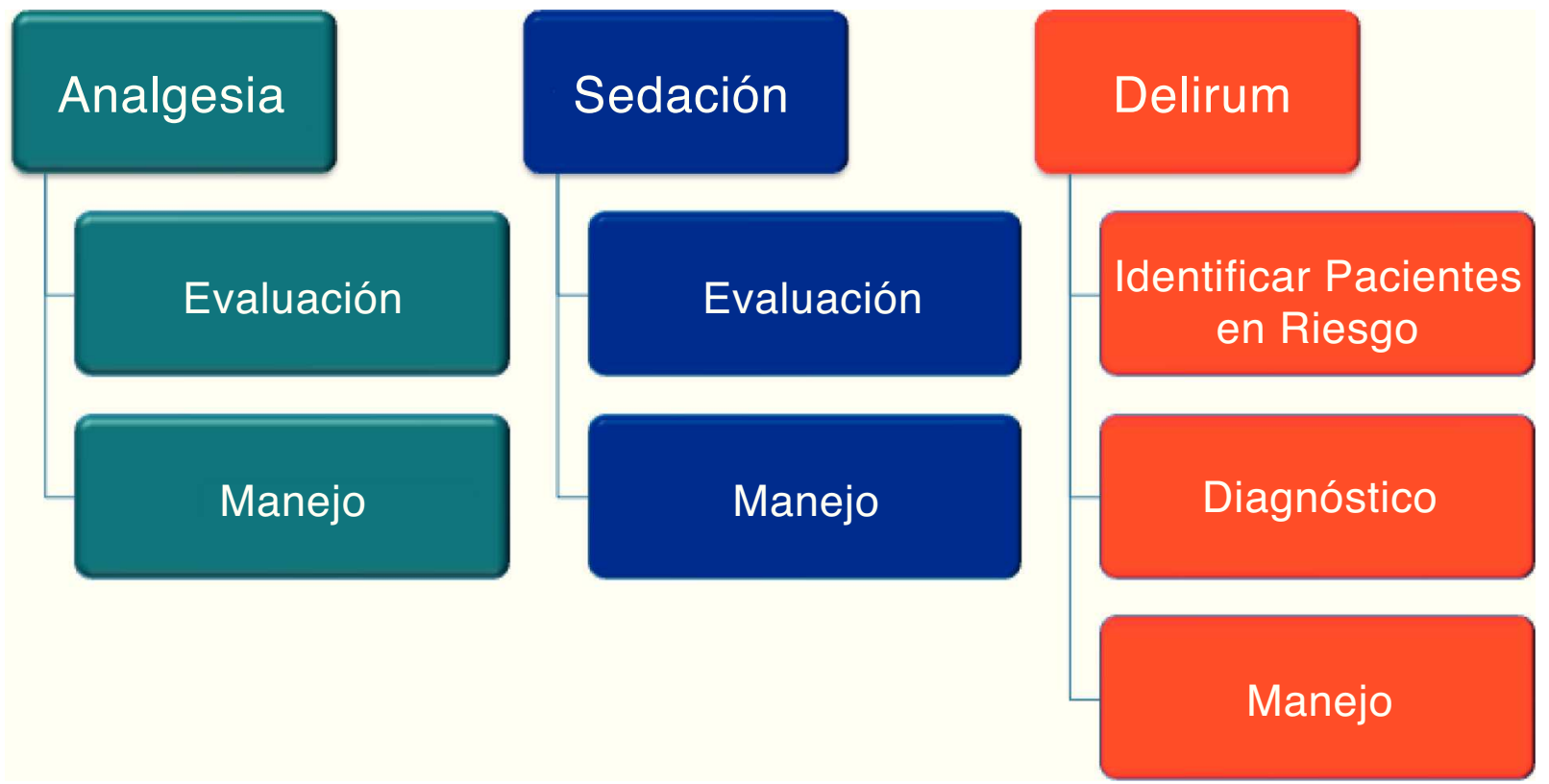

Figura 7 Dominios del «bundle» para el manejo de la analgesia, sedación y delirium.

Todas estas intervenciones tienen las siguientes características: 1. la mayoría de las recomendaciones están basadas en niveles de evidencia alto o moderado ( $\mathrm{A} \circ \mathrm{B})$; 2 . tienen gran impacto en el desenlace de los pacientes; 3 . son consistentes entre los diferentes estudios; y 4. son aprobadas por la totalidad de los miembros del grupo de expertos.

Los desenlaces a los que se hace referencia son los objetivos de este conjunto de medidas: mortalidad, delirium, déficit cognitivo, síndrome de abstinencia, falta de adaptación, duración de la VM, estancia en $\mathrm{UCl}$, estancia hospitalaria, efectos secundarios de los medicamentos, costes y comodidad del paciente.

Cada una de estas intervenciones ha demostrado generar buen resultado cuando se han aplicado por separado. Lo que se persigue al aplicarlas de manera conjunta es llevar al máximo el grado de impacto sobre los objetivos mencionados, similar a lo alcanzado con otros «bundles» (prevención de las infecciones asociadas al uso de catéteres intravasculares, de la neumonía asociada a la VM y de la infección del tracto urinario asociada a sondaje vesical). Para el logro de las metas propuestas se requiere la total implementación de estas medidas, salvo que alguna esté contraindicada o no pueda aplicarse.

\section{C.2. Intervenciones (fig. 7)}

1. Analgesia.

1.1 Evalúe el nivel de dolor (escala visual analógica, BPS o Campbell). Mantener nivel de dolor $\leq 4 / 10$.

1.2 Inicie el tratamiento del dolor: titule el medicamento opioide o no opioide y use técnicas de analgesia multimodal.

2. Sedación y agitación.

2.1 Evalué la necesidad de sedación y defina el nivel de sedación objetivo (escala RASS o BIS).

i. No sedación. ii. Sedación cooperativa (RASS alrededor de -1).

iii. Sedación profunda (RASS alrededor de -4).

2.2 Escoja el medicamento apropiado y titule para alcanzar el nivel de sedación objetivo (se sugiere el uso de no-benzodiazepínicos como propofol o dexmedetomidina).

2.3 Prefiera niveles de sedación superficial y promueva la movilización temprana.

2.4 En episodios de agitación severa utilice medidas de contención: inicialmente verbales, luego farmacológicas, por último físicas.

3. Delirium.

3.1 Identifique factores de riesgo modificables para delirium (infección, hipoxemia, acidosis metabólica, uremia, severidad de la enfermedad, entorno del paciente, sedantes tipo GABA, dosis altas de opioides, alteración del patrón natural de sueño y memoria).

3.2 Detecte la aparición de delirium (use el CAM-ICU).

3.3 Escoja el medicamento más apropiado y titule su dosis (haloperidol, antipsicóticos atípicos o dexmedetomidina; evite el uso de benzodiazepinas).

\section{Bibliografía}

1. Tung $A$, Rosenthal M. Patients requiring sedation. Crit Care Clin. 1995;11:791-802.

2. Cohen IL, Gallagher TJ, Pohlman AS, Dasta JF, Abraham E, Papadokos PJ. Management of the agitated intensive care unit patient. Crit Care Med. 2002;30:597-123.

3. Celis-Rodríguez E, Besso J, Birchenall C, de la Cal MA, Carrillo R, Castorena G, et al. Guía de práctica clínica basada en la evidencia para el manejo de la sedo-analgesia en el paciente adulto críticamente enfermo. Med Intensiva. 2007;31:428-71.

4. Guyatt G, Gutterman D, Baumann MH, Addrizzo-Harris D, Hylek EM, Phillips B, et al. Grading strength of recommendations and quality of evidence in clinical guidelines: report from 
an american college of chest physicians task force. Chest. 2006;129:174-81.

5. Fraser GL, Prato BS, Riker RR, Berthiaume D, Wilkins ML. Frequency, severity, and treatment of agitation in young versus elderly patients in the ICU. Pharmacotherapy. 2000;20: 75-82.

6. Woods JC, Mion LC, Connor JT, Viray F, Jahan L, Huber C, et al. Severe agitation among ventilated medical intensive care unit patients: frequency, characteristics and outcomes. Intensive Care Med. 2004;30:1066-72.

7. Kress JP, Pohlman AS, Hall JB. Sedation and analgesia in the intensive care unit. Am J Respir Crit Care Med. 2002;166:1024-8.

8. Sessler CN. Comfort and distress in the ICU: scope of the problem. Semin Respir Crit Care Med. 2001;22:111-4.

9. Carrión MI, Ayuso D, Marcos M, Paz Robles M, de la Cal MA, Alía I, et al. Accidental removal of endotracheal and nasogastric tubes and intravascular catheters. Crit Care Med. 2000;28:63-6.

10. Fraser GL, Riker RR, Prato BS, Wilkins ML. The frequency and cost of patient-initiated device removal in the ICU. Pharmacotherapy. 2001;21:1-6.

11. Weissman C, Kemper M. The oxygen uptake-oxygen delivery relationship during ICU interventions. Chest. 1991;99: 430-5.

12. Frazier SK, Moser DK, O'Brien JL, Garvin BJ, An K, Macko M. Management of anxiety after acute myocardial infarction. Heart Lung. 2002;31:411-20.

13. Ramsay MA, Savege TM, Simpson BR, Goodwin R. Controlled sedation with alphaxalone-alphadolone. $\mathrm{Br}$ Med J. 1974;2:656-9.

14. Devlin JW, Boleski G, Mlynarek M, Nerenz DR, Peterson E, Jankowski M, et al. Motor Activity Assessment Scale: a valid and reliable sedation scale for use with mechanically ventilated patients in an adult surgical intensive care unit. Crit Care Med. 1999;27:1271-5.

15. Riker RR, Picard JT, Fraser GL. Prospective evaluation of the Sedation-Agitation Scale for adult critically ill patients. Crit Care Med. 1999;27:1325-9.

16. Riker RR, Fraser GL, Simmons LE, Wilkins ML. Validating the Sedation-Agitation Scale with the Bispectral Index and Visual Analog Scale in adult ICU patients after cardiac surgery. Intensive Care Med. 2001;27:853-8.

17. Ely EW, Truman B, Shintani A, Thomason JWW, Wheeler AP, Gordon S, et al. Monitoring sedation status over time in ICU patients: reliability and validity of the Richmond AgitationSedation Scale (RASS). JAMA. 2003;289:2983-91.

18. Sessler CN, Gosnell MS, Grap MJ, Brophy GM, O’Neal PV, Keane KA, et al. The Richmond Agitation-Sedation Scale: validity and reliability in adult intensive care unit patients. Am J Respir Crit Care Med. 2002;166:1338-44.

19. Mistraletti G, Taverna M, Sabbatini G, Carloni E, Bolgiaghi L, Pirrone $M$, et al. Actigraphic monitoring in critically ill patients: preliminary results toward an «observation-guided sedation». J Crit Care. 2009;24:563-7.

20. Chinchilla A. Manual de urgencias psiquiatricas. Parte I: conceptos básicos. Barcelona: Masson; 2004.

21. Lucidarme O, Seguin A, Daubin C, Ramakers M, Terzi N, Beck P, et al. Nicotine withdrawal and agitation in ventilated critically ill patients. Crit Care. 2010;14:R58.

22. Kiekkas P, Samios A, Skartsani C, Tsotas D, Baltopoulos GI. Fever and agitation in elderly ICU patients: a descriptive study. Intensive Crit Care Nurs. 2010;26:169-74.

23. Manninen PH, Chan AS, Papworth D. Conscious sedation for interventional neuroradiology: a comparison of midazolam and propofol infusion. Can J Anaesth. 1997;44:26-30.

24. Waring JP, Baron TH, Hirota WK, Goldstein JL, Jacobson $B C$, Leighton JA, et al. Guidelines for conscious sedation and monitoring during gastrointestinal endoscopy. Gastrointest Endosc. 2003;58:317-22.

25. Chávez O, Mendoza M, Guedes R, Zavala M, Lazorza C. Sedación de pacientes en ventilación mecánica. Parte I. Medicrit. 2005;2:49-54

26. Mehta S, Burry L, Martinez-Motta JC, Stewart TE, Hallett D, McDonald $\mathrm{E}$, et al. A randomized trial of daily awakening in critically ill patients managed with a sedation protocol: a pilot trial. Crit Care Med. 2008;36:2092-9.

27. Treggiari MM, Romand J-A, Yanez ND, Deem SA, Goldberg J, Hudson L, et al. Randomized trial of light versus deep sedation on mental health after critical illness. Crit Care Med. 2009;37:2527-34

28. Breen D, Karabinis A, Malbrain M, Morais R, Albrecht S, Jarnvig $\mathrm{I}-\mathrm{L}$, et al. Reased duration of mechanical ventilation when comparing analgesia-based sedation using remifentanil with standard hypnotic-based sedation for up to 10 days in intensive care unit patients: a randomised trial. Crit Care. 2005;9:R200-10.

29. Shehabi Y, Riker RR, Bokesch PM, Wisemandle W, Shintani A, Ely EW. Delirium duration and mortality in lightly sedated, mechanically ventilated intensive care patients. Crit Care Med. 2010;38:2311-8.

30. Girard TD, Kress JP, Fuchs BD, Thomason JWW, Schweickert WD, Pun BT, et al. Efficacy and safety of a paired sedation and ventilator weaning protocol for mechanically ventilated patients in intensive care (Awakening and Breathing Controlled trial): a randomised controlled trial. Lancet. 2008;371:126-34.

31. Strøm T, Martinussen T, Toft P. A protocol of no sedation for critically ill patients receiving mechanical ventilation: a randomised trial. Lancet. 2010;375:475-80.

32. Mirski MA, Lewin JJ, Ledroux S, Thompson C, Murakami P, Zink EK, et al. Cognitive improvement during continuous sedation in critically ill, awake and responsive patients: the Acute Neurological ICU Sedation Trial (ANIST). Intensive Care Med. 2010;36:1505-13.

33. Augustes R, Ho KM. Meta-analysis of randomised controlled trials on daily sedation interruption for critically ill adult patients. Anaesth Intensive Care. 2011;39: 401-9.

34. De Wit M, Gennings C, Jenvey WI, Epstein SK. Randomized trial comparing daily interruption of sedation and nursingimplemented sedation algorithm in medical intensive care unit patients. Crit Care. 2008;12:R70.

35. Pandharipande PP, Pun BT, Herr DL, Maze M, Girard TD, Miller RR, et al. Effect of sedation with dexmedetomidine vs lorazepam on acute brain dysfunction in mechanically ventilated patients: the MENDS randomized controlled trial. JAMA. 2007; 298:2644-53

36. Riker RR, Shehabi Y, Bokesch PM, Ceraso D, Wisemandle W, Koura F, et al. Dexmedetomidine vs midazolam for sedation of critically ill patients: a randomized trial. JAMA. 2009;301:489-99.

37. Duke P, Maze M, Morrison L. Dexmedetomidine: a general overview. En: Maze M, Morrison P, editores. Redefining sedation: International Congress and Symposium Series. London: The Royal Society of Medicine Press; 1998. p. 11-22.

38. Venn RM, Bradshaw CJ, Spencer R, Brealey D, Caudwell E, Naughton C, et al. Preliminary UK experience of dexmedetomidine, a novel agent for postoperative sedation in the intensive care unit. Anaesthesia. 1999;54:1136-42.

39. Bhana N, Goa KL, McClellan KJ. Dexmedetomidine. Drugs. 2000;59:263-8, discusión 269-270.

40. Venn RM, Hell J, Grounds RM. Respiratory effects of dexmedetomidine in the surgical patient requiring intensive care. Crit Care. 2000;4:302-8. 
41. Venn RM, Grounds RM. Comparison between dexmedetomidine and propofol for sedation in the intensive care unit: patient and clinician perceptions. Br J Anaesth. 2001;87:684-90.

42. Shehabi $Y$, Ruettimann U, Adamson H, Innes R, Ickeringill $M$. Dexmedetomidine infusion for more than 24 hours in critically ill patients: sedative and cardiovascular effects. Intensive Care Med. 2004;30:2188-96.

43. Gerlach AT, Dasta JF. Dexmedetomidine: an updated review. Ann Pharmacother. 2007;41:245-52.

44. Wagner BK, O'Hara DA. Pharmacokinetics and pharmacodynamics of sedatives and analgesics in the treatment of agitated critically ill patients. Clin Pharmacokinet. 1997;33:426-53.

45. Reves JG, Fragen RJ, Vinik HR, Greenblatt DJ. Midazolam: pharmacology and uses. Anesthesiology. 1985;62:310-24.

46. Albanese J, Martin C, Lacarelle B, Saux P, Durand A, Gouin F. Pharmacokinetics of long-term propofol infusion used for sedation in ICU patients. Anesthesiology. 1990;73:214-7.

47. Shafer A, Doze VA, White PF. Pharmacokinetic variability of midazolam infusions in critically ill patients. Crit Care Med. 1990;18:1039-41.

48. Bailie GR, Cockshott ID, Douglas EJ, Bowles BJ. Pharmacokinetics of propofol during and after long-term continuous infusion for maintenance of sedation in ICU patients. $\mathrm{Br} \mathrm{J}$ Anaesth. 1992;68:486-91.

49. Malacrida R, Fritz ME, Suter PM, Crevoisier C. Pharmacokinetics of midazolam administered by continuous intravenous infusion to intensive care patients. Crit Care Med. 1992;20:1123-6.

50. Taylor E, Ghouri AF, White PF. Midazolam in combination with propofol for sedation during local anesthesia. J Clin Anesth. 1992;4:213-6.

51. Fulton B, Sorkin EM. Propofol. An overview of its pharmacology and a review of its clinical efficacy in intensive care sedation. Drugs. 1995;50:636-57.

52. Miller DR, Blew PG, Martineau RJ, Hull KA. Midazolam and awareness with recall during total intravenous anaesthesia. Can J Anaesth. 1996;43:946-53.

53. Pachulski RT, Adkins DC, Mirza H. Conscious sedation with intermittent midazolam and fentanyl in electrophysiology procedures. J Interv Cardiol. 2001;14:143-6.

54. Anderson KJ, Leitch JA, Green JS, Kenny GNC. Effect-site controlled patient maintained propofol sedation: a volunteer safety study. Anaesthesia. 2005;60:235-8.

55. Baldessarini R, Tarazi F. Pharmacotherapy of psychosis and mania. En: Brunton L, Lazo J, Parker K, editores. Goodman \& Gilman's the Pharmacological Basis of Therapeutics. 11th ed. New York: McGraw-Hill; 2005. p. 474.

56. Kao LW, Kirk MA, Evers SJ, Rosenfeld SH. Droperidol, QT prolongation, and sudden death: what is the evidence? Ann Emerg Med. 2003;41:546-58.

57. White PF, Song D, Abrao J, Klein KW, Navarette B. Effect of low-dose droperidol on the QT interval during and after general anesthesia: a placebo-controlled study. Anesthesiology. 2005; 102:1101-5.

58. Fletcher D, Fermanian C, Mardaye A, Aegerter P. A patientbased national survey on postoperative pain management in France reveals significant achievements and persistent challenges. Pain. 2008;137:441-51.

59. Payen J-F, Bosson J-L, Chanques G, Mantz J, Labarere J. Pain assessment is associated with decreased duration of mechanical ventilation in the intensive care unit: a post $\mathrm{Hoc}$ analysis of the DOLOREA study. Anesthesiology. 2009;111:1308-16.

60. De Jonghe B, Bastuji-Garin S, Fangio P, Lacherade J-C, Jabot J, Appéré-de-Vecchi $C$, et al. Sedation algorithm in critically ill patients without acute brain injury. Crit Care Med. 2005;33:120-7.

61. Chanques G, Jaber S, Barbotte E, Violet S, Sebbane M, Perrigault P-F, et al. Impact of systematic evaluation of pain and agitation in an intensive care unit. Crit Care Med. 2006;34:1691-9.

62. Robinson BRH, Mueller EW, Henson K, Branson RD, Barsoum S, Tsuei BJ. An analgesia-delirium-sedation protocol for critically ill trauma patients reduces ventilator days and hospital length of stay. J Trauma. 2008;65:517-26.

63. Arabi Y, Haddad S, Hawes R, Moore T, Pillay M, Naidu B, et al. Changing sedation practices in the intensive care unit-protocol implementation, multifaceted multidisciplinary approach and teamwork. Middle East J Anesthesiol. 2007;19:429-47.

64. Brattebø G, Hofoss D, Flaatten H, Muri AK, Gjerde S, Plsek PE. Effect of a scoring system and protocol for sedation on duration of patients' need for ventilator support in a surgical intensive care unit. BMJ. 2002;324:1386-9.

65. Awissi D-K, Bégin C, Moisan J, Lachaine J, Skrobik Y. I-SAVE study: impact of sedation, analgesia, and delirium protocols evaluated in the intensive care unit: an economic evaluation. Ann Pharmacother. 2012;46:21-8.

66. Kastrup M, von Dossow V, Seeling M, Ahlborn R, Tamarkin A, Conroy $\mathrm{P}$, et al. Key performance indicators in intensive care medicine. A retrospective matched cohort study. J Int Med Res. 2009;37:1267-84.

67. Gélinas C. Management of pain in cardiac surgery ICU patients: have we improved over time? Intensive Crit Care Nurs. 2007;23:298-303.

68. Herr K, Coyne PJ, Key T, Manworren R, McCaffery M, Merkel $\mathrm{S}$, et al. Pain assessment in the nonverbal patient: position statement with clinical practice recommendations. Pain Manag Nurs. 2006;7:44-52.

69. Pardo C, Muñoz T, Chamorro C. Monitoring pain: recommendations of the Analgesia and Sedation Work Group of SEMICYUC. Med Intensiva. 2006;30:379-85.

70. Ahlers SJ, van Gulik L, van der Veen AM, van Dongen HP, Bruins P, Belitser SV, et al. Comparison of different pain scoring systems in critically ill patients in a general ICU. Crit Care. 2008;12:R15.

71. Chanques G, Viel E, Constantin J-M, Jung B, de Lattre S, Carr J, et al. The measurement of pain in intensive care unit: comparison of 5 self-report intensity scales. Pain. 2010;151:711-21.

72. Payen JF, Bru O, Bosson JL, Lagrasta A, Novel E, Deschaux I, et al. Assessing pain in critically ill sedated patients by using a behavioral pain scale. Crit Care Med. 2001;29: 2258-63.

73. Aïssaoui Y, Zeggwagh AA, Zekraoui A, Abidi K, Abouqal R. Validation of a behavioral pain scale in critically ill, sedated, and mechanically ventilated patients. Anesth Analg. 2005;101:1470-6.

74. Ahlers SJGM, van der Veen AM, van Dijk M, Tibboel D, Knibbe CAJ. The use of the Behavioral Pain Scale to assess pain in conscious sedated patients. Anesth Analg. 2010;110:127-33.

75. Chanques G, Payen J-F, Mercier G, de Lattre S, Viel E, Jung $B$, et al. Assessing pain in non-intubated critically ill patients unable to self report: an adaptation of the Behavioral Pain Scale. Intensive Care Med. 2009;35:2060-7.

76. Gélinas C, Fillion L, Puntillo KA. Item selection and content validity of the Critical-Care Pain Observation Tool for nonverbal adults. J Crit Care. 2009;65:203-16.

77. Gélinas C, Harel F, Fillion L, Puntillo KA, Johnston CC. Sensitivity and specificity of the critical-care pain observation tool for the detection of pain in intubated adults after cardiac surgery. J Pain Symptom Manage. 2009;37:58-67.

78. Voepel-Lewis T, Zanotti J, Dammeyer JA, Merkel S. Reliability and validity of the face, legs, activity, cry, consolability behavioral tool in assessing acute pain in critically ill patients. Am J Crit Care. 2010;19:55-61.

79. Erdek MA, Pronovost PJ. Improving assessment and treatment of pain in the critically ill. Int J Qual Health Care. 2004;16:59-64. 
80. Latorre Marco I, Solís Muñoz M, Falero Ruiz T, Larrasquitu Sánchez A, Romay Pérez AB, Millán Santos I. Validation of the Scale of Behavior Indicators of Pain (ESCID) in critically ill, noncommunicative patients under mechanical ventilation: results of the ESCID scale. Enferm Intensiva. 2011;22:3-12.

81. Li D, Miaskowski C, Burkhardt D, Puntillo K. Evaluations of physiologic reactivity and reflexive behaviors during noxious procedures in sedated critically ill patients. J Crit Care. 2009;12:e9-13.

82. Gélinas C, Tousignant-Laflamme Y, Tanguay A, Bourgault P. Exploring the validity of the bispectral index, the Critical-Care Pain Observation Tool and vital signs for the detection of pain in sedated and mechanically ventilated critically ill adults: a pilot study. Intensive Crit Care Nurs. 2011;27:46-52.

83. Gimeno G, Alcolea M, Arana M, Bartolomé N, Cruspinera A, Figueras MJ, et al. Are all sedation scales equally useful for nursing assessment? Enferm Intensiva. 1999;10:3-12.

84. De Lemos J, Tweeddale M, Chittock D. Measuring quality of sedation in adult mechanically ventilated critically ill patients. The Vancouver Interaction and Calmness Scale. Sedation Focus Group. J Clin Epidemiol. 2000;53:908-19.

85. Chernik DA, Gillings D, Laine H, Hendler J, Silver JM, Davidson $A B$, et al. Validity and reliability of the Observer's Assessment of Alertness/Sedation Scale: study with intravenous midazolam. J Clin Psychopharmacol. 1990;10:244-51.

86. De Jonghe B, Cook D, Griffith L, Appere-de-Vecchi C, Guyatt G, Théron $\mathrm{V}$, et al. Adaptation to the Intensive Care Environment (ATICE): development and validation of a new sedation assessment instrument. Crit Care Med. 2003;31:2344-54.

87. Brandl KM, Langley KA, Riker RR, Dork LA, Quails CR, Levy H. Confirming the reliability of the sedation-agitation scale administered by ICU nurses without experience in its use. Pharmacotherapy. 2001;21:431-6.

88. Ryder-Lewis MC, Nelson KM. Reliability of the SedationAgitation Scale between nurses and doctors. Intensive Crit Care Nurs. 2008;24:211-7.

89. Mendes CL, Vasconcelos LCS, Tavares JS, Fontan SB, Ferreira DC, Diniz LAC, et al. Escalas de Ramsay e Richmond são equivalentes para a avaliação do nível de sedação em pacientes gravemente enfermos. RBTI. 2008;20:344-8.

90. Ely EW, Inouye SK, Bernard GR, Gordon S, Francis J, May L, et al. Delirium in mechanically ventilated patients: validity and reliability of the confusion assessment method for the intensive care unit (CAM-ICU). JAMA. 2001;286:2703-10.

91. Johansen JW, Sebel PS. Development and clinical application of electroencephalographic bispectrum monitoring. Anesthesiology. 2000;93:1336-44.

92. Ferenets R, Lipping T, Anier A, Jäntti V, Melto S, Hovilehto S. Comparison of entropy and complexity measures for the assessment of depth of sedation. IEEE Trans Biomed Eng. 2006;53:1067-77.

93. Consales G, Chelazzi C, Rinaldi S, de Gaudio AR. Bispectral Index compared to Ramsay score for sedation monitoring in intensive care units. Minerva Anestesiol. 2006;72:329-36.

94. Hernández-Gancedo C, Pestaña D, Pérez-Chrzanowska $H$, Martinez-Casanova E, Criado A. Comparing Entropy and the Bispectral index with the Ramsay score in sedated ICU patients. J Clin Monit Comput. 2007;21:295-302.

95. Karamchandani K, Rewari V, Trikha A, Batra RK. Bispectral index correlates well with Richmond agitation sedation scale in mechanically ventilated critically ill patients. J Anesth. 2010;24:394-8.

96. Turkmen A, Altan A, Turgut N, Vatansever S, Gokkaya S. The correlation between the Richmond agitation-sedation scale and bispectral index during dexmedetomidine sedation. Eur J Anaesthesiol. 2006;23:300-4.

97. Deogaonkar A, Gupta R, DeGeorgia M, Sabharwal V, Gopakumaran B, Schubert A, et al. Bispectral Index monitoring correlates with sedation scales in brain-injured patients. Crit Care Med. 2004;32:2403-6.

98. Yamashita K, Terao Y, Inadomi C, Takada M, Fukusaki M, Sumikawa K. Age-dependent relationship between bispectral index and sedation level. J Clin Anesth. 2008;20:492-5.

99. Frenzel D, Greim C-A, Sommer C, Bauerle K, Roewer N. Is the bispectral index appropriate for monitoring the sedation level of mechanically ventilated surgical ICU patients? Intensive Care Med. 2002;28:178-83.

100. Arbour R, Waterhouse J, Seckel MA, Bucher L. Correlation between the Sedation-Agitation Scale and the Bispectral Index in ventilated patients in the intensive care unit. Heart Lung. 2009;38:336-45.

101. Olson DM, Thoyre SM, Peterson ED, Graffagnino C. A randomized evaluation of bispectral index-augmented sedation assessment in neurological patients. Neurocrit Care. 2009;11:20-7.

102. Vivien B, di Maria S, Ouattara A, Langeron O, Coriat P, Riou B. Overestimation of Bispectral Index in sedated intensive care unit patients revealed by administration of muscle relaxant. Anesthesiology. 2003;99:9-17.

103. Lu C-H, Man K-M, Ou-Yang H-Y, Chan S-M, Ho S-T, Wong C-S, et al. Composite auditory evoked potential index versus bispectral index to estimate the level of sedation in paralyzed critically ill patients: a prospective observational study. Anesth Analg. 2008;107:1290-4.

104. Tonner PH, Wei C, Bein B, Weiler N, Paris A, Scholz J. Comparison of two bispectral index algorithms in monitoring sedation in postoperative intensive care patients. Crit Care Med. 2005;33:580-4.

105. Lu C-H, Ou-Yang H-Y, Man K-M, Hsiao P-C, Ho S-T, Wong C$S$, et al. Relative reliability of the auditory evoked potential and Bispectral Index for monitoring sedation level in surgical intensive care patients. Anaesth Intensive Care. 2008;36: 553-9.

106. Hernández-Gancedo C, Pestaña D, Peña N, Royo C, PérezChrzanowska H, Criado A. Monitoring sedation in critically ill patients: bispectral index. Ramsay and observer scales. Eur J Anaesthesiol. 2006;23:649-53.

107. Weatherburn C, Endacott R, Tynan P, Bailey M. The impact of bispectral index monitoring on sedation administration in mechanically ventilated patients. Anaesth Intensive Care. 2007;35:204-8.

108. Trouiller P, Fangio P, Paugam-Burtz C, Appéré-de-Vecchi C, Merckx $\mathrm{P}$, Louvet $\mathrm{N}$, et al. Frequency and clinical impact of preserved bispectral index activity during deep sedation in mechanically ventilated ICU patients. Intensive Care Med. 2009;35:2096-104

109. Anderson J, Henry L, Hunt S, Ad N. Bispectral index monitoring to facilitate early extubation following cardiovascular surgery. Clin Nurse Spec. 2010;24:140-8.

110. Solanki A, Puri GD, Mathew PJ. Bispectral index-controlled postoperative sedation in cardiac surgery patients: a comparative trial between closed loop and manual administration of propofol. Eur J Anaesthesiol. 2010;27:708-13.

111. Arbour R. Using bispectral index monitoring to detect potential breakthrough awareness and limit duration of neuromuscular blockade. American J Crit Care. 2004;13:66-73.

112. Watson PL, Shintani AK, Tyson R, Pandharipande PP, Pun BT, Ely EW. Presence of electroencephalogram burst suppression in sedated, critically ill patients is associated with increased mortality. Crit Care Med. 2008;36: 3171-7.

113. Hwang S, Lee S-G, Park J-I, Song G-W, Ryu J-H, Jung D-H, et al. Continuous peritransplant assessment of consciousness using bispectral index monitoring for patients with fulminant hepatic failure undergoing urgent liver transplantation. Clin Transplant. 2010;24:91-7. 
114. Inouye SK, Charpentier PA. Precipitating factors for delirium in hospitalized elderly persons. Predictive model and interrelationship with baseline vulnerability. JAMA. 1996;275:852-7.

115. Van Rompaey B, Elseviers MM, Schuurmans MJ, ShortridgeBaggett LM, Truijen S, Bossaert L. Risk factors for delirium in intensive care patients: a prospective cohort study. Crit Care. 2009;13:R77.

116. Van den Boogaard M, Pickkers P, Slooter a JC, Kuiper MA, Spronk PE, van der Voort PH, et al. Development and validation of PRE-DELIRIC (PREdiction of DELIRium in ICu patients) delirium prediction model for intensive care patients: observational multicentre study. BMJ. 2012;344:e420.

117. Wei LA, Fearing MA, Sternberg EJ, Inouye SK. The Confusion Assessment Method: a systematic review of current usage. J Am Geriatr Soc. 2008;56:823-30.

118. Bergeron N, Dubois MJ, Dumont M, Dial S, Skrobik Y. Intensive Care Delirium Screening Checklist: evaluation of a new screening tool. Intensive Care Med. 2001;27:859-64.

119. Inouye SK, Bogardus ST, Charpentier PA, Leo-Summers L, Acampora D, Holford TR, et al. A multicomponent intervention to prevent delirium in hospitalized older patients. $\mathrm{N}$ Engl J Med. 1999;340:669-76.

120. ICU Delirium and Cognitive Impairment Study Group. [consultado 6 May 2011]. Disponible en: http://www.mc.vanderbilt.edu/icudelirium/

121. Milisen K, Foreman MD, Abraham IL, de Geest S, Godderis J, Vandermeulen $\mathrm{E}$, et al. A nurse-led interdisciplinary intervention program for delirium in elderly hip-fracture patients. J Am Geriatr Soc. 2001;49:523-32.

122. Campbell N, Boustani MA, Ayub A, Fox GC, Munger SL, Ott C, et al. Pharmacological management of delirium in hospitalized adults-a systematic evidence review. J Gen Intern Med. 2009;24:848-53.

123. Lonergan E, Britton AM, Luxenberg J, Wyller T. Antipsychotics for delirium. Cochrane Database Syst Rev. 2007. CD005594.

124. Devlin JW, Roberts RJ, Fong JJ, Skrobik Y, Riker RR, Hill NS, et al. Efficacy and safety of quetiapine in critically ill patients with delirium: a prospective, multicenter, randomized, double-blind, placebo-controlled pilot study. Crit Care Med. 2010;38:419-27.

125. Reade MC, O'Sullivan K, Bates S, Goldsmith D, Ainslie WR, Bellomo R. Dexmedetomidine vs. haloperidol in delirious, agitated, intubated patients: a randomised open-label trial. Crit Care. 2009;13:R75.

126. Lonergan E, Luxenberg J, Areosa Sastre A. Benzodiazepines for delirium. Cochrane Database Syst Rev. 2009. CD006379.

127. Overshott R, Karim S, Burns A. Cholinesterase inhibitors for delirium. Cochrane Database Syst Rev. 2008. CD005317.

128. Marx CM, Rosenberg DI, Ambuel B, Hamlett KW, Blumer JL. Pediatric intensive care sedation: survey of fellowship training programs. Pediatrics. 1993;91:369-78.

129. Fonsmark L, Rasmussen YH, Carl P. Occurrence of withdrawal in critically ill sedated children. Crit Care Med. 1999;27:196-9.

130. Tobias JD. Subcutaneous administration of fentanyl and midazolam to prevent withdrawal after prolonged sedation in children. Crit Care Med. 1999;27:2262-5.

131. Hantson P, Clemessy JL, Baud FJ. Withdrawal syndrome following midazolam infusion. Intensive Care Med. 1995;21:190-1.

132. Katz R, Kelly HW, Hsi A. Prospective study on the occurrence of withdrawal in critically ill children who receive fentanyl by continuous infusion. Crit Care Med. 1994;22:763-7.

133. Mellman TA, Uhde TW. Withdrawal syndrome with gradual tapering of alprazolam. Am J Psychiatry. 1986;143:1464-6.

134. Finley PR, Nolan PE. Precipitation of benzodiazepine withdrawal following sudden discontinuation of midazolam. Ann Pharmacother. 1989;23:151-2.

135. Bergman I, Steeves M, Burckart G, Thompson A. Reversible neurologic abnormalities associated with prolonged intravenous midazolam and fentanyl administration. J Pediatr. 1991;119:644-9.

136. Rosen DA, Rosen KR. Midazolam for sedation in the paediatric intensive care unit. Intensive Care Med. 1991;17 Suppl $1: \mathrm{S} 15-9$.

137. Freda JJ, Bush HL, Barie PS. Alprazolam withdrawal in a critically ill patient. Crit Care Med. 1992;20:545-6.

138. Sury MR, Billingham I, Russell GN, Hopkins CS, Thornington R, Vivori E. Acute benzodiazepine withdrawal syndrome after midazolam infusions in children. Crit Care Med. 1989;17:301-2.

139. Van Engelen BG, Gimbrere JS, Booy LH. Benzodiazepine withdrawal reaction in two children following discontinuation of sedation with midazolam. Ann Pharmacother. 1993;27:579-81.

140. Victory RA, Magee D. A case of convulsion after propofol anaesthesia. Anaesthesia. 1988;43:904.

141. Au J, Walker WS, Scott DH. Withdrawal syndrome after propofol infusion. Anaesthesia. 1990;45:741-2.

142. Boyle WA, Shear JM, White PF, Schuller D. Tolerance and hyperlipemia during long-term sedation with propofol. Anesthesiology. 1990;73(3A):A245.

143. Imray JM, Hay A. Withdrawal syndrome after propofol. Anaesthesia. 1991;46:704.

144. Valente JF, Anderson GL, Branson RD, Johnson DJ, Davis K, Porembka DT. Disadvantages of prolonged propofol sedation in the critical care unit. Crit Care Med. 1994;22:710-2.

145. Mirenda J, Broyles G. Propofol as used for sedation in the ICU. Chest. 1995;108:539-48.

146. Mayhew JF, Abouleish AE. Lack of tolerance to propofol. Anesthesiology. 1996;85:1209.

147. Setlock MA, Palmisano BW, Berens RJ, Rosner DR, Troshynski TJ, Murray KJ. Tolerance to propofol generally does not develop in pediatric patients undergoing radiation therapy. Anesthesiology. 1996;85:207-9.

148. Buckley PM. Propofol in patients needing long-term sedation in intensive care: an assessment of the development of tolerance. A pilot study. Intensive Care Med. 1997;23:969-74.

149. Walder B, Tramèr MR, Seeck M. Seizure-like phenomena and propofol: a systematic review. Neurology. 2002;58:1327-32.

150. Cawley MJ. Short-term lorazepam infusion and concern for propylene glycol toxicity: case report and review. Pharmacotherapy. 2001;21:1140-4.

151. Lane JC, Tennison MB, Lawless ST, Greenwood RS, Zaritsky AL. Movement disorder after withdrawal of fentanyl infusion. $J$ Pediatr. 1991;119:649-51.

152. Arnold JH, Truog RD, Rice SA. Prolonged administration of isoflurane to pediatric patients during mechanical ventilation. Anesth Analg. 1993;76:520-6.

153. Katz R, Kelly HW. Pharmacokinetics of continuous infusions of fentanyl in critically ill children. Crit Care Med. 1993;21:995-1000.

154. Anand KJ, Arnold JH. Opioid tolerance and dependence in infants and children. Crit Care Med. 1994;22: 334-42.

155. Tobias J. Opioid withdrawal presenting as stridor. J Intensive Care Med. 1997;12:104-6.

156. Zapantis A, Leung S. Tolerance and withdrawal issues with sedation. Crit Care Nurs Clin North Am. 2005;17:211-23.

157. Roy-Byrne PP, Hommer D. Benzodiazepine withdrawal: overview and implications for the treatment of anxiety. Am J Med. 1988;84:1041-52.

158. Gold MS, Redmond DE, Kleber HD. Clonidine blocks acute opiate-withdrawal symptoms. Lancet. 1978;2:599-602.

159. Hoder EL, Leckman JF, Ehrenkranz R, Kleber H, Cohen DJ, Poulsen JA. Clonidine in neonatal narcotic-abstinence syndrome. N Engl J Med. 1981;305:1284.

160. Maccioli GA. Dexmedetomidine to facilitate drug withdrawal. Anesthesiology. 2003;98:575-7. 
161. Multz AS. Prolonged dexmedetomidine infusion as an adjunct in treating sedation-induced withdrawal. Anesth Analg. 2003;96:1054-5.

162. Finkel JC, Elrefai A. The use of dexmedetomidine to facilitate opioid and benzodiazepine detoxification in an infant. Anesth Analg. 2004;98:1658-9.

163. Gowing L, Ali R, White JM. Buprenorphine for the management of opioid withdrawal. Cochrane Database Syst Rev. 2009. CD002025.

164. Gist RS, Sullivan M, Serianni RP. Management of substance abuse in the hospital setting. Int Anesthesiol Clin. 2011;49:15-30.

165. Amato L, Minozzi S, Vecchi S, Davoli M. Benzodiazepines for alcohol withdrawal. Cochrane Database Syst Rev. 2010. CD005063.

166. May-Smith MF. Pharmacological management of alcohol withdrawal. A meta-analysis and evidence-based practice guideline. American Society of Addiction Medicine Working Group on Pharmacological Management of Alcohol Withdrawal. JAMA. 1997;278:144-51.

167. Rayner SG, Weinert CR, Peng H, Jepsen S, Broccard AF. Dexmedetomidine as adjunct treatment for severe alcohol withdrawal in the ICU. Ann Intensive Care. 2012;2:12.

168. Weinberg JA, Magnotti LJ, Fischer PE, Edwards NM, Schroeppel T, Fabian TC, et al. Comparison of intravenous ethanol versus diazepam for alcohol withdrawal prophylaxis in the trauma ICU: results of a randomized trial. J Trauma. 2008;64:99-104.

169. Kosten TR, O'Connor PG. Management of drug and alcohol withdrawal. N Engl J Med. 2003;348:1786-95.

170. Kampman KM, Volpicelli JR, Mulvaney F, Alterman Al, Cornish J, Gariti P, et al. Effectiveness of propranolol for cocaine dependence treatment may depend on cocaine withdrawal symptom severity. Drug Alcohol Depend. 2001;1:69-78.

171. Shoptaw SJ, Kao U, Heinzerling K, Ling W. Treatment for amphetamine withdrawal. Cochrane Database Syst Rev. 2009. CD003021.

172. Girard TD, Jackson JC, Pandharipande PP, Pun BT, Thompson $\mathrm{JL}$, Shintani AK, et al. Delirium as a predictor of long-term cognitive impairment in survivors of critical illness. Crit Care Med. 2010;38:1513-20.

173. Ely EW, Shintani A, Truman B, Speroff T, Gordon SM, Harrell FE, et al. Delirium as a predictor of mortality in mechanically ventilated patients in the intensive care unit. JAMA. 2004:291:1753-62.

174. Iwashyna TJ, Ely EW, Smith DM, Langa KM. Long-term cognitive impairment and functional disability among survivors of severe sepsis. JAMA. 2010;304:1787-94.

175. Van den Boogaard M, Schoonhoven L, Evers AW, van der Hoeven JG, van Achterberg T, Pickkers P. Delirium in critically ill patients: impact on long-term health-related quality of life and cognitive functioning. Crit Care Med. 2012;40: $112-8$.

176. Jones C, Griffiths RD, Slater T, Benjamin KS, Wilson S. Significant cognitive dysfunction in non-delirious patients identified during and persisting following critical illness. Intensive Care Med. 2006;32:923-6.

177. Hopkins RO, Suchyta MR, Snow GL, Jephson A, Weaver LK, Orme JF. Blood glucose dysregulation and cognitive outcome in ARDS survivors. Brain Inj. 2010;24:1478-84.

178. Duning T, van den Heuvel I, Dickmann A, Volkert T, Wempe C, Reinholz J, et al. Hypoglycemia aggravates critical illnessinduced neurocognitive dysfunction. Diabetes Care. 2010;33:639-44

179. Larson MJ, Weaver LK, Hopkins RO. Cognitive sequelae in acute respiratory distress syndrome patients with and without recall of the intensive care unit. J Int Neuropsychol Soc. 2007;13:595-605.
180. Nelson JE, Tandon N, Mercado AF, Camhi SL, Ely EW, Morrison RS. Brain dysfunction: another burden for the chronically critically ill. Arch Intern Med. 2006;166:1993-9.

181. Wechsler D, editor. Wechsler Adult Intelligence Scale. 3 rd ed. San Antonio: The Psychological Corporation; 1997.

182. Rey A. L'examen clinique en psychologic. Paris: Presse Universitaire de France; 1958.

183. Reitan R, Wolfson D. The Halstead-Reitan neuropsychological test battery: theory and clinical interpretation. Tucson: Neuropsychology Press; 1985.

184. Naugle R, Cullum C, Bigler E, editores. Introduction to clinical neuropsychology: a casebook. Austin: PRO-ED, Inc; 1998.

185. Folstein MF, Folstein SE, McHugh PR. «Mini-mental state». A practical method for grading the cognitive state of patients for the clinician. J Psychiatr Res. 1975;12:189-98.

186. Downes JJ, Roberts AC, Sahakian BJ, Evenden JL, Morris RG, Robbins TW. Impaired extra-dimensional shift performance in medicated and unmedicated Parkinson's disease: evidence for a specific attentional dysfunction. Neuropsychologia. 1989;27:1329-43.

187. Jorm AF. A short form of the Informant Questionnaire on Cognitive line in the Elderly (IQCODE): development and crossvalidation. Psychol Med. 1994;24:145-53.

188. Schweickert WD, Pohlman MC, Pohlman AS, Nigos C, Pawlik AJ, Esbrook CL, et al. Early physical and occupational therapy in mechanically ventilated, critically ill patients: a randomised controlled trial. Lancet. 2009;373:1874-82.

189. Skrobik Y, Ahern S, Leblanc M, Marquis F, Awissi DK, Kavanagh BP. Protocolized intensive care unit management of analgesia, sedation, and delirium improves analgesia and subsyndromal delirium rates. Anesth Analg. 2010;111:451-63.

190. Needham DM, Korupolu R. Rehabilitation quality improvement in an intensive care unit setting: implementation of a quality improvement model. Top Stroke Rehabil. 2010;17: 271-81.

191. Van Rompaey B, Elseviers MM, van Drom W, Fromont V, Jorens PG. The effect of earplugs during the night on the onset of delirium and sleep perception: a randomized controlled trial in intensive care patients. Crit Care. 2012;16:R73.

192. Durbin CG. Sedation of the agitated, critically ill patient without an artificial airway. Crit Care Clin. 1995;11: 913-36.

193. Jacobi J, Fraser GL, Coursin DB, Riker RR, Fontaine D, Wittbrodt ET, et al. Clinical practice guidelines for the sustained use of sedatives and analgesics in the critically ill adult. Crit Care Med. 2002;30:119-41.

194. Fernández Guerra J, López-Campos Bodineau JL, Perea-Milla López E, Pons Pellicer J, Rivera Irigoin R, Moreno Arrastio LF. [Non invasive ventilation for acute exacerbation of chronic obstructive pulmonary disease: a meta-analysis]. Med Clin (Barc). 2003;120:281-6.

195. Senoglu N, Oksuz H, Dogan Z, Yildiz H, Demirkiran H, Ekerbicer $\mathrm{H}$. Sedation during noninvasive mechanical ventilation with dexmedetomidine or midazolam: a randomized, double-blind, prospective study. Curr Ther Res. 2010;71:141-53.

196. Akada S, Takeda S, Yoshida Y, Nakazato K, Mori M, Hongo $\mathrm{T}$, et al. The efficacy of dexmedetomidine in patients with noninvasive ventilation: a preliminary study. Anesth Analg. 2008; 107:167-70.

197. Rocco M, Conti G, Alessandri E, Morelli A, Spadetta G, Laderchi A, et al. Rescue treatment for noninvasive ventilation failure due to interface intolerance with remifentanil analgosedation: a pilot study. Intensive Care Med. 2010;36: 2060-5.

198. Constantin J-M, Schneider E, Cayot-Constantin S, Guerin R, Bannier F, Futier E, et al. Remifentanil-based sedation to treat noninvasive ventilation failure: a preliminary study. Intensive Care Med. 2007;33:82-7. 
199. Huang Z, Chen Y-S, Yang Z-L, Liu J-Y. Dexmedetomidine versus midazolam for the sedation of patients with non-invasive ventilation failure. Intern Med. 2012;51:2299-305.

200. Maccioli GA, Dorman T, Brown BR, Mazuski JE, McLean BA, Kuszaj JM, et al. Clinical practice guidelines for the maintenance of patient physical safety in the intensive care unit: use of restraining therapies-American College of Critical Care Medicine Task Force 2001-2002. Crit Care Med. 2003;31:2665-76.

201. Vance DL. Effect of a treatment interference protocol on clinical decision making for restraint use in the intensive care unit: a pilot study. AACN Clin Issues. 2003;14:82-91.

202. Kapadia FN, Bajan KB, Raje KV. Airway accidents in intubated intensive care unit patients: an epidemiological study. Crit Care Med. 2000;28:659-64.

203. Joint Commission. Standards and intents for sedation and anesthesia care 2000-2001. Comprehensive accreditation manual for long term care. Joint Commission Accreditation Hosp. 2001.

204. Martin B, Mathisen L. Use of physical restraints in adult critical care: a bicultural study. Am J Crit Care. 2005;14:133-42.

205. Benbenbishty J, Adam S, Endacott R. Physical restraint use in intensive care units across Europe: the PRICE study. Intensive Crit Care Nurs. 2010;26:241-5.

206. Chang LY, Wang KW, Chao YF. Influence of physical restraint on unplanned extubation of adult intensive care patients: a case-control study. Am J Crit Care. 2008;17:408-15.

207. Curry K, Cobb S, Kutash M, Diggs C. Characteristics associated with unplanned extubations in a surgical intensive care unit. Am J Crit Care. 2008;17:45-51.

208. Hatchett C, Langley G. Psychological sequelae following ICU admission at a level 1 academic South African hospital. Afr J Crit Care. 2010;26:52-8.

209. Richman PS, Baram D, Varela M, Glass PS. Sedation during mechanical ventilation: a trial of benzodiazepine and opiate in combination. Crit Care Med. 2006;34:1395-401.

210. Oliver WC, Nuttall GA, Murari T, Bauer LK, Johnsrud KH, Hall Long $\mathrm{KJ}$, et al. A prospective, randomized, double-blind trial of 3 regimens for sedation and analgesia after cardiac surgery. J Cardiothorac Vasc Anesth. 2011;25:110-9.

211. Shapiro BA, Warren J, Egol AB, Greenbaum DM, Jacobi J, Nasraway SA, et al. Practice parameters for intravenous analgesia and sedation for adult patients in the intensive care unit: an executive summary. Society of Critical Care Medicine. Crit Care Med. 1995;23:1596-600.

212. Kollef MH, Levy NT, Ahrens TS, Schaiff R, Prentice D, Sherman G. The use of continuous i.v. sedation is associated with prolongation of mechanical ventilation. Chest. 1998;114:541-8.

213. Durbin CG. Neuromuscular blocking agents and sedative drugs. Clinical uses and toxic effects in the critical care unit. Crit Care Clin. 1991;7:489-506.

214. Bair N, Bobek MB, Hoffman-Hogg L, Mion LC, Slomka J, Arroliga AC. Introduction of sedative, analgesic, and neuromuscular blocking agent guidelines in a medical intensive care unit: physician and nurse adherence. Crit Care Med. 2000;28:707-13.

215. Williams TA, Martin S, Leslie G, Thomas L, Leen T, Tamaliunas S, et al. Duration of mechanical ventilation in an adult intensive care unit after introduction of sedation and pain scales. Am J Crit Care. 2008;17:349-56.

216. Juarez P, Bach A, Baker M, Duey D, Durkin S, Gulczynski B, et al. Comparison of two pain scales for the assessment of pain in the ventilated adult patient. Dimens Crit Care Nurs. 2010;29:307-15.

217. Mehta S, Meade MO, Hynes P, Filate WA, Burry L, Hallett D, et al. A multicenter survey of Ontario intensive care unit nurses regarding the use of sedatives and analgesics for adults receiving mechanical ventilation. J Crit Care. 2007;22:191-6.
218. Payen J-F, Chanques G, Mantz J, Hercule C, Auriant I, Leguillou J-L, et al. Current practices in sedation and analgesia for mechanically ventilated critically ill patients: a prospective multicenter patient-based study. Anesthesiology. 2007;106:687-95.

219. Quenot J-P, Ladoire S, Devoucoux F, Doise J-M, Cailliod R, Cunin N, et al. Effect of a nurse-implemented sedation protocol on the incidence of ventilator-associated pneumonia. Crit Care Med. 2007;35:2031-6.

220. Jackson DL, Proudfoot CW, Cann KF, Walsh TS. The incidence of sub-optimal sedation in the ICU: a systematic review. Crit Care. 2009;13:R204.

221. Guttormson JL, Chlan L, Weinert C, Savik K. Factors influencing nurse sedation practices with mechanically ventilated patients: a U.S. national survey. Intensive Crit Care Nurs. 2010;26:44-50.

222. Bucknall TK, Manias E, Presneill JJ. A randomized trial of protocol-directed sedation management for mechanical ventilation in an Australian intensive care unit. Crit Care Med. 2008;36:1444-50.

223. O'Connor M, Bucknall T, Manias E. Sedation management in Australian and New Zealand intensive care units: doctors' and nurses' practices and opinions. Am J Crit Care. 2010;19:285-95.

224. Arias-Rivera S, Sánchez-Sánchez MM, Santos-Díaz R, GallardoMurillo J, Sánchez-Izquierdo R, Frutos-Vivar F, et al. Effect of a nursing-implemented sedation protocol on weaning outcome. Crit Care Med. 2008;36:2054-60.

225. Marshall J, Finn CA, Theodore AC. Impact of a clinical pharmacist-enforced intensive care unit sedation protocol on duration of mechanical ventilation and hospital stay. Crit Care Med. 2008;36:427-33.

226. Aitken LM, Marshall AP, Elliott R, McKinley S. Critical care nurses' decision making: sedation assessment and management in intensive care. J Clin Nurs. 2009;18:36-45.

227. Tanios MA, de Wit M, Epstein SK, Devlin JW. Perceived barriers to the use of sedation protocols and daily sedation interruption: a multidisciplinary survey. J Crit Care. 2009;24:66-73.

228. Fry C, Edelman LS, Cochran A. Response to a nursing-driven protocol for sedation and analgesia in a burn-trauma ICU. J Burn Care Res. 2009;30:112-8.

229. Jakob SM, Lubszky S, Friolet R, Rothen HU, Kolarova A, Takala J. Sedation and weaning from mechanical ventilation: effects of process optimization outside a clinical trial. J Crit Care. 2007;22:219-28.

230. Tobar AE, Lanas MA, Pino PS, Aspée LP, Rivas VS, Prat RD, et al. Sedación guiada por protocolo versus manejo convencional en pacientes críticos en ventilación mecánica. Rev Med Chil. 2008;136:711-8.

231. Samuelson KAM, Lundberg D, Fridlund B. Light vs. heavy sedation during mechanical ventilation after oesophagectomy-a pilot experimental study focusing on memory. Acta Anaesthesiol Scand. 2008;52:1116-23.

232. Cigada M, Corbella D, Mistraletti G, Forster CR, Tommasino C, Morabito A, et al. Conscious sedation in the critically ill ventilated patient. J Crit Care. 2008;23:349-53.

233. Needham DM, Korupolu R, Zanni JM, Pradhan P, Colantuoni E, Palmer JB, et al. Early physical medicine and rehabilitation for patients with acute respiratory failure: a quality improvement project. Arch Phys Med Rehabil. 2010;91: 536-42.

234. Jakob SM, Ruokonen E, Grounds RM, Sarapohja T, Garratt C, Pocock SJ, et al. Dexmedetomidine vs midazolam or propofol for sedation during prolonged mechanical ventilation: two randomized controlled trials. JAMA. 2012;307: $1151-60$

235. Metheny NA, Clouse RE, Chang Y-H, Stewart BJ, Oliver DA, Kollef $\mathrm{MH}$. Tracheobronchial aspiration of gastric contents in 
critically ill tube-fed patients: frequency, outcomes, and risk factors. Crit Care Med. 2006;34:1007-15.

236. Samuelson K, Lundberg D, Fridlund B. Memory in relation to depth of sedation in adult mechanically ventilated intensive care patients. Intensive Care Med. 2006;32:660-7.

237. Unoki T, Grap MJ, Sessler CN, Best AM, Wetzel P, Hamilton A, et al. Autonomic nervous system function and depth of sedation in adults receiving mechanical ventilation. Am J Crit Care. 2009;18:42-50.

238. Kress JP, Vinayak AG, Levitt J, Schweickert WD, Gehlbach BK, Zimmerman $F$, et al. Daily sedative interruption in mechanically ventilated patients at risk for coronary artery disease. Crit Care Med. 2007;35:365-71.

239. Spies C, Macguill M, Heymann A, Ganea C, Krahne D, Assman A, et al. A prospective, randomized, double-blind, multicenter study comparing remifentanil with fentanyl in mechanically ventilated patients. Intensive Care Med. 2011;37:469-76.

240. Rozendaal FW, Spronk PE, Snellen FF, Schoen A, van Zanten ARH, Foudraine NA, et al. Remifentanil-propofol analgosedation shortens duration of ventilation and length of ICU stay compared to a conventional regimen: a centre randomised, cross-over, open-label study in the Netherlands. Intensive Care Med. 2009;35:291-8.

241. Park G, Lane M, Rogers S, Bassett P. A comparison of hypnotic and analgesic based sedation in a general intensive care unit. Br J Anaesth. 2007;98:76-82.

242. Tan JA, Ho KM. Use of remifentanil as a sedative agent in critically ill adult patients: a meta-analysis. Anaesthesia. 2009;64:1342-52.

243. Al MJ, Hakkaart L, Tan SS, Bakker J. Cost-consequence analysis of remifentanil-based analgo-sedation vs. conventional analgesia and sedation for patients on mechanical ventilation in the Netherlands. Crit Care. 2010;14:R195.

244. Soltész S, Biedler A, Silomon M, Schöpflin I, Molter GP. Recovery after remifentanil and sufentanil for analgesia and sedation of mechanically ventilated patients after trauma or major surgery. $\mathrm{Br} J$ Anaesth. 2001;86:763-8.

245. Muellejans B, López A, Cross MH, Bonome C, Morrison L, Kirkham AJT. Remifentanil versus fentanyl for analgesia based sedation to provide patient comfort in the intensive care unit: a randomized, double-blind controlled trial. Crit Care. 2004;8:R1-11.

246. Akinci SB, Kanbak M, Guler A, Aypar U. Remifentanil versus fentanyl for short-term analgesia-based sedation in mechanically ventilated postoperative children. Paediatr Anaesth. 2005; 15:870-8.

247. Huey-Ling L, Chun-Che S, Jen-Jen T, Shau-Ting L, Hsing-I C. Comparison of the effect of protocol-directed sedation with propofol vs. midazolam by nurses in intensive care: efficacy, haemodynamic stability and patient satisfaction. J Clin Nurs. 2008;17:1510-7.

248. Ruokonen E, Parviainen I, Jakob SM, Nunes S, Kaukonen M, Shepherd ST, et al. Dexmedetomidine versus propofol/midazolam for long-term sedation during mechanical ventilation. Intensive Care Med. 2009;35:282-90.

249. Wunsch H, Kahn JM, Kramer AA, Rubenfeld GD. Use of intravenous infusion sedation among mechanically ventilated patients in the United States. Crit Care Med. 2009;37: 3031-9.

250. Wunsch H, Kahn JM, Kramer AA, Wagener G, Li G, Sladen RN, et al. Dexmedetomidine in the care of critically ill patients from 2001 to 2007: an observational cohort study. Anesthesiology. 2010;113:386-94.

251. Horinek EL, Kiser TH, Fish DN, MacLaren R. Propylene glycol accumulation in critically ill patients receiving continuous intravenous lorazepam infusions. Ann Pharmacother. 2009;43:1964-71.
252. Hall RI, Sandham D, Cardinal P, Tweeddale M, Moher D, Wang $X$, et al. Propofol vs midazolam for ICU sedation: a Canadian multicenter randomized trial. Chest. 2001;119:1151-9.

253. Carson SS, Kress JP, Rodgers JE, Vinayak A, Campbell-Bright $\mathrm{S}$, Levitt $\mathrm{J}$, et al. A randomized trial of intermittent lorazepam versus propofol with daily interruption in mechanically ventilated patients. Crit Care Med. 2006;34:1326-32.

254. Saito M, Terao Y, Fukusaki M, Makita T, Shibata O, Sumikawa K. Sequential use of midazolam and propofol for long-term sedation in postoperative mechanically ventilated patients. Anesth Analg. 2003;96:834-8.

255. Knibbe CA, Naber H, Aarts LP, Kuks PF, Danhof M. Long-term sedation with propofol $60 \mathrm{mg} \mathrm{ml(-1)} \mathrm{vs.} \mathrm{propofol} 10 \mathrm{mg}(-1) \mathrm{ml}$ in critically ill, mechanically ventilated patients. Acta Anaesthesiol Scand. 2004;48:302-7.

256. Pandharipande PP, Sanders RD, Girard TD, McGrane S, Thompson JL, Shintani AK, et al. Effect of dexmedetomidine versus lorazepam on outcome in patients with sepsis: an a prioridesigned analysis of the MENDS randomized controlled trial. Crit Care. 2010;14:R38.

257. Dasta JF, Kane-Gill SL, Pencina M, Shehabi Y, Bokesch PM, Wisemandle $W$, et al. A cost-minimization analysis of dexmedetomidine compared with midazolam for long-term sedation in the intensive care unit. Crit Care Med. 2010;38: 497-503.

258. Gerlach AT, Dasta JF, Steinberg S, Martin LC, Cook CH. A new dosing protocol reduces dexmedetomidine-associated hypotension in critically ill surgical patients. J Crit Care. 2009;24:568-74.

259. Anger KE, Szumita PM, Baroletti SA, Labreche MJ, Fanikos J. Evaluation of dexmedetomidine versus propofol-based sedation therapy in mechanically ventilated cardiac surgery patients at a tertiary academic medical center. Crit Pathw Cardiol. 2010;9:221-6.

260. Yapici N, Coruh T, Kehlibar T, Yapici F, Tarhan A, Can Y, et al. Dexmedetomidine in cardiac surgery patients who fail extubation and present with a delirium state. Heart Surg Forum. 2011;14:E93-8.

261. Venn RM, Bryant A, Hall GM, Grounds RM. Effects of dexmedetomidine on adrenocortical function, and the cardiovascular, endocrine and inflammatory responses in post-operative patients needing sedation in the intensive care unit. $\mathrm{Br} \mathrm{J}$ Anaesth. 2001;86:650-6.

262. Tasdogan M, Memis D, Sut N, Yuksel M. Results of a pilot study on the effects of propofol and dexmedetomidine on inflammatory responses and intraabdominal pressure in severe sepsis. $J$ Clin Anesth. 2009;21:394-400.

263. Memiș D, Dökmeci D, Karamanlioğlu B, Turan A, Türe M. A comparison of the effect on gastric emptying of propofol or dexmedetomidine in critically ill patients: preliminary study. Eur J Anaesthesiol. 2006;23:700-4.

264. Hofer S, Steppan J, Wagner T, Funke B, Lichtenstern C, Martin $E$, et al. Central sympatholytics prolong survival in experimental sepsis. Crit Care. 2009;13:R11.

265. Malerba G, Romano-Girard F, Cravoisy A, Dousset B, Nace L, Lévy B, et al. Risk factors of relative adrenocortical deficiency in intensive care patients needing mechanical ventilation. Intensive Care Med. 2005;31:388-92.

266. Cotton BA, Guillamondegui OD, Fleming SB, Carpenter RO, Patel SH, Morris JA, et al. Increased risk of adrenal insufficiency following etomidate exposure in critically injured patients. Arch Surg. 2008;143:62-7, discusión 67.

267. Kress JP, Pohlman AS, O'Connor MF, Hall JB. Daily interruption of sedative infusions in critically ill patients undergoing mechanical ventilation. N Engl J Med. 2000;342: 1471-7.

268. Schweickert WD, Gehlbach BK, Pohlman AS, Hall JB, Kress JP. Daily interruption of sedative infusions and complications of 
critical illness in mechanically ventilated patients. Crit Care Med. 2004;32:1272-6.

269. Oto J, Yamamoto K, Koike S, Imanaka H, Nishimura M. Effect of daily sedative interruption on sleep stages of mechanically ventilated patients receiving midazolam by infusion. Anaesth Intensive Care. 2011;39:392-400.

270. Anifantaki S, Prinianakis G, Vitsaksaki E, Katsouli V, Mari S, Symianakis A, et al. Daily interruption of sedative infusions in an adult medical-surgical intensive care unit: randomized controlled trial. J Crit Care. 2009;65:1054-60.

271. Roberts RJ, de Wit M, Epstein SK, Didomenico D, Devlin JW. Predictors for daily interruption of sedation therapy by nurses: a prospective, multicenter study. J Crit Care. 2010;25:e1-7.

272. Belhadj Amor M, Ouezini R, Lamine K, Barakette M, Labbène I, Ferjani M. Daily interruption of sedation in intensive care unit patients with renal impairment: remifentanil-midazolam compared to fentanyl-midazolam. Ann Fr Anesth Reanim. 2007;26:1041-4.

273. Jackson JC, Girard TD, Gordon SM, Thompson JL, Shintani AK, Thomason JWW, et al. Long-term cognitive and psychological outcomes in the awakening and breathing controlled trial. Am J Respir Crit Care Med. 2010;182:183-91.

274. Nieszkowska A, Combes A, Luyt C-E, Ksibi H, Trouillet JL, Gibert C, et al. Impact of tracheotomy on sedative administration, sedation level, and comfort of mechanically ventilated intensive care unit patients. Crit Care Med. 2005;33: 2527-33.

275. Ventilation with lower tidal volumes as compared with traditional tidal volumes for acute lung injury and the acute respiratory distress, syndrome. The Acute Respiratory Distress Syndrome Network. N Engl J Med. 2000;342:1301-8.

276. Needham CJ, Brindley PG. Best evidence in critical care medicine: The role of neuromuscular blocking drugs in early severe acute respiratory distress syndrome. Can J Anaesth. 2012;59:105-8.

277. Vinayak AG, Gehlbach B, Pohlman AS, Hall JB, Kress JP. The relationship between sedative infusion requirements and permissive hypercapnia in critically ill, mechanically ventilated patients. Crit Care Med. 2006;34:1668-73.

278. Cheng IW, Eisner MD, Thompson BT, Ware LB, Matthay MA, Acute Respiratory Distress Syndrome Network. Acute effects of tidal volume strategy on hemodynamics, fluid balance, and sedation in acute lung injury. Crit Care Med. 2005;33:63-70240, discusión 239-240.

279. Kahn JM, Andersson L, Karir V, Polissar NL, Neff MJ, Rubenfeld GD. Low tidal volume ventilation does not increase sedation use in patients with acute lung injury. Crit Care Med. 2005;33:766-71.

280. Hunter BC, Oliva R, Sahler OJZ, Gaisser D, Salipante DM, Arezina $\mathrm{CH}$. Music therapy as an adjunctive treatment in the management of stress for patients being weaned from mechanical ventilation. J Music Ther. 2010;47:198-219.

281. Jaber S, Bahloul H, Guétin S, Chanques G, Sebbane M, Eledjam J-J. Effects of music therapy in intensive care unit without sedation in weaning patients versus non-ventilated patients. Ann Fr Anesth Reanim. 2007;26:30-8.

282. Dijkstra BM, Gamel C, van der Bijl JJ, Bots ML, Kesecioglu $J$. The effects of music on physiological responses and sedation scores in sedated, mechanically ventilated patients. J Clin Nurs. 2010;19:1030-9.

283. Hurlock-Chorostecki C. Management of pain during weaning from mechanical ventilation: the nature of nurse decisionmaking. Can J Nurs Res. 2002;34:33-47.

284. Karabinis A, Mandragos K, Stergiopoulos S, Komnos A, Soukup J, Speelberg B, et al. Safety and efficacy of analgesia-based sedation with remifentanil versus standard hypnotic-based regimens in intensive care unit patients with brain injuries: a randomised, controlled trial. Crit Care. 2004;8:R268-80.
285. Barrientos-Vega R, Mar Sánchez-Soria M, Morales-García C, Robas-Gómez A, Cuena-Boy R, Ayensa-Rincon A. Prolonged sedation of critically ill patients with midazolam or propofol: impact on weaning and costs. Crit Care Med. 1997;25: 33-40.

286. Walder B, Borgeat A, Suter PM, Romand JA. Propofol and midazolam versus propofol alone for sedation following coronary artery bypass grafting: a randomized, placebo-controlled trial. Anaesth Intensive Care. 2002:171-8.

287. Herr DL, Sum-Ping STJ, England M. ICU sedation after coronary artery bypass graft surgery: dexmedetomidine-based versus propofol-based sedation regimens. J Cardiothorac Vasc Anesth. 2003;17:576-84.

288. Dahaba AA, Grabner T, Rehak PH, List WF, Metzler H. Remifentanil versus morphine analgesia and sedation for mechanically ventilated critically ill patients: a randomized double blind study. Anesthesiology. 2004;101:640-6.

289. Kollef MH, Shapiro SD, Silver P, St John RE, Prentice D, Sauer S, et al. A randomized, controlled trial of protocol-directed versus physician-directed weaning from mechanical ventilation. Crit Care Med. 1997;25:567-74.

290. Devabhakthuni S, Armahizer MJ, Dasta JF, Kane-Gill SL. Analgosedation: a paradigm shift in intensive care unit sedation practice. Ann Pharmacother. 2012;46:530-40.

291. Cammarano WB, Pittet JF, Weitz S, Schlobohm RM, Marks JD. Acute withdrawal syndrome related to the administration of analgesic and sedative medications in adult intensive care unit patients. Crit Care Med. 1998;26:676-84.

292. Wanzuita R, Poli-de-Figueiredo LF, Pfuetzenreiter F, Cavalcanti $A B$, Westphal GA. Replacement of fentanyl infusion by enteral methadone decreases the weaning time from mechanical ventilation: a randomized controlled trial. Crit Care. 2012;16:R49.

293. Kulkarni A, Price G, Saxena M, Skowronski G. Difficult extubation: calming the sympathetic storm. Anaesth Intensive Care. 2004;32:413-6.

294. Siobal MS, Kallet RH, Kivett VA, Tang JF. Use of dexmedetomidine to facilitate extubation in surgical intensive-care-unit patients who failed previous weaning attempts following prolonged mechanical ventilation: a pilot study. Respir Care. 2006;51:492-6.

295. Szumita PM, Baroletti SA, Anger KE, Wechsler ME. Sedation and analgesia in the intensive care unit: evaluating the role of dexmedetomidine. Am J Health Syst Pharm. 2007;64:37-44.

296. Tan JA, Ho KM. Use of dexmedetomidine as a sedative and analgesic agent in critically ill adult patients: a meta-analysis. Intensive Care Med. 2010;36:926-39.

297. Arpino PA, Kalafatas K, Thompson BT. Feasibility of dexmedetomidine in facilitating extubation in the intensive care unit. J Clin Pharm Ther. 2008;33:25-30.

298. Shehabi Y, Nakae H, Hammond N, Bass F, Nicholson L, Chen $J$. The effect of dexmedetomidine on agitation during weaning of mechanical ventilation in critically ill patients. Anaesth Intensive Care. 2010;38:82-90.

299. MacLaren R, Forrest LK, Kiser TH. Adjunctive dexmedetomidine therapy in the intensive care unit: a retrospective assessment of impact on sedative and analgesic requirements, levels of sedation and analgesia, and ventilatory and hemodynamic parameters. Pharmacotherapy. 2007;27: $351-9$.

300. Beller JP, Pottecher T, Lugnier A, Mangin P, Otteni JC. Prolonged sedation with propofol in ICU patients: recovery and blood concentration changes during periodic interruptions in infusion. Br J Anaesth. 1988;61:583-8.

301. Ronan KP, Gallagher TJ, George B, Hamby B. Comparison of propofol and midazolam for sedation in intensive care unit patients. Crit Care Med. 1995;23:286-93.

302. Kelly DF, Goodale DB, Williams J, Herr DL, Chappell ET, Rosner MJ, et al. Propofol in the treatment of moderate and severe 
head injury: a randomized, prospective double-blinded pilot trial. J Neurosurg. 1999;90:1042-52.

303. Cremer OL, Moons KG, Bouman EA, Kruijswijk JE, de Smet AM, Kalkman CJ. Long-term propofol infusion and cardiac failure in adult head-injured patients. Lancet. 2001;357:117-8.

304. Soja SL, Pandharipande PP, Fleming SB, Cotton BA, Miller LR, Weaver SG, et al. Implementation, reliability testing, and compliance monitoring of the Confusion Assessment Method for the Intensive Care Unit in trauma patients. Intensive Care Med. 2008;34:1263-8.

305. Shinozaki M, Usui Y, Yamaguchi S, Okuda Y, Kitajima T. Recovery of psychomotor function after propofol sedation is prolonged in the elderly. Can J Anaesth. 2002;49:927-31.

306. Fujisawa T, Suzuki S, Tanaka K, Kamekura N, Fukushima K, Kemmotsu O. Recovery of postural stability following conscious sedation with midazolam in the elderly. J Anesth. 2002;16:198-202.

307. Pandharipande P, Shintani A, Peterson J, Pun BT, Wilkinson GR, Dittus RS, et al. Lorazepam is an independent risk factor for transitioning to delirium in intensive care unit patients. Anesthesiology. 2006;104:21-6.

308. Wang W, Li H-L, Wang D-X, Zhu X, Li S-L, Yao G-Q, et al. Haloperidol prophylaxis decreases delirium incidence in elderly patients after noncardiac surgery: a randomized controlled trial. Crit Care Med. 2012;40:731-9.

309. Drugs at FDA: FDA approved drug products. [consultado 6 May 2011]. Disponible en: http://www.accessdata.fda.gov/ scripts/cder/drugsatfda/index.cfm

310. Numazaki M, Fujii Y. Subhypnotic dose of propofol for the prevention of nausea and vomiting during spinal anaesthesia for caesarean section. Anaesth Intensive Care. 2000;28: 262-5.

311. Higuchi H, Adachi Y, Arimura S, Kanno M, Satoh T. Early pregnancy does not reduce the $C(50)$ of propofol for loss of consciousness. Anesth Analg. 2001;93:1565-9.

312. Jauniaux E, Gulbis B, Shannon C, Maes V, Bromley L, Rodeck C. Placental propofol transfer and fetal sedation during maternal general anaesthesia in early pregnancy. Lancet. 1998;352:290-1.

313. Bonnot O, Vollset SE, Godet PF, d'Amato T, Robert E. Maternal exposure to lorazepam and anal atresia in newborns: results from a hypothesis-generating study of benzodiazepines and malformations. J Clin Psychopharmacol. 2001;21:456-8.

314. Bonnot O, Vollset SE, Godet P-F, d'Amato T, Dalery J, Robert E. In utero exposure to benzodiazepine. Is there a risk for anal atresia with lorazepam? Encephale. 2003;29:553-9.

315. Fletcher N. IV paracetamol vs other opiates and analgesics. Arch Dis Child Fetal Neonatal Ed. 2010;95 Suppl 1:Fa83.

316. Zor F, Ozturk S, Bilgin F, Isik S, Cosar A. Pain relief during dressing changes of major adult burns: ideal analgesic combination with ketamine. Burns. 2010;36:501-5.

317. Gündüz M, Sakalli S, Güneș Y, Kesiktaș E, Ozcengiz D, Ișik G. Comparison of effects of ketamine, ketaminedexmedetomidine and ketamine-midazolam on dressing changes of burn patients. J Anaesthesiol Clin Pharmacol. 2011;27:220-4.

318. Girtler R, Gustorff B. Pain management of burn injuries. Anaesthesist. 2011;60:243-50.

319. Brennan F, Carr DB, Cousins M. Pain management: a fundamental human right. Anesth Analg. 2007;105:205-21.

320. Wake PJ, Cheng DC. Postoperative intensive care in cardiac surgery. Curr Opin Anaesthesiol. 2001;14:41-5.

321. Dowd NP, Karski JM, Cheng DC, Gajula S, Seneviratne P, Munro JA, et al. Fast-track cardiac anaesthesia in the elderly: effect of two different anaesthetic techniques on mental recovery. $\mathrm{Br}$ J Anaesth. 2001;86:68-76.

322. Hall RI, MacLaren C, Smith MS, Mclntyre AJ, Allen CT, Murphy JT, et al. Light versus heavy sedation after cardiac surgery: myocardial ischemia and the stress response. Maritime Heart Centre and Dalhousie University. Anesth Analg. 1997;85:971-8.

323. Muellejans B, Matthey T, Scholpp J, Schill M. Sedation in the intensive care unit with remifentanil/propofol versus midazolam/fentanyl: a randomised, open-label, pharmacoeconomic trial. Crit Care. 2006;10:R91.

324. O'Halloran P, Brown R. Patient-controlled analgesia compared with nurse-controlled infusion analgesia after heart surgery. Intensive Crit Care Nurs. 1997;13:126-9.

325. Checketts MR, Gilhooly CJ, Kenny GN. Patient-maintained analgesia with target-controlled alfentanil infusion after cardiac surgery: a comparison with morphine PCA. Br J Anaesth. 1998;80:748-51.

326. Hansdottir V, Philip J, Olsen MF, Eduard C, Houltz E, Ricksten S-E. Thoracic epidural versus intravenous patient-controlled analgesia after cardiac surgery: a randomized controlled trial on length of hospital stay and patient-perceived quality of recovery. Anesthesiology. 2006;104:142-51.

327. Fitzpatrick GJ, Moriarty DC. Intrathecal morphine in the management of pain following cardiac surgery. A comparison with morphine i.v. Br J Anaesth. 1988;60:639-44.

328. Vanstrum GS, Bjornson KM, Ilko R. Postoperative effects of intrathecal morphine in coronary artery bypass surgery. Anesth Analg. 1988;67:261-7.

329. Chaney MA, Smith KR, Barclay JC, Slogoff S. Large-dose intrathecal morphine for coronary artery bypass grafting. Anesth Analg. 1996;83:215-22.

330. Zarate E, Latham P, White PF, Bossard R, Morse L, Douning LK, et al. Fast-track cardiac anesthesia: use of remifentanil combined with intrathecal morphine as an alternative to sufentanil during desflurane anesthesia. Anesth Analg. 2000;91:283-7.

331. Bettex DA, Schmidlin D, Chassot P-G, Schmid ER. Intrathecal sufentanil-morphine shortens the duration of intubation and improves analgesia in fast-track cardiac surgery. Can J Anaesth. 49:711-7.

332. Lena P, Balarac N, Arnulf JJ, Teboul J, Bonnet F. Intrathecal morphine and clonidine for coronary artery bypass grafting. $\mathrm{Br}$ J Anaesth. 2003;90:300-3.

333. Chaney MA, Nikolov MP, Blakeman BP, Bakhos M. Intrathecal morphine for coronary artery bypass graft procedure and early extubation revisited. J Cardiothorac Vasc Anesth. 1999;13:574-8.

334. Chaney MA, Furry PA, Fluder EM, Slogoff S. Intrathecal morphine for coronary artery bypass grafting and early extubation. Anesth Analg. 1997;84:241-8.

335. Roediger L, Joris J, Senard M, Larbuisson R, Canivet JL, Lamy $M$. The use of pre-operative intrathecal morphine for analgesia following coronary artery bypass surgery. Anaesthesia. 2006;61:838-44.

336. Loick HM, Schmidt C, van Aken H, Junker R, Erren M, Berendes $\mathrm{E}$, et al. High thoracic epidural anesthesia, but not clonidine, attenuates the perioperative stress response via sympatholysis and reduces the release of troponin $\mathrm{T}$ in patients undergoing coronary artery bypass grafting. Anesth Analg. 1999;88:701-9.

337. Ho AM, Chung DC, Joynt GM. Neuraxial blockade and hematoma in cardiac surgery: estimating the risk of a rare adverse event that has not (yet) occurred. Chest. 2000;117:551-5.

338. Cantó M, Sánchez MJ, Casas MA, Bataller ML. Bilateral paravertebral blockade for conventional cardiac surgery. Anaesthesia. 2003;58:365-70.

339. White PF, Rawal S, Latham P, Markowitz S, Issioui T, Chi $L$, et al. Use of a continuous local anesthetic infusion for pain management after median sternotomy. Anesthesiology. 2003;99:918-23.

340. McDonald SB, Jacobsohn E, Kopacz DJ, Desphande S, Helman JD, Salinas F, et al. Parasternal block and local anesthetic infiltration with levobupivacaine after cardiac surgery 
with desflurane: the effect on postoperative pain, pulmonary function, and tracheal extubation times. Anesth Analg. 2005; 100:25-32.

341. Mehta Y, Vats M, Sharma M, Arora R, Trehan N. Thoracic epidural analgesia for off-pump coronary artery bypass surgery in patients with chronic obstructive pulmonary disease. Ann Card Anaesth. 2010;13:224-30.

342. Rapanos T, Murphy P, Szalai JP, Burlacoff L, Lam-McCulloch J, Kay J. Rectal indomethacin reduces postoperative pain and morphine use after cardiac surgery. Can J Anaesth. 1999;46:725-30.

343. Hynninen MS, Cheng DC, Hossain I, Carroll J, Aumbhagavan SS, Yue R, et al. Non-steroidal anti-inflammatory drugs in treatment of postoperative pain after cardiac surgery. Can J Anaesth. 2000;47:1182-7.

344. Maldonado JR, Wysong A, van der Starre PJA, Block T, Miller C, Reitz BA. Dexmedetomidine and the reduction of postoperative delirium after cardiac surgery. Psychosomatics. 2009;50:206-17.

345. Shehabi Y, Grant P, Wolfenden H, Hammond N, Bass F, Campbell $M$, et al. Prevalence of delirium with dexmedetomidine compared with morphine based therapy after cardiac surgery: a randomized controlled trial (DEXmedetomidine COmpared to Morphine-DEXCOM Study). Anesthesiology. 2009;111:1075-84.

346. Wong GTC, Huang Z, Ji S, Irwin MG. Remifentanil reduces the release of biochemical markers of myocardial damage after coronary artery bypass surgery: a randomized trial. J Cardiothorac Vasc Anesth. 2010;24:790-6.

347. Greco M, Landoni G, Biondi-Zoccai G, Cabrini L, Ruggeri L, Pasculli N, et al. Remifentanil in cardiac surgery: a meta-analysis of randomized controlled trials. J Cardiothorac Vasc Anesth. 2012;26:110-6.

348. Kadoi Y, Hinohara H, Kunimoto F, Saito S, Goto F. Fentanylinduced hemodynamic changes after esophagectomy or cardiac surgery. J Clin Anesth. 2005;17:598-603.

349. Searle NR, Côté S, Taillefer J, Carrier M, Gagnon L, Roy M, et al. Propofol or midazolam for sedation and early extubation following cardiac surgery. Can J Anaesth. 1997;44: 629-35.

350. Hsu Y-W, Cortinez LI, Robertson KM, Keifer JC, Sum-Ping ST, Moretti EW, et al. Dexmedetomidine pharmacodynamics: part I: crossover comparison of the respiratory effects of dexmedetomidine and remifentanil in healthy volunteers. Anesthesiology. 2004;101:1066-76.

351. Ickeringill M, Shehabi Y, Adamson H, Ruettimann U. Dexmedetomidine infusion without loading dose in surgical patients requiring mechanical ventilation: haemodynamic effects and efficacy. Anaesth Intensive Care. 2004;32:741-5.

352. Dasta JF, Jacobi J, Sesti A-M, McLaughlin TP. Addition of dexmedetomidine to standard sedation regimens after cardiac surgery: an outcomes analysis. Pharmacotherapy. 2006;26:798-805

353. Abd Aziz N, Chue MC, Yong CY, Hassan Y, Awaisu A, Hassan J, et al. Efficacy and safety of dexmedetomidine versus morphine in post-operative cardiac surgery patients. Int J Clin Pharm. 2011;33:150-4

354. Alfonsi P. Postanaesthetic shivering: epidemiology, pathophysiology, and approaches to prevention and management. Drugs. 2001;61:2193-205.

355. Bajwa SJ, Gupta S, Kaur J, Singh A, Parmar S. Reduction in the incidence of shivering with perioperative dexmedetomidine: $A$ randomized prospective study. J Anaesthesiol Clin Pharmacol. 2012;28:86-91.

356. Pesonen A, Suojaranta-Ylinen R, Hammarén E, Kontinen VK, Raivio P, Tarkkila P, et al. Pregabalin has an opioid-sparing effect in elderly patients after cardiac surgery: a randomized placebo-controlled trial. Br J Anaesth. 2011;106:873-81.
357. Soliman HM, Mélot C, Vincent JL. Sedative and analgesic practice in the intensive care unit: the results of a European survey. Br J Anaesth. 2001;87:186-92.

358. Vincent J-L, Berré J. Primer on medical management of severe brain injury. Crit Care Med. 2005;33:1392-9.

359. Brain Trauma Foundation; American Association of Neurological Surgeons; Congress of Neurological Surgeons. Guidelines for the management of severe traumatic brain, injury. J Neurotrauma. 2007;24 Suppl 1:S1-106.

360. Chesnut RM, Marshall LF, Klauber MR, Blunt BA, Baldwin N, Eisenberg HM, et al. The role of secondary brain injury in determining outcome from severe head injury. J Trauma. 1993;34:216-22.

361. De Nadal M, Munar F, Poca MA, Sahuquillo J, Garnacho A, Rosselló J. Cerebral hemodynamic effects of morphine and fentanyl in patients with severe head injury: absence of correlation to cerebral autoregulation. Anesthesiology. 2000;92: 11-9.

362. McCollam JS, O'Neil MG, Norcross ED, Byrne TK, Reeves ST. Continuous infusions of lorazepam, midazolam, and propofol for sedation of the critically ill surgery trauma patient: a prospective, randomized comparison. Crit Care Med. 1999;27:2454-8.

363. Triltsch AE, Welte M, von Homeyer P, Grosse J, Genähr A, Moshirzadeh $M$, et al. Bispectral index-guided sedation with dexmedetomidine in intensive care: a prospective, randomized, double blind, placebo-controlled phase II study. Crit Care Med. 2002;30:1007-14.

364. Sanchez-Izquierdo-Riera JA, Caballero-Cubedo RE, Perez-Vela JL, Ambros-Checa A, Cantalapiedra-Santiago JA, Alted-Lopez E. Propofol versus midazolam: safety and efficacy for sedating the severe trauma patient. Anesth Analg. 1998;86: 1219-24.

365. Martin J, Heymann A, Bäsell K, Baron R, Biniek R, Bürkle H, et al. Evidence and consensus-based German guidelines for the management of analgesia, sedation and delirium in intensive care-short version. Ger Med Sci. 2010;8:Doc02.

366. Ghori KA, Harmon DC, Elashaal A, Butler M, Walsh F, O’Sullivan $M G J$, et al. Effect of midazolam versus propofol sedation on markers of neurological injury and outcome after isolated severe head injury: a pilot study. Crit Care Resusc. 2007;9:166-71.

367. Eisenberg HM, Frankowski RF, Contant CF, Marshall LF, Walker MD. High-dose barbiturate control of elevated intracranial pressure in patients with severe head injury. J Neurosurg. 1988;69:15-23.

368. Cormio M, Gopinath SP, Valadka A, Robertson CS. Cerebral hemodynamic effects of pentobarbital coma in head-injured patients. J Neurotrauma. 1999;16:927-36.

369. Stocchetti N, Zanaboni C, Colombo A, Citerio G, Beretta L, Ghisoni L, et al. Refractory intracranial hypertension and «second-tier» therapies in traumatic brain injury. Intensive Care Med. 2008;34:461-7.

370. Chen HI, Malhotra NR, Oddo M, Heuer GG, Levine JM, LeRoux PD. Barbiturate infusion for intractable intracranial hypertension and its effect on brain oxygenation. Neurosurgery. 2008;63:880-67, discusión 886-887.

371. Roberts DJ, Hall RI, Kramer AH, Robertson HL, Gallagher CN, Zygun DA. Sedation for critically ill adults with severe traumatic brain injury: a systematic review of randomized controlled trials. Crit Care Med. 2011;39: 2743-51.

372. Bourgoin A, Albanèse J, Wereszczynski N, Charbit M, Vialet R, Martin C. Safety of sedation with ketamine in severe head injury patients: comparison with sufentanil. Crit Care Med. 2003;31:711-7.

373. Dean M. Opioids in renal failure and dialysis patients. J Pain Symptom Manage. 2004;28:497-504. 
374. Child C, Turcotte J. Surgery and portal hypertension. The liver and portal hypertension. Volume 1 of Major problems in clinical surgery. 3 rd ed. Saunders: Ann Arbor, MI; 1964. p. 50.

375. Pugh RN, Murray-Lyon IM, Dawson JL, Pietroni MC, Williams R. Transection of the oesophagus for bleeding oesophageal varices. Br J Surg. 1973;60:646-9.

376. Yurdaydin C, Karavelioglu D, Onaran O, Celik T, Yașa MH, Uzunalimoglu O. Opioid receptor ligands in human hepatic encephalopathy. J Hepatol. 1998;29:796-801.

377. Assy N, Rosser BG, Grahame GR, Minuk GY. Risk of sedation for upper $\mathrm{Gl}$ endoscopy exacerbating subclinical hepatic encephalopathy in patients with cirrhosis. Gastrointest Endosc. 1999;49:690-4.

378. Bergasa NV, Rothman RB, Mukerjee E, Vergalla J, Jones EA. Upregulation of central mu-opioid receptors in a model of hepatic encephalopathy: a potential mechanism for increased sensitivity to morphine in liver failure. Life Sci. 2002;70:1701-8.

379. Vasudevan AE, Goh KL, Bulgiba AM. Impairment of psychomotor responses after conscious sedation in cirrhotic patients undergoing therapeutic upper GI endoscopy. Am J Gastroenterol. 2002;97:1717-21.

380. Kurella M, Bennett WM, Chertow GM. Analgesia in patients with ESRD: a review of available evidence. Am J Kidney Dis. 2003;42:217-28.

381. Bennett W. Prescribing drugs for dialysis patients. En: Heinrich W, editor. Principles and practice of dialysis. $3 \mathrm{rd}$ ed. Philadelphia: Lipincott Williams and Wilkins; 2004. p. 150-61.

382. Murphy EJ. Acute pain management pharmacology for the patient with concurrent renal or hepatic disease. Anaesth Intensive Care. 2005;33:311-22.

383. McGuire BM. Safety of endoscopy in patients with end-stage liver disease. Gastrointest Endosc Clin N Am. 2001;11:111-30.

384. Als-Nielsen B, Gluud LL, Gluud C. Dopaminergic agonists for hepatic encephalopathy. Cochrane Database Syst Rev. 2004. CD003047.

385. Weston BR, Chadalawada V, Chalasani N, Kwo P, Overley CA, Symms M, et al. Nurse-administered propofol versus midazolam and meperidine for upper endoscopy in cirrhotic patients. Am J Gastroenterol. 2003;98:2440-7.

386. Höhne C, Donaubauer B, Kaisers U. Opioids during anesthesia in liver and renal failure. Anaesthesist. 2004;53:291-303.

387. Pitsiu M, Wilmer A, Bodenham A, Breen D, Bach V, Bonde J, et al. Pharmacokinetics of remifentanil and its major metabolite, remifentanil acid, in ICU patients with renal impairment. Br J Anaesth. 2004;92:493-503.

388. Murray A, Hagen NA. Hydromorphone. J Pain Symptom Manage. 2005;29 5 Suppl:S57-66.

389. Davison SN, May PR. Pain management in chronic kidney disease: the pharmacokinetics and pharmacodynamics of hydromorphone and hydromorphone-3-glucuronide in hemodialysis patients. J Opioid Manag. 2008;4:339-44.

390. Iirola T, Aantaa R, Laitio R, Kentala E, Lahtinen M, Wighton $A$, et al. Pharmacokinetics of prolonged infusion of highdose dexmedetomidine in critically ill patients. Crit Care. 2011;15:R257.

391. De Wolf AM, Fragen RJ, Avram MJ, Fitzgerald PC, RahimiDanesh F. The pharmacokinetics of dexmedetomidine in volunteers with severe renal impairment. Anesth Analg. 2001;93:1205-9.

392. Venn RM, Karol MD, Grounds RM. Pharmacokinetics of dexmedetomidine infusions for sedation of postoperative patients requiring intensive caret. $\mathrm{Br} \mathrm{J}$ Anaesth. 2002;88: $669-75$

393. Swart EL, de Jongh J, Zuideveld KP, Danhof M, Thijs LG, Strack van Schijndel RJM. Population pharmacokinetics of lorazepam and midazolam and their metabolites in intensive care patients on continuous venovenous hemofiltration. Am J Kidney Dis. 2005;45:360-71.
394. Eddleston JM, Pollard BJ, Blades JF, Doran B. The use of propofol for sedation of critically ill patients undergoing haemodiafiltration. Intensive Care Med. 1995;21:342-7.

395. Ickx B, Cockshott ID, Barvais L, Byttebier G, de Pauw L, Vandesteene $\mathrm{A}$, et al. Propofol infusion for induction and maintenance of anaesthesia in patients with end-stage renal disease. $\mathrm{Br} \mathrm{J}$ Anaesth. 1998;81:854-60.

396. Barr J, Zaloga GP, Haupt MT, Weinmann M, Murray MJ, Bandi $V$, et al. Cation metabolism during propofol sedation with and without EDTA in patients with impaired renal function. Intensive Care Med. 2000;26 Suppl 4:S433-42.

397. Sanga M, Shigemura J. Pharmacokinetics of haloperidol in patients on hemodialysis. Nihon Shinkei Seishin Yakurigaku Zasshi. 1998;18:45-7.

398. Nakasone H, Sugama R, Sakugawa H, Matayoshi R, Miyagi T, Maeshiro T, et al. Alcoholic liver cirrhosis complicated with torsade de pointes during plasma exchange and hemodiafiltration. J Gastroenterol. 2001;36:564-8.

399. Dumont L, Picard V, Marti RA, Tassonyi E. Use of remifentanil in a patient with chronic hepatic failure. $\mathrm{Br} J$ Anaesth. 1998;81:265-7.

400. Ben Ari A, Elinav E, Elami A, Matot I. Off-pump coronary artery bypass grafting in a patient with Child class $\mathrm{C}$ liver cirrhosis awaiting liver transplantation. Br J Anaesth. 2006;97:468-72.

401. Blei AT, Córdoba J. Hepatic encephalopathy. Am J Gastroenterol. 2001;96:1968-76.

402. Andersen G, Christrup L, Sjøgren P. Relationships among morphine metabolism, pain and side effects during longterm treatment: an update. J Pain Symptom Manage. 2003;25:74-91

403. Taurá P, Fuster J, Blasi A, Martinez-Ocon J, Anglada T, Beltran J, et al. Postoperative pain relief after hepatic resection in cirrhotic patients: the efficacy of a single small dose of ketamine plus morphine epidurally. Anesth Analg. 2003;96: 475-80.

404. Baughman VL, Cunningham FE, Layden T, Tonkovich L. Pharmacokinetic/pharmacodynamic effects of dexmedetomidine in patients with hepatic failure. Abstract in International Anesthesia Research Society 74th Annual Meeting 2000. p. S391. [consultado 6 May 2011]. Disponible en: http://www.iars.org/abstracts/browsefile/browse.asp? command=P\&absnum $=7 \&$ dir $=$ S386

405. Rovasalo A, Tohmo H, Aantaa R, Kettunen E, Palojoki R. Dexmedetomidine as an adjuvant in the treatment of alcohol withdrawal delirium: a case report. Gen Hosp Psychiatry. 2006;28:362-3.

406. May-Smith MF, Beecher LH, Fischer TL, Gorelick DA, Guillaume JL, Hill A, et al. Management of alcohol withdrawal delirium. An evidence-based practice guideline. Arch Intern Med. 2004;12:1405-12.

407. Ntais C, Pakos E, Kyzas P, loannidis JPA. Benzodiazepines for alcohol withdrawal. Cochrane Database Syst Rev. 2010. CD005063.

408. Ebell MH. Benzodiazepines for alcohol withdrawal. Am Fam Physician. 2006;73:1191.

409. Wijdicks EFM, Nyberg SL. Propofol to control intracranial pressure in fulminant hepatic failure. Transplant Proc. 2002;34:1220-2.

410. Jalan R. Intracranial hypertension in acute liver failure: pathophysiological basis of rational management. Semin Liver Dis. 2003;23:271-82.

411. Raghavan M, Marik PE. Therapy of intracranial hypertension in patients with fulminant hepatic failure. Neurocrit Care. 2006;4:179-89.

412. Faigel DO, Metz DC, Kochman ML. Torsade de pointes complicating the treatment of bleeding esophageal varices: association with neuroleptics, vasopressin, and electrolyte imbalance. Am J Gastroenterol. 1995;90:822-4. 
413. Strouse T. Neuropsychiatric outcomes in liver trauma. En: Busuttil R, Klintmaln G, editores. Transplantation of the Liver. 1 st ed. Philadelphia: W. B. Saunders Company; 1996. p. $660-1$.

414. Prabhakar S, Bhatia R. Management of agitation and convulsions in hepatic encephalopathy. Indian J Gastroenterol. 2003;22 Suppl 2:S54-8.

415. Panzer O, Moitra V, Sladen RN. Pharmacology of sedativeanalgesic agents: dexmedetomidine, remifentanil, ketamine, volatile anesthetics, and the role of peripheral mu antagonists. Crit Care Clin. 2009;25:451-69.

416. Correia LM, Bonilha DQ, Gomes GF, Brito JR, Nakao FS, Lenz L, et al. Sedation during upper GI endoscopy in cirrhotic outpatients: a randomized, controlled trial comparing propofol and fentanyl with midazolam and fentanyl. Gastrointest Endosc. 2011;73:45-51.

417. Khamaysi I, William N, Olga A, Alex I, Vladimir M, Kamal $D$, et al. Sub-clinical hepatic encephalopathy in cirrhotic patients is not aggravated by sedation with propofol compared to midazolam: a randomized controlled study. J Hepatol. 2011;54:72-7.

418. Stotts NA, Puntillo K, Stanik-Hutt J, Thompson CL, White C, Rietman Wild L. Does age make a difference in procedural pain perceptions and responses in hospitalized adults? Acute Pain. 2007;9:125-34

419. Arroyo-Novoa CM, Figueroa-Ramos MI, Puntillo KA, Stanik-Hutt J, Thompson CL, White C, et al. Pain related to tracheal suctioning in awake acutely and critically ill adults: a descriptive study. Intensive Crit Care Nurs. 2008;24:20-7.

420. Jeitziner M-M, Schwendimann R, Hamers JPH, Rohrer O, Hantikainen V, Jakob SM. Assessment of pain in sedated and mechanically ventilated patients: an observational study. Acta Anaesthesiol Scand. 2012;56:645-54.

421. Puntillo KA, Wild LR, Morris AB, Stanik-Hutt J, Thompson CL, White $\mathrm{C}$. Practices and predictors of analgesic interventions for adults undergoing painful procedures. Am J Crit Care. 2002:11:415-29.

422. Moon MR, Luchette FA, Gibson SW, Crews J, Sudarshan G, Hurst $J M$, et al. Prospective, randomized comparison of epidural versus parenteral opioid analgesia in thoracic trauma. Ann Surg. 1999;229:684-91, discusión 691-692.

423. Flisberg $P$, Rudin $A$, Linnér $R$, Lundberg CJF. Pain relief and safety after major surgery. A prospective study of epidural and intravenous analgesia in 2696 patients. Acta Anaesthesiol Scand. 2003;47:457-65.

424. Bulger EM, Edwards T, Klotz P, Jurkovich GJ. Epidural analgesia improves outcome after multiple rib fractures. Surgery. 2004;136:426-30.

425. Bimston DN, McGee JP, Liptay MJ, Fry WA. Continuous paravertebral extrapleural infusion for post-thoracotomy pain management. Surgery. 1999;126:650-6, discusión 656-657.

426. Richardson J, Sabanathan S, Jones J, Shah RD, Cheema S, Mearns AJ. A prospective, randomized comparison of preoperative and continuous balanced epidural or paravertebral bupivacaine on post-thoracotomy pain, pulmonary function and stress responses. Br J Anaesth. 1999;83:387-92.

427. Dhole S, Mehta Y, Saxena H, Juneja R, Trehan N. Comparison of continuous thoracic epidural and paravertebral blocks for postoperative analgesia after minimally invasive direct coronary artery bypass surgery. J Cardiothorac Vasc Anesth. 2001;15:288-92.

428. Davies RG, Myles PS, Graham JM. A comparison of the analgesic efficacy and side-effects of paravertebral vs epidural blockade for thoracotomy-a systematic review and meta-analysis of randomized trials. Br J Anaesth. 2006;96:418-26.

429. Luketich JD, Land SR, Sullivan EA, Alvelo-Rivera M, Ward $\mathrm{J}$, Buenaventura PO, et al. Thoracic epidural versus intercostal nerve catheter plus patient-controlled analgesia: a randomized study. Ann Thorac Surg. 2005;79:1849-50, discussion 1845-9.

430. Krachman SL, d'Alonzo GE, Criner GJ. Sleep in the intensive care unit. Chest. 1995;107:1713-20.

431. Gabor JY, Cooper AB, Hanly PJ. Sleep disruption in the intensive care unit. Curr Opin Crit Care. 2001;7:21-7.

432. Freedman NS, Kotzer N, Schwab RJ. Patient perception of sleep quality and etiology of sleep disruption in the intensive care unit. Am J Respir Crit Care Med. 1999;159:1155-62.

433. Nicolás A, Aizpitarte E, Iruarrizaga A, Vázquez M, Margall MA, Asiain MC. Perception of night-time sleep by the surgical patients in an Intensive Care Unit. Enferm Intensiva. 2002;13:57-67.

434. Gabor JY, Cooper AB, Crombach SA, Lee B, Kadikar N, Bettger $\mathrm{HE}$, et al. Contribution of the intensive care unit environment to sleep disruption in mechanically ventilated patients and healthy subjects. Am J Respir Crit Care Med. 2003;167: 708-15.

435. Tracy MF, Chlan L. Nonpharmacological interventions to manage common symptoms in patients receiving mechanical ventilation. Crit Care Nurse. 2011;31:19-28.

436. Richards K, Nagel C, Markie M, Elwell J, Barone C. Use of complementary and alternative therapies to promote sleep in critically ill patients. Crit Care Nurs Clin North Am. 2003; $15: 329-40$

437. Walder B, Haase U, Rundshagen I. Sleep disturbances in critically ill patients. Anaesthesist. 2007;56:7-17.

438. Frisk U, Nordström G. Patients' sleep in an intensive care unit patients' and nurses' perception. Intensive Crit Care Nurs. 2003;19:342-9.

439. Freedman NS, Gazendam J, Levan L, Pack Al, Schwab RJ. Abnormal sleep/wake cycles and the effect of environmental noise on sleep disruption in the intensive care unit. Am J Respir Crit Care Med. 2001;163:451-7.

440. Donchin Y, Seagull FJ. The hostile environment of the intensive care unit. Curr Opin Crit Care. 2002;8:316-20.

441. Van de Leur JP, van der Schans CP, Loef BG, Deelman BG, Geertzen JHB, Zwaveling JH. Discomfort and factual recollection in intensive care unit patients. Crit Care. 2004;8:R467-73.

442. Aaron JN, Carlisle CC, Carskadon MA, Meyer TJ, Hill NS, Millman RP. Environmental noise as a cause of sleep disruption in an intermediate Respir Care unit. Sleep. 1996;19:707-10.

443. Hu R, Jiang X, Zeng Y, Chen X, Zhang Y. Effects of earplugs and eye masks on nocturnal sleep, melatonin and cortisol in a simulated intensive care unit environment. Crit Care. 2010;14:R66.

444. Dennis CM, Lee R, Woodard EK, Szalaj JJ, Walker CA. Benefits of quiet time for neuro-intensive care patients. J Neurosci Nurs. 2010;42:217-24.

445. Walder B, Francioli D, Meyer JJ, Lançon M, Romand JA. Effects of guidelines implementation in a surgical intensive care unit to control nighttime light and noise levels. Crit Care Med. 2000:28:2242-7.

446. Li S-Y, Wang T-J, Vivienne Wu SF, Liang S-Y, Tung H-H. Efficacy of controlling night-time noise and activities to improve patients' sleep quality in a surgical intensive care unit. J Clin Nurs. 2011;20:396-407.

447. Richards KC. Effect of a back massage and relaxation intervention on sleep in critically ill patients. Am J Crit Care. 1998;7:288-99.

448. Hayes J, Cox C. Immediate effects of a five-minute foot massage on patients in critical care. Intensive Crit Care Nurs. 1999;15:77-82.

449. Tsay S-L, Wang J-C, Lin K-C, Chung U-L. Effects of acupressure therapy for patients having prolonged mechanical ventilation support. J Crit Care. 2005;52:142-50.

450. Byers JF, Smyth KA. Effect of a music intervention on noise annoyance, heart rate, and blood pressure in cardiac surgery patients. Am J Crit Care. 1997;6:183-91. 
451. Johnston K, Rohaly-Davis J. An introduction to music therapy: helping the oncology patient in the ICU. Crit Care Nurs Q. 1996;18:54-60.

452. Chlan L. Effectiveness of a music therapy intervention on relaxation and anxiety for patients receiving ventilatory assistance. Heart Lung. 1998;27:169-76.

453. Chlan L, Tracy MF, Nelson B, Walker J. Feasibility of a music intervention protocol for patients receiving mechanical ventilatory support. Altern Ther Health Med. 2001;7:80-3.

454. Chlan LL. Music therapy as a nursing intervention for patients supported by mechanical ventilation. AACN Clin Issues. 2000;11:128-38.

455. Wong HL, Lopez-Nahas V, Molassiotis A. Effects of music therapy on anxiety in ventilator-dependent patients. Heart Lung. 2001;30:376-87.

456. Lee OKA, Chung YFL, Chan MF, Chan WM. Music and its effect on the physiological responses and anxiety levels of patients receiving mechanical ventilation: a pilot study. J Clin Nurs. 2005;14:609-20.

457. Almerud S, Petersson K. Music therapy-a complementary treatment for mechanically ventilated intensive care patients. Intensive Crit Care Nurs. 2003;19:21-30.

458. Han L, Li JP, Sit JWH, Chung L, Jiao ZY, Ma WG. Effects of music intervention on physiological stress response and anxiety level of mechanically ventilated patients in China: a randomised controlled trial. J Clin Nurs. 2010;19:978-87.

459. Korhan EA, Khorshid L, Uyar M. The effect of music therapy on physiological signs of anxiety in patients receiving mechanical ventilatory support. J Clin Nurs. 2011;20:1026-34.
460. Stuhlmiller DFE, Lamba S, Rooney M, Chait S, Dolan B. Music reduces patient anxiety during interfacility ground critical care transport. Air Med J. 2009;28:88-91.

461. Chan MF, Chung YFL, Chung SWA, Lee OKA. Investigating the physiological responses of patients listening to music in the intensive care unit. J Clin Nurs. 2009;18: 1250-7.

462. Novaes MA, Aronovich A, Ferraz MB, Knobel E. Stressors in ICU: patients' evaluation. Intensive Care Med. 1997;23: 1282-5.

463. Kalfon P, Mimoz O, Auquier P, Loundou A, Gauzit R, Lepape $A$, et al. Development and validation of a questionnaire for quantitative assessment of perceived discomforts in critically ill patients. Intensive Care Med. 2010;36:1751-8.

464. Khalifezadeh A, Safazadeh S, Mehrabi T, Mansour BA. Reviewing the effect of nursing interventions on delirious patients admitted to intensive care unit of neurosurgery ward in AlZahra Hospital, Isfahan University of Medical Sciences. Iran J Nurs Midwifery Res. 2011;16:106-12.

465. Karlsson V, Forsberg A, Bergbom I. Relatives' experiences of visiting a conscious, mechanically ventilated patienta hermeneutic study. Intensive Crit Care Nurs. 2010;26: 91-100.

466. Grossbach I, Stranberg S, Chlan L. Promoting effective communication for patients receiving mechanical ventilation. Crit Care Nurse. 2011;31:46-60.

467. Thompson DR, Hamilton DK, Cadenhead CD, Swoboda SM, Schwindel SM, Anderson DC, et al. Guidelines for intensive care unit design. Crit Care Med. 2012;40:1586-600. 